$$
\begin{aligned}
& 3 Q / 96 \\
& \text { DOE BC } 114865-10
\end{aligned}
$$

TITLE: Support of Enhanced Oil Recovery to Independent Producers in Texas

Cooperative Agreement No.: DE-FG22-94BC14865

Contractor Name and Address: Prairie View A\&M University Office of Fiscal Affairs

Dr. Kamel H. Fotouh

W. R. Banks Building, Room 129

Date of Report: October 1, 1996

Award Date: October 1994

Anticipated Completion Date: December 1996

Government Award for current Fiscal Year: $\$ 86,500$

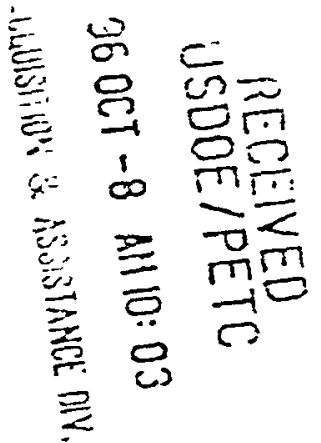

Principal Investigator: Dr. Kamel H. Fotouh

P.O. Box 2553

Prairie View A\&M University

Prairie View, TX 77446

Project Manager: Herbert A. Tiedemann, Bartlesville Project Office

Reporting Period: July 1, 1996 - September 30, 1996

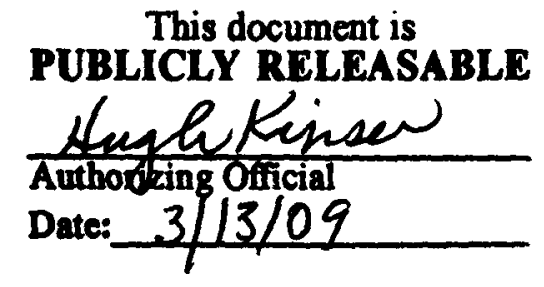

To establish a Technology Transfer Resource Center (TRC) at Prairie View A\&M University (PVAMU) to assist the Independent Oil Producers, in the state of Texas, (TIP) obtain and apply oil recovery technology to their operation. The University will conduct a field pilot project in cooperation with an Independent Producer to demonstrate how technology application improves the economic performance of a project. Experience gained from the project will be disseminated to other Independents. These activities will be coordinated with neighboring state Universities and private research entities active in technology transfer programs.

The University's goal is to stimulate Petroleum Engineering education and research at the university as a result of participating in these activities. The long term goal is to establish the first Petroleum Engineering Department at a Historically Black University.

DISTRIBUTION OF THIS DOCUMENT IS UNLIMITED 


\section{DISCLAIMER}

This report was prepared as an account of work sponsored by an agency of the United States Government. Neither the United States Government nor any agency Thereof, nor any of their employees, makes any warranty, express or implied, or assumes any legal liability or responsibility for the accuracy, completeness, or usefulness of any information, apparatus, product, or process disclosed, or represents that its use would not infringe privately owned rights. Reference herein to any specific commercial product, process, or service by trade name, trademark, manufacturer, or otherwise does not necessarily constitute or imply its endorsement, recommendation, or favoring by the United States Government or any agency thereof. The views and opinions of authors expressed herein do not necessarily state or reflect those of the United States Government or any agency thereof. 


\section{DISCLAIMER}

Portions of this document may be illegible in electronic image products. Images are produced from the best available original document. 


\section{Summary of Progress}

July 1, 1996 - September 30, 1996:

1.) More than 800 brochures that describes the service provided by and activities at PVAMU-TRC have been mailed to the Independent Oil and Gas Producers in the Gulf-Coast area.

2.) The University TRC and the Society of Petroleum Engineers, Gulf Coast Section (GCS), have cosponsored an "Oil Patch Orientation" workshop at the center on July 18. More than 65 individuals representing several independent producers have participated in the workshop. An event list report attached (Appendix I.)

3.) The TRC staffs have conducted a two-day workshop on "Reservoir Simulation" with emphasis given to secondary oil recovery applications. Teaching as well as preparing the manual used in the workshop have been performed by Dr. Farouk M. Allam of PVAMU-TRC. The DOE Black Oil Reservoir Simulator BOAST-II was used in the training. A copy of the training manual and an event report are attached, (Appendix II.)

4.) TEXACO Exploration and the University TRC staffs have conducted a seminar on TEXACO's reservoir description software model (GRIDSTAT). The seminar was conducted by TEXACO Engineers and was held on September 11 at the TRC. Attached is a copy of the hand-out given to the participants, (Appendix III.)

5.) The University TRC staffs and the Society of Petroleum Engineers (GCS) have cosponsored a reservoir simulation seminar for TIP on September 26, 1996 at the Center. Teaching the seminar has been performed by Dr. Farouk Allam of PVAMU-TRC and Dr. John Fanchi of Marathon Oil. Eleven Petroleum Engineers representing several independent and major oil producers have attended the seminar. Also, two PVAMU graduate students, petroleum engineering major, have attended the seminar. A copy of the announcement as it appeared in the GCS newsletter and an event report are attached, (Appendix IV.)

6.) The TRC staffs are currently negotiating with Triad Energy, an Independent Oil and Gas Producer, regarding performing an engineering study for a water-flood unit operated by Triad Energy. The study will be performed by the center's staffs in concert with Triad Engineers. Objectives of the study are directed toward improving the operational and economic performance of the unit.

7.) The two reservoir simulators (BOAST-II and UT-CHEM) installed on the TRC computer workstations are being modified to accommodate a larger number of gridblocks. The DOE waterand CO2-flood prediction software (PROPHIT) and (PC-GEL) are currently being added to the software library installed on the workstations. 
8.) Negotiation with the Petroleum Technology Transfer Council (PTTC) and the Texas Independent Producers and Royalty Owners Association (TIPRO) regarding using the University TRC as their satellite location in the Houston area is in progress. Planning for a TIPRO workshop at the center is underway and an application for a TIPRO membership by the Center is being processed by TIPRO.

9.) In an effort to tap the state universities technical resources and consistent with our stated goals, the TRC staffs have initiated a working relation with the Faculty of the Petroleum Engineering Department at Texas A\&M University. Dr. Robert Wattenbarger and Dr. Ching Wu, professors of petroleum engineering will be participating in future teaching and consultation activities at PVAMU-TRC.

10.) Activities during this period have also included future planning for a series of workshops and seminars with other petroleum organizations active in technology transfer. The following is a summary of scheduled events:

a.) Oil Patch Orientation, Date: November 21, Instructor: John Farina ,Petroleum Consultant.

b.) Reservoir Management with Integrated Software, Date: Jan. 22-23, 1997 Instructor: Dr. Abdus Satter of Texaco Exploration.

c.) Internet Training workshop, Date: to be announced, Instructor: John McGhee of TIPRO.

d.) CO2-Flooding workshop, Date: to be announced, Instructors: Dr. R. A. Wattenbarger, Professor of Petroleum Engineering at Texas A\&M University, and the TRC staffs.

\section{DISCLAIMER}

\footnotetext{
This report was prepared as an account of work sponsored by an agency of the United States Government. Neither the United States Government nor any agency thereof, nor any of their employees, makes any warranty, express or implied, or assumes any legal liability or responsibility for the accuracy, completeness, or usefulness of any information, apparatus, product, or process disclosed, or represents that its use would not infringe privately owned rights. Reference herein to any specific commercial product, process, or service by trade name, trademark. manufacturer, or otherwise does not necessarily constitute or imply its endorsement, recommendation, or favoring by the United States Government or any agency thereof. The views and opinions of authors expressed herein do not necessarily state or reflect those of the United States Government or any agency thereof.
} 


\section{APPENDIX (I)}

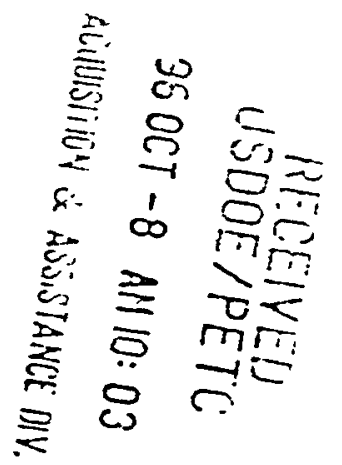




\section{Prairie View A\&M University Technology Resource Center}

Oil Patch Orientation

Event Alpha List 
Attendee Name

Arnette, Cheri

Arozarena, Monica

Baker, Will

Bobo, Roy

Bohanan, Adam

Box, Judy

Bravo, Jose

Casco, Arturo

Castillo, Damian

Cates, Suzy

Chaney, Tara

Cheatheam, Johnnie

Cole, Liz

Cole, Lori

Contreras, Gary

Crapnell, Boyd

Dennison, Barbara

Dierlam, Melissa

Fleck, Katie

Fpiritu, George

Free, Billy

Ganesh, Kris

Goza, Sue

Harrigan, Eddie

Harris, Ërenda

Hooper, Adrian

Hooper, Michele

Howard, Beth

Johnson, Golvin
Company

Phone

Woodco USA

713-672-9491

Schlumberger

713-275-4253

Security DBS

Security DBS

Security DBS

Citation Oil \& Gas

713-469-9664

Frisa

713-268-2612

Frisa

713-268-2612

Schlumberger

713-275-4757

Citation Oil \& Gas

713-469-9664

Citation Oil \& Gas

713-469-9664

Tidewater Compress.

$713-466-4103$

Sonat Exploration

713-840-4912

Sonat Exploration

713-850-3978

Schlumberger

713-275-4801

Schlumberger

Sonat Exploration

$713-940-4012$

Sonat Exploration

T. H. Hill

713-955-8822

Security DBS

Tidewater Compress.

$713-466-4102$

Schlumberger

Citation Oil \& Gas

Schlumberger

Sonat Exploration

Schlumberger

Schlumberger

Schlumberger

$713-275-4303$

Tidewater Compress. 


\begin{tabular}{|c|c|c|}
\hline Martin, Ed & Security DBS & $713-442-8061$ \\
\hline Matthews, Oliver & Security DBS & $713-442-8060$ \\
\hline McGregor, Leslie & Sonat Exploration & $713-850-6108$ \\
\hline Montalvo, Oscar & Sonat Exploration & $713-940-6909$ \\
\hline Morrison, Jeremy & Schlumberger & $713-275-4554$ \\
\hline Moser, Reba & Sonat Exploration & \\
\hline Parr, Lori & Sonat Exploration & \\
\hline Peng, Benjamin & Schlumberger & $713-275-4663$ \\
\hline Periera, Hugh & Sonat Exploration & \\
\hline Philip, Olivier & Schlumberger & $713-275-4603$ \\
\hline Phillips, Pat & Sonat Exploration & 713-871-7837 \\
\hline Phillips, Patricia & Sonat Exploration & $713-940-6921$ \\
\hline Quiroz, Cindy & Sperry Sun & $713-987-5030$ \\
\hline Ramirez, Oswaldo & Frisa & \\
\hline Raper, Amy & Sonat Exploration & $713-940-6908$ \\
\hline Ray, Betty & Conoco & $713-293-4127$ \\
\hline Reid, Lennox & Schlumberger & \\
\hline Rivera, Alfonso & Frisa & $713-780-0665$ \\
\hline Rogers, Ignacius & FMC Corp. & $713-591-4292$ \\
\hline Scasney, Grace & Sonat Exploration & \\
\hline Serrer, Miguel & SouthBound Corp. & $713-268-1623$ \\
\hline Sigueroa, Gloria & Sonat Exploration & $713-871-7874$ \\
\hline Smith, Terry & Schlumberger & \\
\hline Sodolak, Charlotte & S.A. Holditch\&Assoc. & $713-558-9120$ \\
\hline Swanson, Angela & Sonat Exploration & \\
\hline Symonds, Dan & Security DBS & \\
\hline Taylor, Charissa & Sonat Exploration & \\
\hline Tesciuba, Michele & Schlumberger & \\
\hline \multicolumn{3}{|l|}{ T.H. Hill Assoc. } \\
\hline \multicolumn{3}{|l|}{ T.H. Hill Assoc. } \\
\hline Tiouririne, Nedgla & Schlumberger & $713-275-4662$ \\
\hline
\end{tabular}




$\begin{array}{lll}\text { Venkatesan,Prasanna } & \text { Schlumberger } & \\ \text { Welchel, Carol } & \text { Vastar Resources } & 713-584-3712 \\ \text { Whitbeck, Thom } & \text { Sonat Exploration } & 713-940-4069 \\ \text { Williams, Mary Ann } & \text { OXY } & 713-215-7117 \\ \text { Williamson, Jerry } & \text { Production Operators } & 713-896-2576 \\ \text { Winklemann, Norman } & \text { Schlumberger } & 713-275-8500 \\ \text { Zhou, Feng } & \text { Schlumberger } & \end{array}$


APPENDIX ( I ) 
Prairie View A\&M University

Technology Resource

Center

Reservoir Simulation

Workshop Aug. 8-9

\section{Company}

Petresim Integrated

Technology, Inc.

Craft, Candace

Davis, Lonnie

Farina, John

Milan, Francis

Mitchell, Tommy
Triad Energy

Triad Energy

Consultant

PVAMU

Huddleston\&Co., Inc.
713-974-6490

Phone

713-783-2291

713-783-2291

713-358-5064

409-857-2427

713-658-0248 


\section{PRAIRIE VIEW A\&M UNIVERSITY DOE Enhanced Oil Recover Project}

\section{RESERVOIR SIMULATION WORKSHOP}

By

Dr. Farouk M. Allam

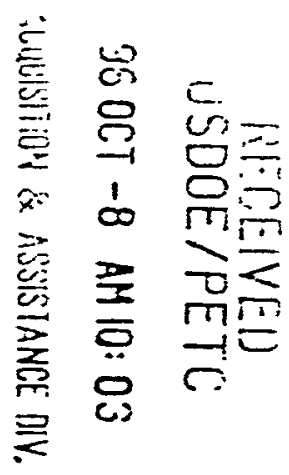




\section{INTRODUCTION}

Simulation of petroleum reservoirs may be defined as the process of constructing and operating a model whose behavior assumes the appearance of the actual reservoir behavior. Petroleum reservoir models can be divided broadly into two basic groups:

\section{1 - Physical Models:}

Include those scaled laboratory models such as potentiometric models (flow of electron in an electric potential field) and fluid flow models (fluid flow in a sand pack or an actual core.)

\section{2- Numerical simulators:}

A set of partial differential equations the engineer believes adequately describe the behavior of all the physical factors governing the process of fluid movements within the reservoir and in some cases the wellbore. The solution of this set of equations in conjunction with the appropriate boundary and initial conditions of the system form the numerical model.

Because of the flexibility of numerical models, physical models are now used only in a narrow spectrum to supplement numerical simulators rather than to compete with them. However, physical models remain an important tool for developing insight into the physical process governing fluid movements within petroleum reservoirs. Indeed physical models are frequently used to check the validity of numerical models.

The ability of numerical simulators to solve problems that can not be solved by conventional engineering methods is not the only incentive to simulate. The engineer has a single 
opportunity to develop and produce a reservoir; the effect of any mistake during this process will remain forever. The simulation study, however, can be made several times to assist in arriving at a better reservoir management plan which in turn increases the profitability through,

1- developing planes for new fields.

2- estimating facility needs.

3- developing plane to increase wells production.

The main incentive for reservoir simulation is to increase profitability through better reservoir management. However, the cost of performing simulation studies for small reservoirs may not be justified. The benefits from the study must outweigh the simulation cost. A simulation study can be performed on a multi-well reservoir or a single well reservoir. In any case, the main objectives of a reservoir simulation study can be summarized in the following:

(1) Computation of the original oil and / or gas in place is one of the most important objective of any study. This quantity is given normally as a reservoir total, however, in cases where the reservoir system is broken geologically into several zones, it may be necessary to obtain the original hydrocarbon in place for each zone separately. This enables the engineer to schedule production and completion operations for these zones more effectively.

In some other cases, the reservoir system is divided into several leases or units. The original oil and gas in place per lease is essential for developing unionization program. Simulation can also be used to study the effect of well location and spacing as well as other operating factors on the recovery. 
(2) Computation of future oil and gas production rates which are essential in economic evaluation of the project. The simulator must provide the production per well, lease or reservoir basis. The ultimate recovery from the reservoir can also be determined. Future production rates are also essential in designing the production facilities needed.

(3) Bottom hole or surface pressure are also evaluated for future planing of downhole or surface lift equipment.

(4) In addition to the above objectives, computation of the volume of injected fluids and the injection rate is essential in secondary and tertiary recovery projects. This information are used to design the size of the injection units and other surface facilities as well as in the economic analysis of the project. Also, the simulator enables the engineer to determine the flood pattern by studying spacing and different alternatives for the location of the injectors and the producers. The results are also used to study the location of new producers and the optimal drilling sequence, the conversion sequence from producers to injectors, and the critical water cut.

(5) The migration of fluids across the lease line presents another case where computer simulation can be used.

(6) In many cases, particularly where the reservoir is relatively complex, simulators are used in reservoir management and surveillance. The model is continually updated and history matched with all new geologic and seismic data. This process can provide important information on the future performance of the reservoir. 
(7) In addition to their use in making operational decisions, results from reservoir simulation study can have considerable educational value. Verifications of the validity of unexpected flow patterns observed during a simulation study may lead to the discovery of geological features and assist in understanding the actual depletion mechanisms.

In cases where a full blown reservoir simulation study is not feasible, simulation of a single well may be employed to develop an optimum completion program for each well. The study may also include the calculation of the critical production rates to prevent gas and water coning. 


\section{FLUID FLOW IN POROUS MEDIA}

1- Darcy's Law

2- Multiphase Flow

3- Relative Permeability

4- Capillary Pressure

5- Diffusivity Equation

6- Finite Difference Scheme

7- Explicit Formulation

8- Implicit Formulation

9- Solution Methods

10- Direct Method

11 - Iterative Method 


\section{RESERVOIR MODEL DESIGN}

Simulation study results are usually more believable as more complexity is added to the model. However, it is best to design the simplest model that adequately simulate the displacement process with sufficient accuracy.

Model design is mainly influenced by the following factors:

1- Type and complexity of the problem.

2- Time available to complete the study.

3- Cost of the study.

4- Quality of data available.

5- Capabilities of the simulator and existing hardware.

The process of designing a model can be summarized in the following sequential steps:

1- Define the problem to be solved and the objectives of the study. Your statement should include what questions to be answered by the study and why.

2- Make a complete inventory of all available data and note the quality of these data. The list should include all geological, rock, fluids and field production data.

3- Select the model configuration (number of dimension) that best represent the reservoir based on the available data. Simplifications that may be needed such as using a 2-D areal model rather than 3-D will require additional testing to check the validity of their assumptions.

4- Selert the gridblock dimensions.

5- Select the fluid PVT model.

6- Depending on the process being simulated, select the number of phases. 
7- Define how wells will be treated in the simulator and the capabilities needed in the well management routines.

8- Select the simulator.

\section{NUMBER OF DIMENSIONS:}

One of the first steps in designing a model is to select the number of space dimensions needed to fully define the geometry of the reservoir. Reservoir geometry is defined by a top and bottom structural map that shows all structural features of the system such as faults. The structural maps must also include the aquifer, if present.

Type of models available:

1- 0-D tank models.

2- 1-D linear.

3- 2-D radial.

3- 2-D areal.

4- 2-D cross-sectional.

5- 3-D models.

6- Multilayer models (stacks of 2-D areal).

\section{O-D Models:}

Tank models or zero dimension models are based on the well known material balance equation which assumes the formation and fluids properties are uniform throughout the reservoir. The formation is essentially homogeneous, isotropic and at any given point in time the pressure gradient is very small and the reservoir pressure can be represented by one average value. 


\section{1-D Models:}

Are used effectively to study the sensitivity of the predicted reservoir performance to variations in reservoir parameters. For example the sensitivity of recoverable oil to the mobility ratio, absolute permeability or the shape of the relative permeability curves can be studied using 1-D models.

\section{2-D Models:}

Cartesian 2-D ( $x$ and $y)$ areal models are the most commonly used models in reservoir studies. 2-D Cartesian models are used mainly to study the entire reservoir in cases where the formation thickness is relatively small or where variations in fluids and formation properties in the vertical direction is very small.

2-D areal models can still be used to study thick reservoirs that are not highly stratified. Normally, the so called pseudofunctions are applied to correct for the gravitational forces in the vertical direction. A cross-sectional model may need to be constructed to check the effectiveness of the pseudofunctions in simulating thick stratified reservoirs.

Curvilinear 2-D models $(x 1, x 2)$ are used in some cases where better definition near the well is required. 


\section{2-D Cross-Sectional Models:}

In cases where the areal sweep efficiency is uniform, 2-D cross-sectional models may be used effectively to develop pseudofunctions for use in 2-D areal models and to simulate peripheral water injection or crestal gas injection. 2-D cross-sectional models are also used to study the effect of the interaction of gravity, capillary, and viscous forces on vertical sweep efficiencies.

\section{2-D Radial:}

Used primarily to develop well-function which is used to predict wells behavior for use in 2-D areal and 3-D models. Also used to evaluate wells behavior when vertical effects dominate performance as in gas or water conning. 2-D radial models are often used to simulate converging or diverging flow in a radially symmetrical region of a reservoir. In some other cases they were used to study the behavior of wells in bottomwater-drive reservoirs, gas-cap drive reservoirs, and reservoirs having a thin oil column overlain by gas and underlain by water.

\section{MULTILAYER MODELS:}

Used to model reservoirs with several layers with no crossflow. However, these layers share the same boundary conditions such as a common aquifer or production is commingled in the well or the trunklines and the same well management routine must be used for all layers.

A 2-D model may be used to simulate the reservoir with each zone is represented by an independent region with the appropriate interaction between layers, wells or surface facilities.

\section{3-D Models:}

Are used where reservoir geometry is too complex to model with 2-D or where the reservoir fluid dynamics are complex as in case of reservoirs in advanced stage of depletion. Also, these 
models are used to simulate fluid displacement where flow regimes are dominated by vertical flow. In some cases using 3-D is simpler than developing pseudofunctions for all the regions included in the reservoir.

\section{SIMPLIFICATION OF COMPLEX MODELS:}

This section presents some concepts that may assist the engineer in simplifying complex models.

\section{1- Vertical Equilibrium Pseudofunctions:}

As mentioned above, one of the most important steps in designing a simulation model is to decide on the number of dimensions. Often this choice is one between 2-D areal model and 3$D$ model. The cost of running 2-D simulation study is considerably lower than 3-D. On the other hand, the results obtained from 2-D studies are always questionable because their inabiity to simulate fluid distribution in the vertical direction particularly in thick heterogeneous reservoirs.

The vertical equilibrium concept is eventually developed to compensate for the missing vertical dimension when 2-D models are used to simulate 3-D problems. The vertical equilibrium concept assumes that gravity and capillary forces are in equilibrium at any time in the vertical direction which leads to the definitions of pseudo-relative permeabilities and pseudo-capillary pressure. 
The validity of the VE assumption is improved by large vertical permeability, small thickness, high gravity and/or capillary forces and low fluid velocities. Pseudofunctions are derived from those corresponding values measured in the laboratory.

\section{2- Dynamic Pseudofunctions:}

If a 2-D areal model is used to simulate thick stratified reservoirs, the dynamic pseudo-relative permeability and pseudo-capillary pressure must be used to correct for the absence of the vertical dimension. Pseudofunctions are even used in 3-D simulation where the vertical dimension of the blocks is large.

Pseudofunctions are saturation dependent and are used to indicate the saturation distribution in the vertical direction. Dynamic Pseudofunctions are derived through detailed simulation of the fluid displacement in a 2-D cross-sectional model of the reservoir. 
Results of the 2-D cross-sectional simulation are processed to give the average saturation and the dynamic pseudofunctions may differ from column to column due to the difference in initial saturation, velocity of the fluids, and formation stratification. However, these differences are frequently minor otherwise a correlation must be developed to reduce the complexity of the pseudofunctions.

The validity of the dynamic pseudofunctions developed from the 2-D cross-sectional model must be tested by running an identical 1-D model and the results are compared.

\section{3- Windowed Models:}

A coarse gridblock model is used initially to simulate the overall performance of the reservoir and the aquifer. Then, a window is selected to cover the reservoir only. The region defined by the window is then modeled with finer gridblock. The flux determined by the coarser model at the window boundary is used as a boundary condition for the finer boundary.

The two models can be linked together for the flux to be passed automatically at the end of each time step. 


\section{REPRESENTATION OF RESERVOIR FLUIDS:}

\section{1-Compressibility:}

A reservoir model may run in the compressible or the incompressible mode depending on the type of process being simulated. Incompressible mode is used where pressure in the reservoir does not change appreciably or remains constant with time such as water-oil displacement. Compressible mode, on the other hand, is used to simulate processes where fluids expansion plays a major role in recovery such as aquifer behavior, solution gas drive, gas cap expansion or combination.

\section{2- Number of Phases:}

a- Single-Phase:

- Depletion of gas reservoirs with no water influx.

- Expansion of water in the aquifer.

- Single well transient pressure problems.

- Lease-line drainage problems.

\section{b- Multi-Phase (BLACK OIL):}

- Are used to simulate oil reservoir having formation volume factor less than 2.

- Water/oil or gas/oil displacement processes.

- Solution gas drive, gas cap expansion injection.

\section{c- Corn.pesitional Models:}

- Gas reservoir that drops below the dew-point during depletion.

- Dry gas injection to cycle such reservoirs. 
- Miscible flooding by high pressure gas or enriched gas injection.

- Volatile oil reservoirs with formation volume factor greater than 2.

\section{VARIABLE FLUID PROPERTIES:}

Fluid properties (viscosity, formation volume factor, solution gas, .....) vary vertically and arealy in some reservoirs. The reservoir must be devided into regions. You must understand how the model treats fluids properties when it moves from one region to another. Models that uses instantaneous mixing are unrealistic. Some models change fluid properties as it crosses the boundary. Compositional models too suffer from the same problem.

\section{REPRESENTATION OF RESERVOIR ROCK:}

The heterogeneity of the reservoir rocks is one of the reasons we use simulation. Heterogeneous reservoirs are characterized by one or more of the following:

1- Areal permeability variation.

2- Vertical stratification.

3- Discontinuities shale or permeable zone.

4- Natural fracture or fissures.

\section{THE WELL MANAGEMENT ROUTINE:}

Well management routine translates production/injection data and desired field operating conditions and constraints into controls for the reservoir model. The simplest form of a well management routine is known as "rate routine." The rate routine assigns rate or pressure to the well blocks in the model at specified times. The function of the well management routine can be summarized as follows: 
1- Sets well rates or pressures.

2- Implements operating policies.

3- Satisfies operating constrains at the levels of producing interval, well, well group, reservoir, or field.

Other sophisticated routines may be designed to execute operating policies such as:

1- drill, workover, or recomplete a well.

2- Calculate well and flowline hydraulics.

3- Install artificial lift.

4- Control gas or water rates.

5- Maintain production targets.

6- Recycle gas or reinject water.

7- External controls such as operating agreements and statutory rules. 


\section{SPATIAL AND TIME DISCRETIZATION}

\section{INTRODUCTION:}

The partial differential equations that describe the flow of fluids in porous media are non-linear in nature and extremely complex. The solution of these equations is further complicated by the application of the boundary conditions.

The analytical solution of these equations is not possible except for the most simplified cases. Therefore, the numerical method, carried out on high speed computers, is the only way to obtain an approximate solution to the mathematical model. In almost all reservoir engineering applications, the numerical solution is obtained through replacing the partial derivatives by finite

difference quotients. Analytical solutions, when exist, give a continuous definitions of the dependent variables (pressure and saturation) as function of space and time. On the other hand, numerical solution by finite difference methods can only be obtained at a preselected discrete points within the system.

The location of these points is normally defined through spatial segmentation of the reservoir model into a pattern of mesh points which divides the system into gridblocks or cells. The time span is also divided up into some discrete small time increments and often referred to as time steps. The process of incrementing space and time is known as discretization. 


\section{SPATIAL DISCRETIZATION:}

Two types of grid systems are generally used depending on the boundary conditions:

\section{Block Centered:}

The dependent parameters are calculated at the center of the block, there are no points on the boundary. Block centered grid system is compatible with a Neumann type boundary conditions. Neumann boundary conditions specifies flow across the boundary. In this case, the flow across the boundary may be represented by a source term in the boundary block.

\section{Point Centered:}

The dependent parameters are calculated at the intersection of the grid lines. There are points on the boundary. This type of grid system is compatible with Dirichlet type boundary condition which specifies no flow across the boundary.

\section{FACTORS INFLUENCING GRIDBLOCK SIZES:}

The gridblock size is mostly influenced by the following factors:

\section{1- Well Location:}

The grid system is selected in such a way so that the location where pressure and saturation values must be known are included. Normally, these locations are represented by all existing and planned wells. In a typical reservoir model, finer segmentation that is defined by the wells location is required to satisfy other factors. 


\section{2- Structure Geometry and Geology:}

Adequate representation of the reservoir geometry, geology and physical properties are the most important factors in designing a gridblock system. The external boundary of the reservoir is the most obvious factor. Internal barriers to fluid flow (shale breaks, reservoir discontinuities, and sealing faults) dictates the gridblock size. Gridblocks are chosen in such a way to approximate the location of the barrier. Highly stratified reservoirs may require extensive grid segmentation in the vertical direction. Grid definition is normally finer in the transition zones.

\section{3- Reservoir Fluid Properties:}

Variation in fluid properties (viscosity, saturation pressure and gas oil ratio) may some time dictate finer grid definition in some regions of the model. Some example of this are viscous oil zone near water/oil contact, saturation pressure changes with depth or areal positions, and in gas reservoirs where gas properties change with depth.

\section{4- Reservoir Fluid Dynamics:}

Adequate representation of dynamic fluid distribution and pressure behavior is required. Coarsely defined solution can lead to error in production rate and displacement efficiency. Numerical dispersion can also result from coarser grid system.

\section{5- Numerical Dispersion:}

Numerical dispersion is a direct consequence of spatial discretization of the system. In reservoir models, saturation fronts that are supposed to be sharp will probably be distorted or smeared to some extent. 
Numerical dispersion occurs mainly in modeling fluids displacement in porous media where the saturation at the front changes rapidly. Saturation values computed by the model is an average for each gridblock. Once any given block has been invaded by the displacing phase, the average saturation of that block rises to some level. If the average saturation rises above the critical level, the previously immobile displacing phase flows to the next block during the next time step even though the actual front has not crossed the boundary of the block.

There is no way to completely eliminate numerical dispersion, however, there are several techniques that may be utilized to reduce dispersion. 


\section{BLOCK SIZE EFFECT ON ESTIMATED PRESSURE AND PRODUCTION:}

Accurate prediction of pressure and flow rate with time is highly dependent on the grid system block size. Relatively few gridblocks would be required to adequately model single phase regions as is the case in modeling gas cap and water aquifer regions. In multi-phase regions, however, gridblocks many times smaller than those used to model single phase region are used to accurately define saturation within the region. Accurate saturation prediction is essential for accurate pressures and production rates computation.

\section{BLOCK SIZE EFFECT ON DISPLACEMENT EFFICIENCY:}

\section{1- Areal Distribution:}

Numerical dispersion causes the computed areal displacement efficiency to be lower than the actual one.

\section{2- Vertical Distribution:}

Failure of the model to represent thin layers due to insufficient vertical segmentation can result in a significant error in the vertical sweep efficiency.

Also, in high permeability formation, the displacing phase tends to form a thin gravity tongue at the bottom of the reservoir in case of water flooding or at the top of the oil zone in case of gas displacement. Again, if the model grids are not fine enough to represent these thin regions, oil mobility will be incorrectly computed. The same can be said in case of undersaturated oil reservoirs where released gas is expected to form a thin secondary cap. In the simulator, however, gas will not migrate to the top if the grid size in the vertical direction is not small enough. 
Continuous shale zone that devides the reservoir up into several zones must be considered in the vertical segmentation of the reservoir. If the model is not capable of handling the segmentation required, the use of the pseudo-relative permeability should be considered.

\section{SEGMENTATION IN WELL CONNING MODELS:}

Special grid definition is needed for the region immediately adjacent to a well. In this region, fluid distribution can undergo rapid changes. Therefore, 2-D or 3-D models with large gridblocks are not suitable to accurately predict pressure and saturation behavior in the well block. One solution to this problem is to incorporate a single well radial model. The results of the radial model can be manually transferred to the field model through the well function routine. Some simulators couple single-well radial model with the reservoir model. The results are automatically transferred at the end of each time step.

\section{VARIABLE GRID SIZE:}

Variable grid size is an effective way to reduce the simulation cost without compromising the accuracy of the result. For example, larger gridblocks are normally used in the single phase zones, gas caps, and aquifers. Also, fine segmentation may be used in area of great interest such as the area around the wellbore. Most models, however, require regular segmentation, in which each block has only one neighboring block on each side.

\section{GRIDBLOCK SIZES SELECTION GUIDELINES:}

The following are some guidelines that can be applied to select gridblock size. Keeping in mind that this process is highly complex and is influenced by the specific problem at hand. 
10-20 vertical gridblocks are sufficient. $20-80$ are usually

icient in the flow direction.

3-3-D models: should have 30 to 100 gridblocks in the flow direction

wells in the model and the horizontal varie blocks are sufficient. The number of gridblocks in un 7 gridblocks are suficient.

4- Radial MODELS: 10 to 30 vertical gridblocks and 10 to 20 horizontal gridblocks.

MODEL SENSITIVITY TO BLOCK SIZES: The solution to the mathematical me adequacy of the selected. Once a grid system is selected, in interest and provide an answer to the questions delecting a smaller region or a cross section of mo finer model is then system is normally verified by compared with those obtained from the full scale model. 


\section{SELECTION OF TIME STEPS SIZE:}

Too large a time step will reduce the quality of the answer. While too small a time step will increase computation and man-hours time.

\section{FACTORS INFLUENCING SELECTION OF TIME STEPS SIZE:}

1- Solution Stability.

2- Gridblocks Size.

3- Fluids Mobilities.

4- Gas-Percolation.

5- Numerical Dispersion.

Gas percolation tends to occur in simulating solution gas drive reservoirs with more than one gridblock in the vertical direction. As the pressure drops in the oil column in the vicinity of the producers, gas comes out of solution. Due to the low density and viscosity of the gas in comparison to the oil, there is a high gas velocity in the upward direction. The upward gas flow is often high enough to deplete all the gas in the finite cell during a time step. More gas may flow upward out of the cell than actually is present creating low or even negative gas saturation at the end of the time step. This creates instability and oscillations in the saturation.

One of the methods used to control this phenomena is to use smaller time steps. However, in some cases the time step size required to control gas percolation is very small and impractical. 


\section{VARIABLE TIME STEP:}

Small time steps are required to simulate a reservoir at very early time until potential gradient and flow directions are established. 5 to 10 days are usually small enough to begin the simulation. The time step size is gradually increased until the model basic time step is reached.

Smaller time steps may also be required at the time of significant change in production or injection rates. For example, when producers are changed to injectors, time steps may have to be reduced to less than 0.01 day immediately after the rate change.

\section{AUTOMATIC TIME STEP:}

MOST simulators have the capability to set time steps automatically without the interference of the user. The size of each time step is automatically selected based on the magnitude of the changes to some preselected parameters such as pressure, saturation and truncation error.

\section{MODEL SENSITIVITY TO TIME STEPS SIZE:}

To check the sensitivity of the result to the selected time steps, a portion of the reservoir is selected and simulated. The same region is simulated again using a smaller time step. The results are eventually compared and the selected time steps size is adjusted accordingly.

\section{CONTROLLING NUMERICAL DISPERSION:}

Pressure and saturation values estimated by the model is an average for each gridblock with no definition given as to how fluids are distributed within the cell. This lack of definitions within each individual gridblock coupled with a rapid change in saturation or rock properties create several problems that must be recognized and dealt with. 


\section{MOBILITY WEIGHTING:}

The flow of fluids in a reservoir simulators is computed on a cell by cell basis and therefore, is dependent on the mobility assigned for each phase and the pressure difference between any given two blocks.

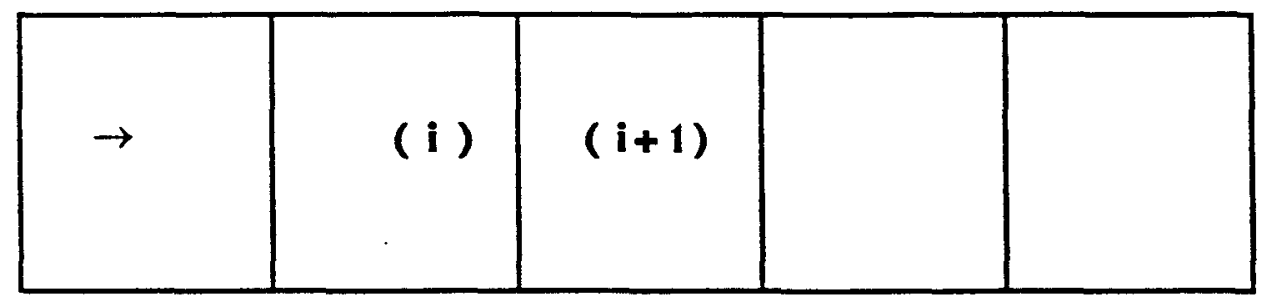

Consider the adjacent cells (i) and ( $i+1)$ of a reservoir model. The pressure in cell (i) is greater than that in cell ( $(i+1)$. Cell (i) is called the upstream cell and cell $(i+1)$ is the downstream cell. Obviously, fluids in this case would flow from cell (i) to cell (i+1). However, a mobility must be assigned for each phase to compute the flow between the two cells. We know mobility of any given phase is function of the saturation which may significantly differ from cell to cell. The question that must be answered is therefore, which mobility should we use to compute the flow between two adjacent cells with different saturation. There are several methods:

\section{1- Upstream weighting:}

The fluids mobility is determined based on the relative permeability and viscosity data computed from fluids saturation and pressure in the upstream block. 


\section{2- Downstream weighting:}

The fluids mobility is based on the relative permeability and viscosity data computed from fluid saturation and pressure in the downstream block.

\section{3- average weighting (50/50):}

A weighted average of the mobilities in the upstream and the downstream blocks.

\section{4- Two-point upstream weighting:}

Is based on extrapolating the mobilities of two upstream blocks to determine the mobility between the upstream and the downstream blocks. Upstream weighting is more reliable than downstream or average weighing as long as the gridblock size is not course enough to cause numerical dispersion. Two-point upstream weighting is more effective in controlling numerical dispersion.

\section{PSEUDOFUNCTIONS:}

In case of 2-D areal model studies, a relatively fine cross-sectional model is run initially and the results are used to modify the relative permeability curves. Modification of the relative permeability curves sharpens the front and causes linear flow through a single block to behave like flow through several blocks in the vertical direction. 


\section{AQUIFER MODELS:}

- Numerical

Aquifer and reservoir are simulated in one model using smaller grids to define the reservoir and increasingly larger grid in the aquifer region.

\footnotetext{
- Analytical

- Pot Aquifer

- Steady-State Aquifer.

- Carter-Tracy Aquifer.
} 


\section{HISTORY MATCHING}

\section{Introduction:}

The main objective of a reservoir simulation study is to predict the future performance of the reservoir with more accuracy than other simple prediction techniques. It is evident that the behavior of the numerical model must be similar to that of the reservoir for the results to be within acceptable accuracy.

Because of the uncertainty inherent in the data required to construct the model, we must find a way to test the behavior of the model before using it to predict the future performance. The only available way to test the model is to simulate the past performance of the reservoir and compare the results with the actual historical data.

The process of testing the model through matching past performance is also used to identify the inconsistencies of the model and eventually test the modifications required to overcome these inconsistencies. History matching is, therefore, the process of refining the model through adjusting rock, fluids, and geological parameters to yield the minimum difference between the

observed field data and the simulator results. History matching also assists in understanding the current status of the reservoir such as the fluid distribution and identification of current depletion mechanisms.

\section{HISTORY MATCHING PARAMETERS:}

1 - Pressure

2 - Flow rates

3 - Gas/ oil ratios 
4 - Water/ oil ratio

5 - Water or gas breakthrough time

The objective is to minimize the difference between these parameters and those predicted by the simulator.

\section{PARAMETERS THAT CAN BE MODIFIED:}

There are several parameters that can be varied either singly or collectively to match the history matching parameters, namely:

1 - Reservoir permeability and thickness.

2 - Aquifer permeability and thickness.

3 - Aquifer storage.

4 - Relative permeability data.

5 - Capillary pressure data.

6 - Well data such as skin factor.

Additional parameters that are usually known with greater certainty but they may sometimes be varied:

7 - Reservoir porosity and thickness.

8 - Reservoir geological definition.

9 - Rock compressibility.

10 - Fluids properties.

11 - Water / oil and gas / oil contacts.

12 - Bottom hole flowing pressure. 


\section{MECHANICS OF HISTORY MATCHING:}

1 - Assemble production history data.

2 - Screen the data and evaluate their quality.

3 - Define the objectives of the history match.

4 - Develop a preliminary model based on the best available data.

5 - Run simulator in history match mode and compare simulator results with actual reservoir performance.

6 - Decide whether the results match actual performance within an acceptable tolerance.

7 - Decide whither an automatic history match is necessary.

8 - Make adjustments to the model and simulate again to improve match.

\section{Screening Field Data:}

Production data should be plotted on a well by well basis to identify and eliminate any inconsistencies. The plot may include:

1 - Oil production.

2 - Gas production and injection.

3 - Water production and injection.

4 - Flowing or shut - in pressure corrected to datum.

Inaccuracies resulting from production allocation to individual well or any given zone should also be evaluated. Special care must be given in refining the data so that anomalies that may represent some reservoir feature is not eliminated. Water production and injections data normally are not as accurate as oil production. Leaks through the casing or through a bad 


\section{DO NOT SCAN}

\section{MECHANICS OF HISTORY MATCHING:}

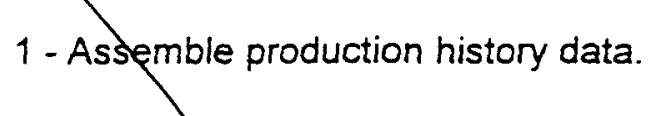

2 - Screen the data and evaluate their quality.

3 - Define the qujectives of the history match.

4 - Develop a preliminary model based on the best available data.

5 - Run simulator in history match mode and compare simulator resuits with actual reservoir performance.

6 - Decide whether the results match actual performance within an acceptable tolerance.

7 - Decide whither an automatic history match is necessapy.

8 - Make adjustments to the model and simulate again to improve match.

\section{Screening Field Data:} inconsistencies. The plot may include:

1 - Oil production.

2 - Gas production and injection.

3 - Water production and jhjection.

4 - Flowing or shut - in pressure corrected to datum.

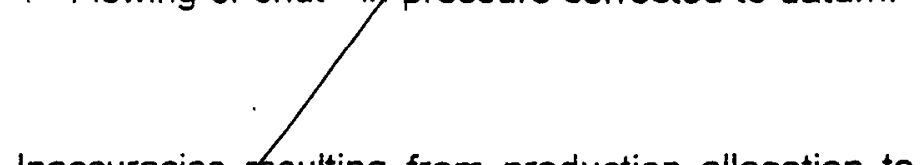

Inaccuracies pesulting from production allocation to individual well or any given zone should also be eyaluated. Special care must be given in refining the data so that anpmalies that may represent some reservoir feature is not eliminated. Water production and injections data norfmally are not as accurate as oil production. Leaks through the casing or thraugh a bad 
cement jobs would also reduce the accuracy of production data. Many leaks have been suspected during history matching and confirmed later by other means.

Initial hydrocarbon in place as well as initial oil/ water and gas/ water contact must be compared with known estimates and the difference, if any, is resolved before proceeding with the forecast.

\section{Matching Pressure History:}

The following steps are recommended for a successful pressure match:

1 - Identify the parameters that need to be adjusted. Normally rock permeability is the least less defined variable used to produce a pressure match. Porosity obtained from log and core analysis should not be changed. Aquifer porosity, thickness and the areal extent are less known than in the reservoir and may be adjusted to obtain pressure match.

2 - Estimate the bound of uncertainty for the variables listed above. It is helpful to consult with field engineer and geologist before establishing those bound.

3 - Conduct a first trial simulation run and decide whether the volumetric average pressure of the entire reservoir is satisfactory matched by the model. If not, use some simple techniques and available geological information to estimate changes that should be made. At this stage, the role of different depletion mechanism is evaluated and adjusted to produce an overall pressure history match. 
4 - After an overall match is achieved, a detailed match of the major regions of the reservoir is performed. At this stage, the reservoir heterogeneity, flow barrier and aquifer parameters are adjusted to produce match.

\section{Matching GOR and WOR:}

Matching GOR and WOR is the strongest indication of the validity of the model in representing the reservoir. Procedures used in matching GOR and WOR vary from one reservoir to another, however, the following outlines the procedures in general:

1 - Identify those varying parameters that influence the movement of water and gas within the reservoir and the aquifer.

2 - Estimate an upper and lower limit for each parameter based on the uncertainty of the parameter. Also, recognize that an incorrect field data, such as allocated production, will not produce precise match.

3 - Decide if a well function is needed to simulate certain condition such as partial penetration and coning or water under-running. Matching performance of a well in which water underlies or gas overlies the completion zone will require the use of coning model. The model is adjusted by varying the permeability in layers where uncertainty is greater. Vertical permeability is a very critical matching factor in the model.

4 - Examine simulation runs made to match pressure. Pressure match simulation runs may be used to identify the severity of stratification. This will require adjustment of vertical permeability. 
Vertical permeability can not be determined reliably from field or core measurements. The sensitivity of the model to varying the vertical permeability must be tested.

5 - The areal permeability distribution is also an important factor and may be adjusted to produce GOR and WOR match. The location of the reservoir internal geological features such as faults may also need to be adjusted, consult with the geologist to determine what should be adjusted.

6 - Decide whether relative permeability data should be adjusted. Avoid changing the relative permeability unless you determined the data are not reliable.

7 - Determine the effect of gridlock size on the performance of a selected group of wells. Larger blocks create apparent differences between the model and field behavior because of the errors in computed displacement efficiencies.

8 - As you proceed to make these changes, continue to compare calculated and actual pressure behavior. Pressure match should be maintained while GOR and WOR is being matched.

\section{Matching Well Pressure:}

The size of a block containing production or injection well in a simulator is normally much larger than the wellbore radius. The measured bottomhole pressure represents the pressure at $r=r_{w}$ at the time of the test. On the other hand, the calculated pressure represents the average pressure within the well block at the end of any given time step. Therefore, the measured 
bottom hole pressure of an active well can not be directly compared with the estimated pressures for the block. Before any comparison can be made, either the test pressure or the estimated block pressure must be adjusted so that both pressures correspond to the same point in space and time.

The relation between the measured pressure and the model estimated pressure as established by Peaceman is:

$r=0.2 \Delta x$,

where: $r$ the radius at which the two pressures correspond, and

$\Delta x$ the block width.

If the well is located off the center of the block, the data must be compared with the interpolated pressure.

\section{Matching Block Saturation to Contact Depths:}

Block size is normally too large for accurate determination of water / oil and gas / oil contacts positions from the block saturation in $2 D$ areal or $3 D$ models. WOC and $G O C$ obtained from the logs, therefore, can not be compared directly to block saturation. One approach used is to develop a correlation with results from a detailed cross - sectional model are plotted versus the pore volume, weighted average of the cross - sectional blocks corresponding to areal model blocks. Contact depths are read from the plot at times corresponding to those times when contact measurements were made in the field. 


\section{Automatic History Matching:}

Most models incorporate one or more of the several automatic history matching techniques available. These techniques use nonlinear optimization methods to achieve best fit of the field data. Most models do not permit matching more than one parameter simultaneously. Pressure is normally matched first then GOR or WOR with the option of selecting the type of data to vary.

To match the pressure, for example, the reservoir is divided into several regions and a multiplying factor is selected for each region and for each parameter. The varying parameters such as porosity or permeability, are either lowered or raised throughout the whole region. The number of regions in which porosity or permeability are to be varied should not exceed the number of observation points in the reservoir and the aquifer.

The idea of automatic history matching was initiated by rising computing cost during the past decades. However, in recent years computer cost has been drastically lowered and depending on the type of problem automatic history matching is selected, start with manual history matching to identify important matching variables before proceeding with the automatic history match.

Automatic history matching procedures may vary from one model to another, but generally will include:

1 - Assign the best current reservoir description to the model.

2 - Set up the matching parameters ( pressure, GOR, and WOR) in a format compatible to the history matching model. 
3 - Simplify the model: Several simulation runs will be required to achieve automatic history matching. Therefore, the model must be simplified as much as possible without compromising the accuracy of the model in representing the reservoir. For example, if production history is short and the original contacts have not moved significantly, a single phase model may be used. Also, courser grids is some time used in the history match phase.

4 - Select the variables to be adjusted: Select the variables that are to be adjusted by the automatic history match. It is important to select only those parameters that produce the greatest effect on the matching parameter and to ignore those with small affect.

5 - Set constraints on each of these variables: a realistic limits must be assigned for each varying parameter based on experience and understanding of the reservoir. Parameters that have small effect on the matching variable may drift aimlessly to produce the match. 


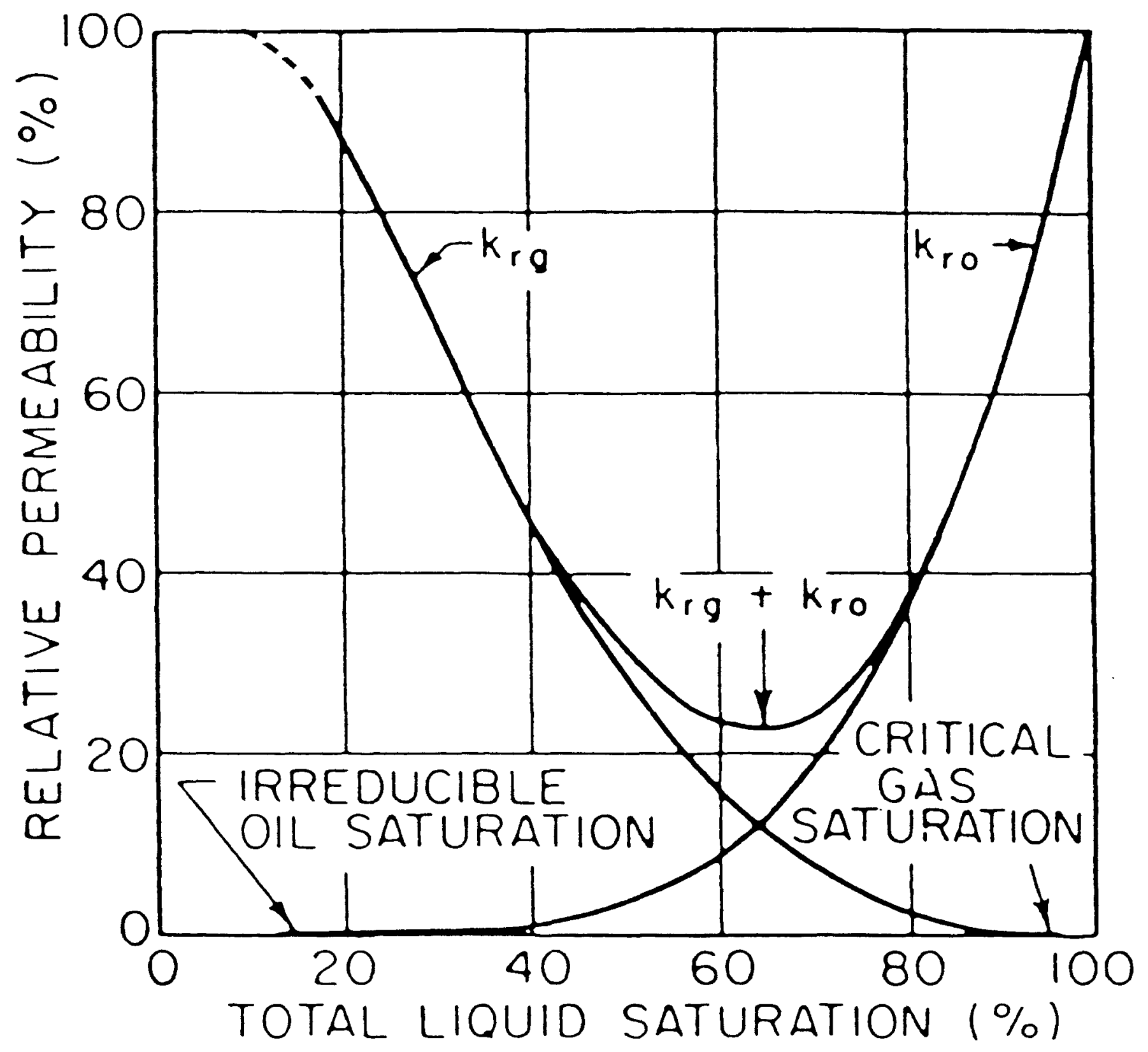


Starting with an element of the reservoir, the basic equation

for oll flow is derived by combining the continuity equation, the Darcy flow equation-and equation of state.

011 Mass Rate

In

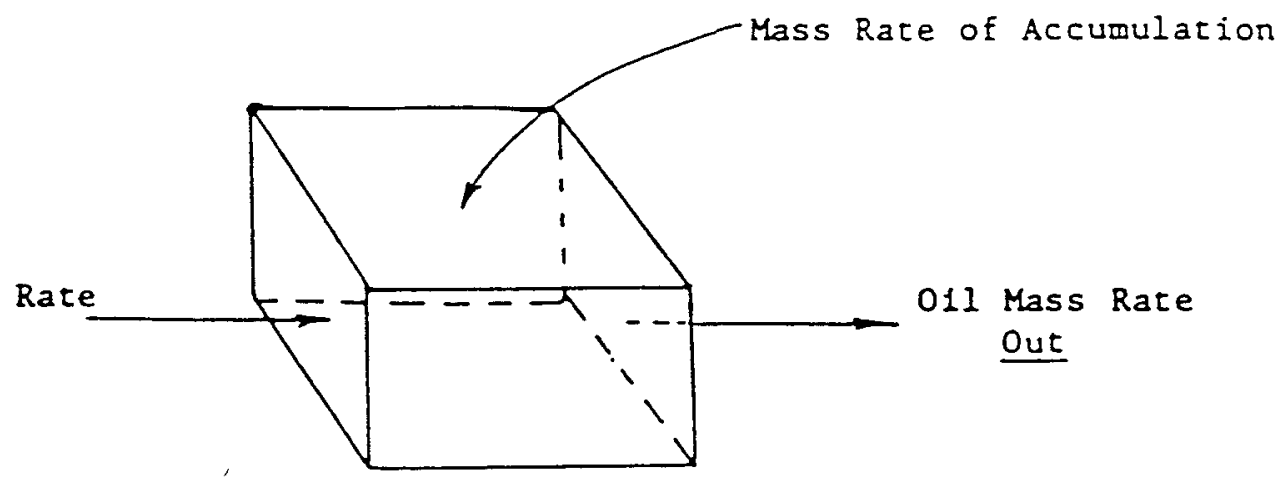

011 Mass balance on element

Using a balance on the STB oll flowing in a linear system:

Mass Rate 1n - Mags Rate out = Mass Rate of Accumulation

Thus :

$$
\left(-A \frac{k_{0}}{\mu_{0} B_{0}} \frac{\partial P}{\partial x}\right)_{x}-\left(-A \frac{k_{0}}{\mu_{0} B_{0}} \frac{\partial P}{\partial x}\right)_{x+\Delta x}=v\left[\frac{\left(\frac{\phi S_{0}}{B_{0}}\right)^{n+1}-\left(\frac{S_{0}}{B_{0}}\right)^{n}}{\Delta t}\right]
$$

which becomes in the limit:

$$
\frac{\partial}{\partial x}\left(\frac{k_{0}}{\mu_{0} B_{0}} \frac{\partial P}{\partial x}\right)=\frac{\partial}{\partial t}\left(\frac{\phi S_{0}}{B_{0}}\right)
$$

c. Water:

This is essentally the same as the oll phase:

For a linear system:

$$
\frac{\partial}{\partial x}\left[\frac{k_{w}}{H_{w} B_{w}} \frac{\partial P}{\partial x}\right]=\frac{\partial}{\partial t}\left[\phi \frac{S_{w}}{B_{w}}\right]
$$




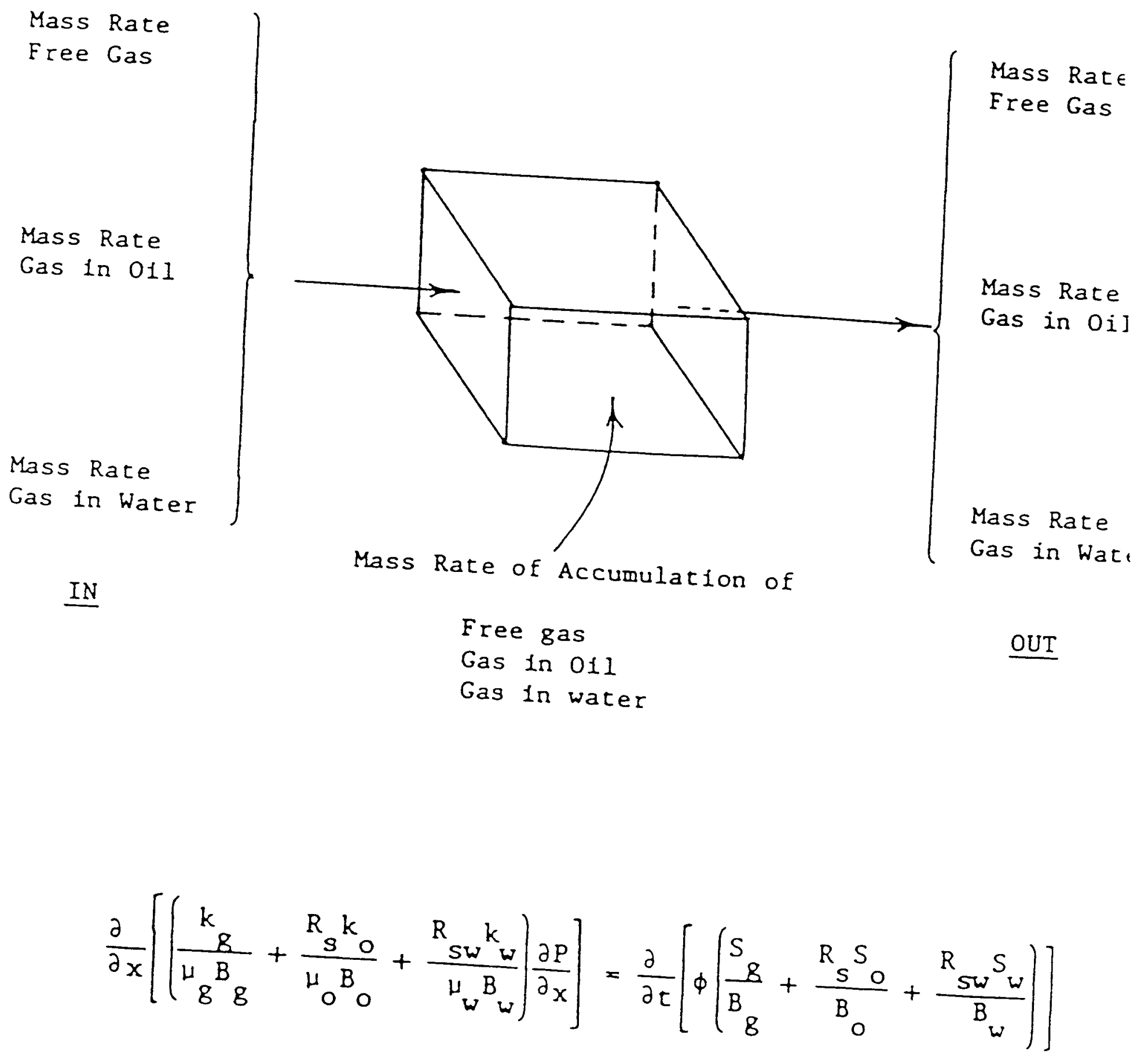


$\frac{\partial^{2} P}{\partial r^{2}}+\frac{1}{r} \frac{\partial P}{\partial r}=\frac{\phi \mu c}{k} \frac{\partial P}{\partial t} \quad$ radial flow

$\frac{\partial^{2} P}{\partial x^{2}}+\frac{\partial^{2} P}{\partial y^{2}}=\frac{\phi \mu c}{k} \frac{\partial P}{\partial t}$

two dimensional

$\frac{\partial^{2} p}{\partial x^{2}}+\frac{\partial^{2} p}{\partial y^{2}}+\frac{\partial^{2} p}{\partial z^{2}}=\frac{\phi \mu c}{k} \frac{\partial p}{\partial t}$
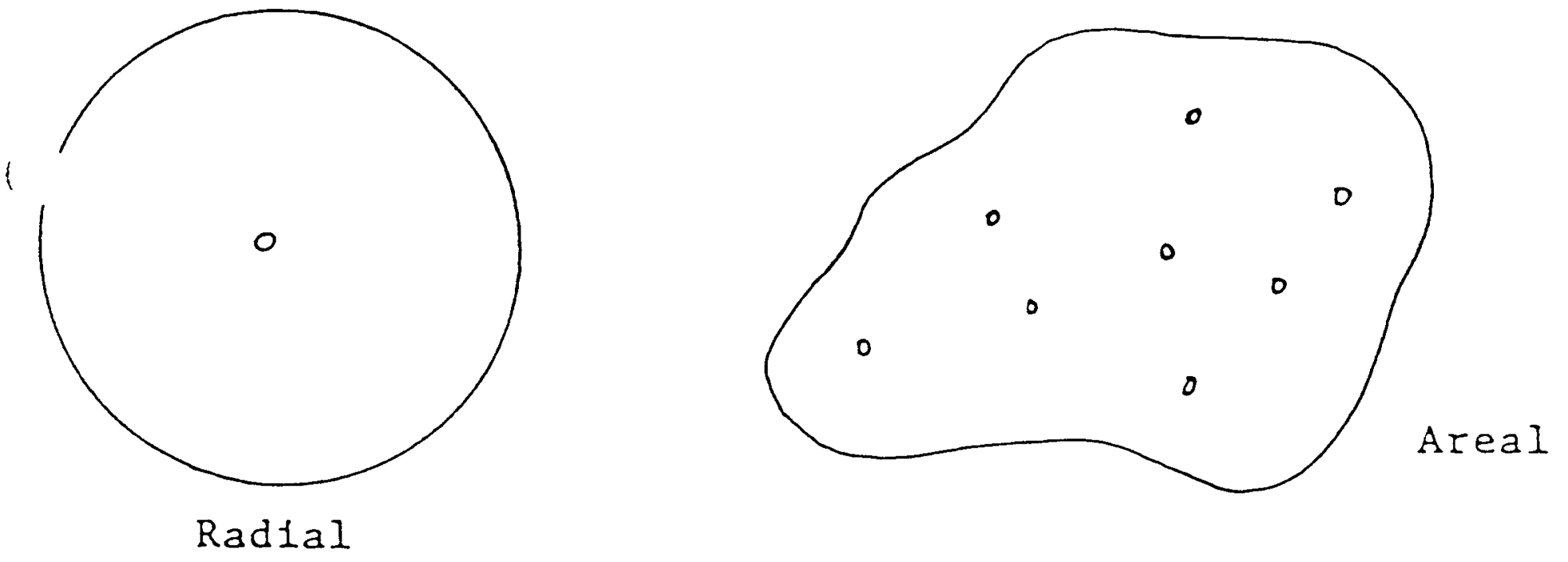

Radial

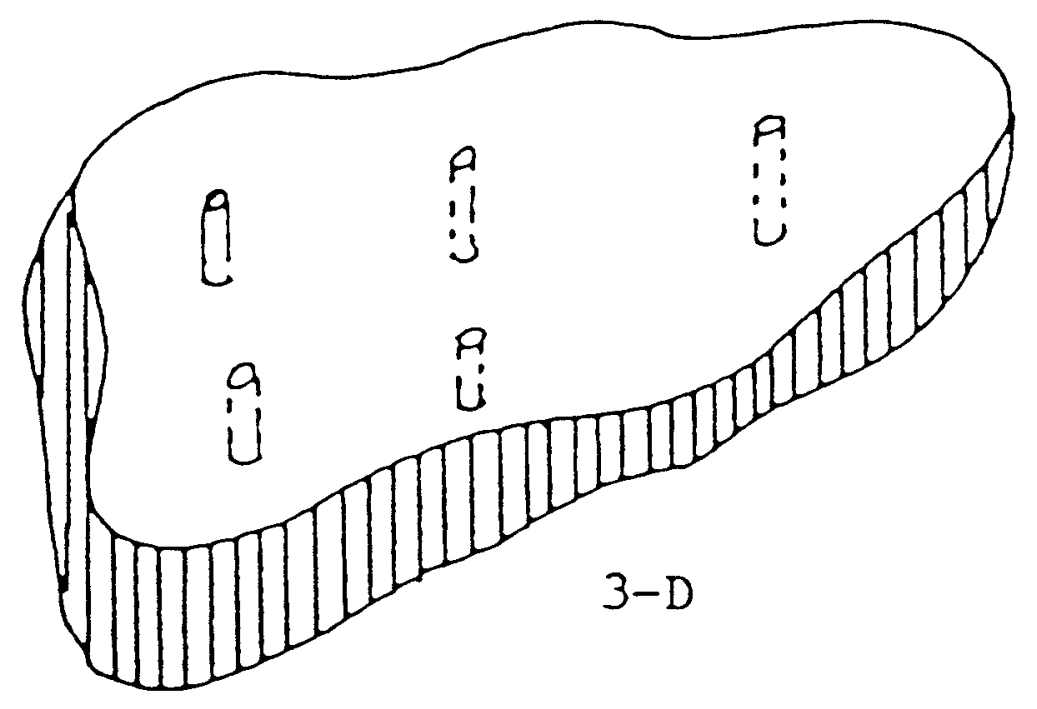


FIRST.DIFFERENCF. QUOTIFNTS

Consider a function of three independent variables $u(x, y, l)$. $\wedge$ first derivative can be defined as a limit in several ways:

$$
\begin{aligned}
& \frac{\partial u}{\partial x}(x, y, t)=\lim _{\Delta x \rightarrow 0} \frac{u(x+\Delta x, y, t)-u(x, y, t)}{\Delta x} \\
& \frac{\partial u}{\partial x}(x, y, t)=\lim _{\Delta x \rightarrow 0} \frac{u(x, y, t)-u(x-\Delta x, y, t)}{\Delta x} \\
& \frac{\partial u}{\partial_{r}}(x, y, t)=\lim _{\Delta x \rightarrow 0} \frac{u(x+\Delta x, y, t)-u(x-\Delta x, y, t)}{2 \Delta x}
\end{aligned}
$$

Now, if we replace a derivative by a difference quoticnt, we want to know how good an approximation it is. For this, we use Taylor's scries with remainder. For example:

$u(x+\Delta x, y, t)=u(x, y, t)+\Delta x \frac{\partial u}{\partial x}(x, y, t)+\frac{\Delta x^{2}}{2} \frac{\partial^{2} u}{\partial x^{2}}(x * y, t)$

where $x \leqslant x^{*} \leqslant x+\Delta x$. In this case, the last term is a remainder that involves the secund derivative of $u$ evaluated somewhere in the interval between $x$ and $x+\Delta x$. Solving for $\partial u / \partial x$ : 


\section{Finte Difference Schemes}

Expl1c1t: One Dimensional

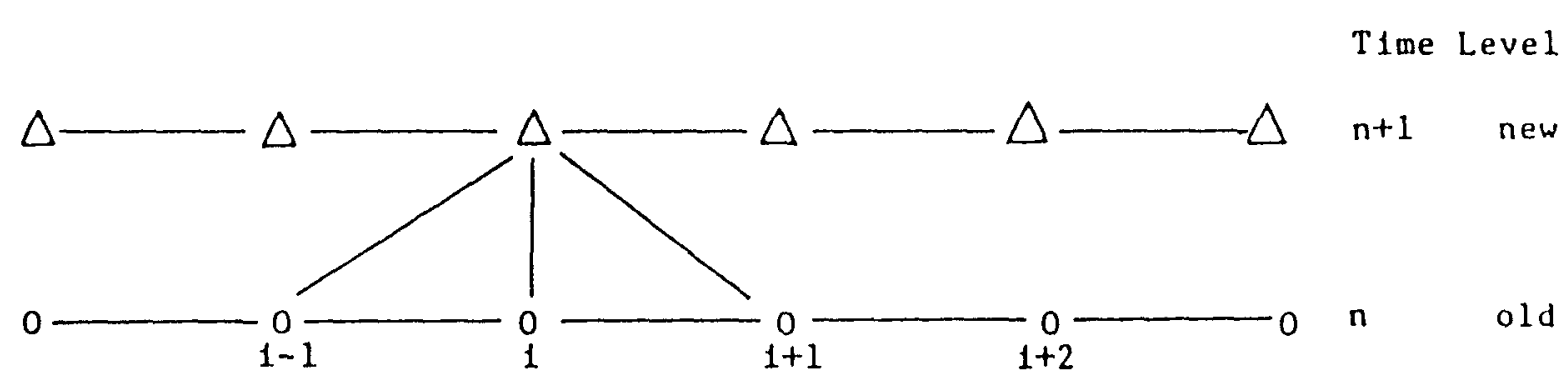

Differential Equation: $\frac{\partial^{2} p}{\partial x^{2}}=\frac{\partial p}{\partial t}$

Finfte Difference Equation:

$$
\frac{p_{1+1}^{n}-2 p_{1}^{n}+p_{1-1}^{n}}{\Delta x^{2}}=\frac{p_{1}^{n+1}-p_{1}^{n}}{\Delta t}
$$




\section{Finite Difference Schemes}

$\operatorname{Imp} 11 \mathrm{c} 1 \mathrm{t}$

TIme Level

new n+

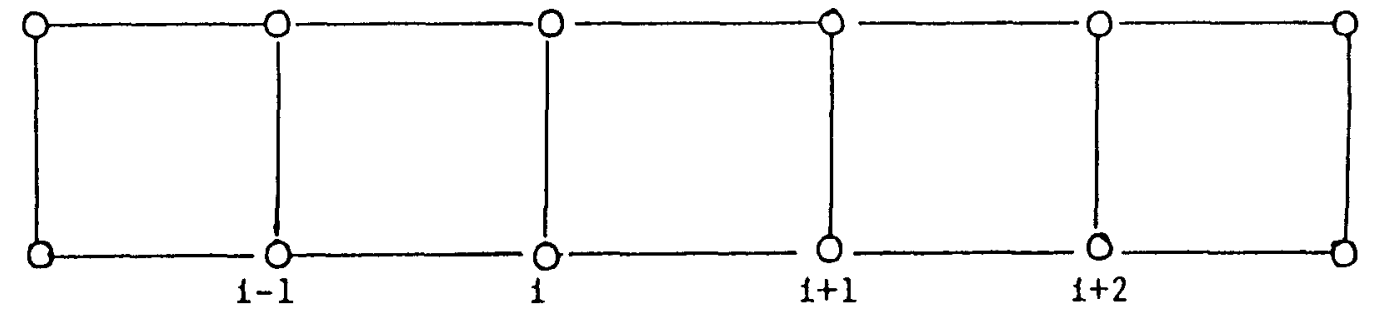

Differential Equation: $\frac{\partial^{2} p}{\partial x^{2}}=\frac{\partial p}{\partial t}$

Finfte Difference Equation:

$$
\frac{p_{1+1}^{n+1}-2 P_{1}^{n+1}+P_{1-1}^{n+1}}{\Delta x^{2}}=\frac{p_{1}^{n+1}-P_{1}^{n}}{\Delta t}
$$

Implicit formulation in one dimension 
Finite Difference Schemes

Mixed (Crank-N1cholson):

TIme Level new $n+1$ $n+\frac{1}{2}$

old

$n$

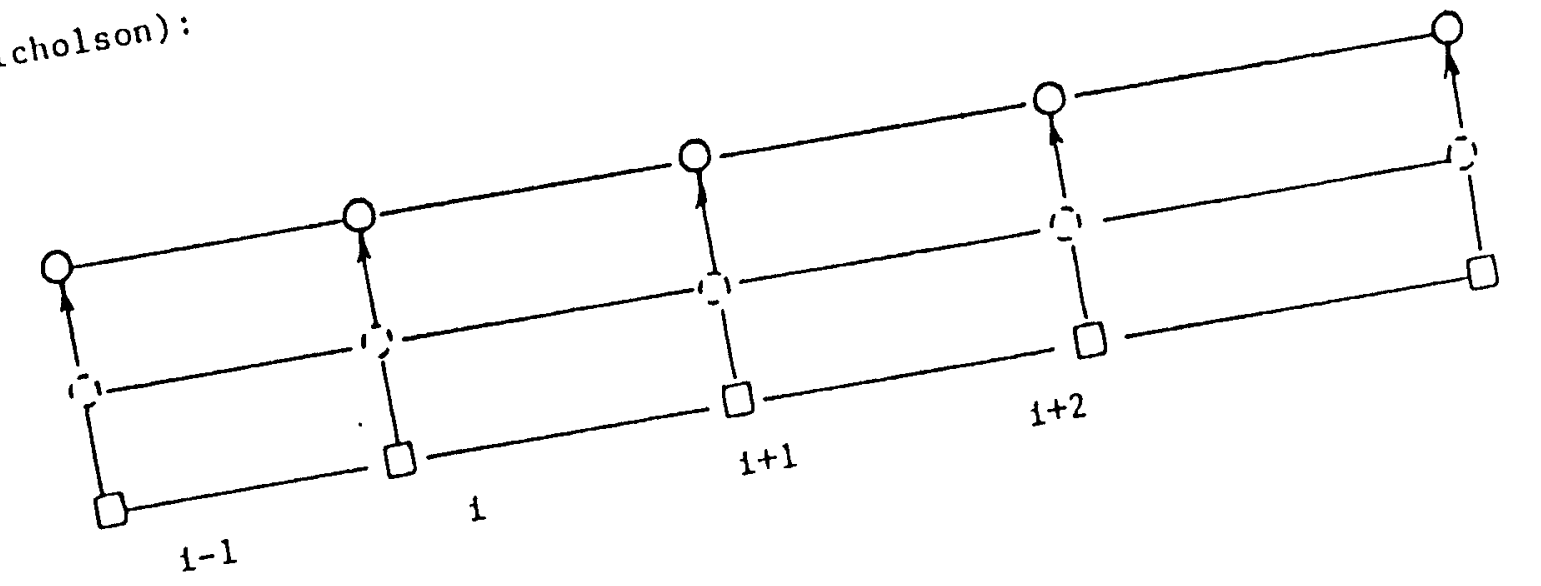

Differential Equation: $\frac{\partial^{2} p}{\partial x^{2}}=\frac{\partial p}{\partial t}$

Elate Difference Equation:

$$
\frac{\theta\left[P_{1+1}^{n}-2 P_{1}^{n}+P_{1-1}^{n}\right]}{\Delta x^{2}}+\frac{(1-\theta)\left(P_{1+1}^{n+1}-2 P_{1}^{n+1}+P_{1-1}^{n+1}\right]}{\Delta x^{2}} \cdot \frac{p_{1}^{n+1}-P_{1}^{n}}{\Delta t}
$$

Med formulations 


$$
\begin{aligned}
& a_{11} p_{1}+a_{12} p_{2}+a_{13} p_{3}=q_{1} \\
& a_{21} p_{1}+a_{22} p_{2}+a_{23} p_{3}=q_{2} \\
& a_{31} p_{1}+a_{32} p_{2}+a_{33} p_{3}=q_{3}
\end{aligned}
$$

$$
\left[\begin{array}{lll}
a_{11} & a_{12} & a_{13} \\
a_{21} & a_{22} & a_{23} \\
a_{31} & a_{32} & a_{33}
\end{array}\right]\left[\begin{array}{l}
p_{1} \\
p_{2} \\
p_{3}
\end{array}\right]=\left[\begin{array}{l}
q_{1} \\
q_{2} \\
q_{3}
\end{array}\right]
$$




\begin{tabular}{|c|c|c|c|c|c|}
\hline 13 & 28 & 14 & 29 & 15 & 30 \\
\hline 25 & 10 & 26 & 11 & 27 & 12 \\
\hline 7 & 22 & 8 & 23 & 9 & 24 \\
\hline 19 & 4 & 20 & 5 & 21 & 6 \\
\hline 1 & 16 & 2 & 17 & 3 & 18 \\
\hline
\end{tabular}

(a)

\begin{tabular}{|c|c|c|c|c|c|}
\hline 5 & 22 & 10 & 27 & 14 & 30 \\
\hline 18 & 6 & 23 & 11 & 28 & 15 \\
\hline 2 & 19 & 7 & 24 & 12 & 29 \\
\hline 16 & 3 & 20 & 8 & 25 & 13 \\
\hline 1 & 17 & 4 & 21 & 9 & 26 \\
\hline
\end{tabular}

(b)

-Ordering of gridblocks: (a) A3 and (b) D4. 

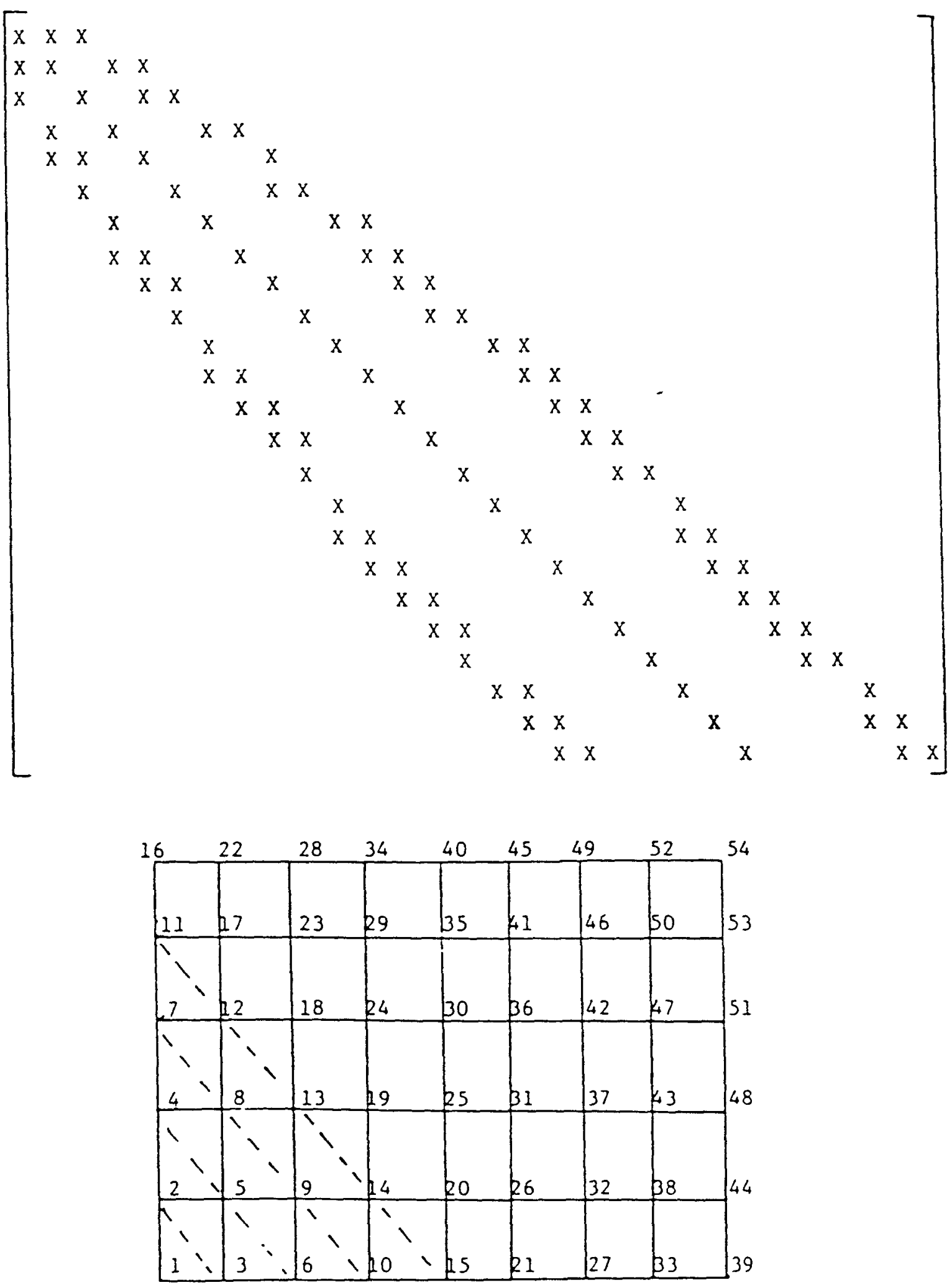

Diagonal Ordering and Matrix System 


\section{PLANNING A SIMULATION STUDY}

\section{Problem Definition}

Data Review
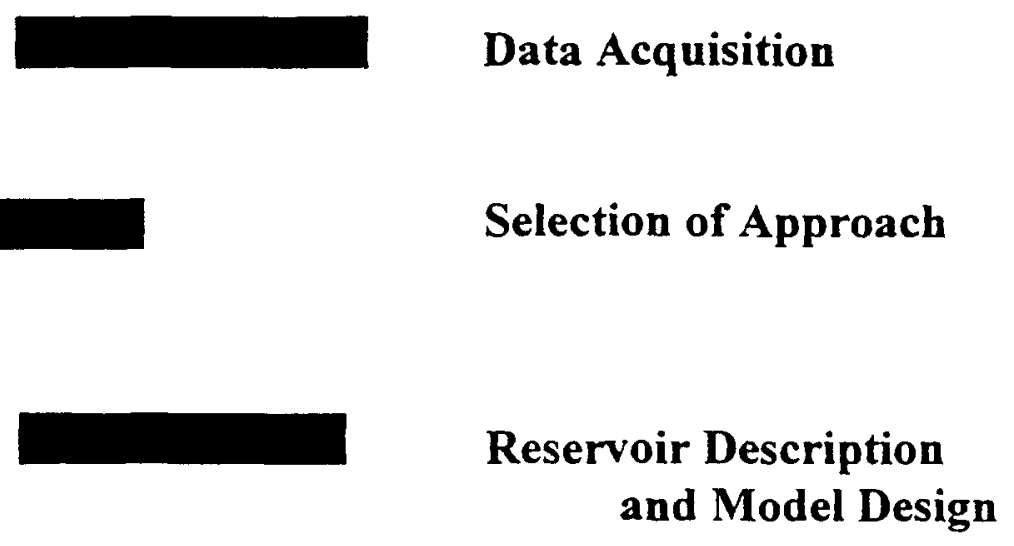

$$
\text { and Model Design }
$$
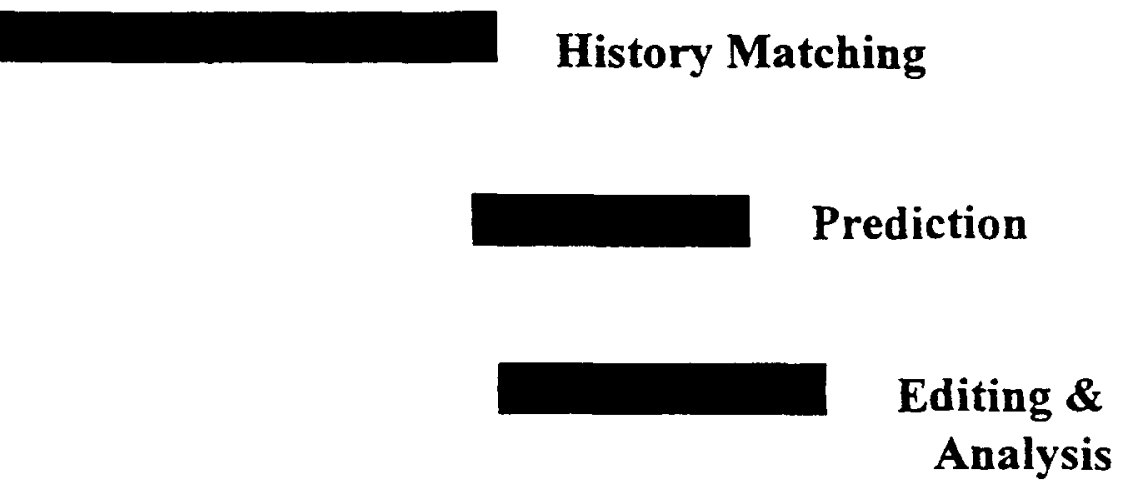

Reporting 
If a 2-D areal model is used to simulate thick stratified reservoirs, the dynamic pseudo-relative permeability and pseudo-capillary pressure must be used to correct for the absence of the vertical dimension.

Pseudofunctions are even used in 3-D simulation where the vertical dimensions of the blocks is large.

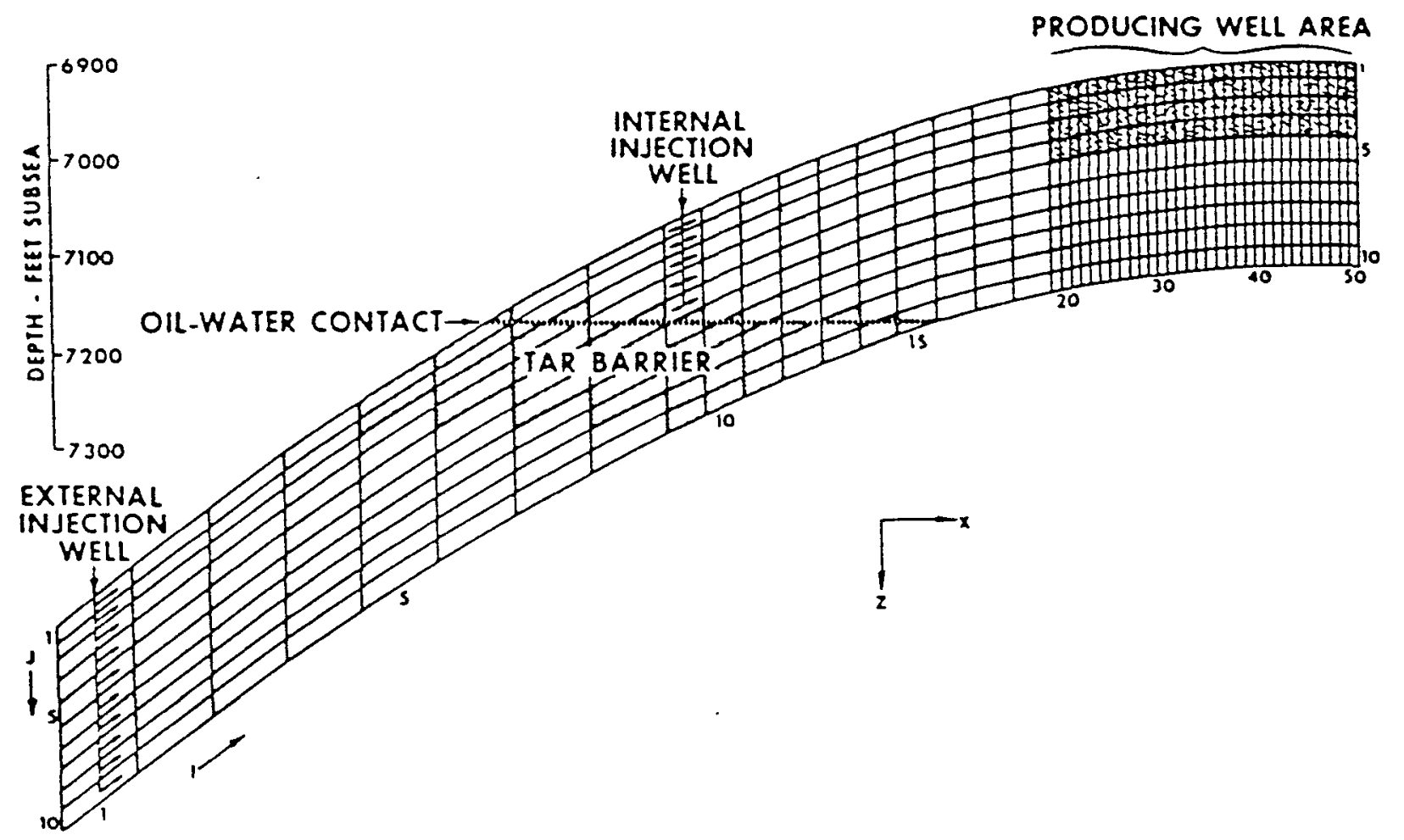

Typical 2-D cross-sectional model used to derive dynamic pseudofunctions.

Pseudofunctions are saturation dependent and are used to indicate the saturation distritution in the vertical direction. Dynamic Pseudofunctions are derived through detailed simulation of the fluid displacement in a 2-D cross-sectional model of the reservoir. 

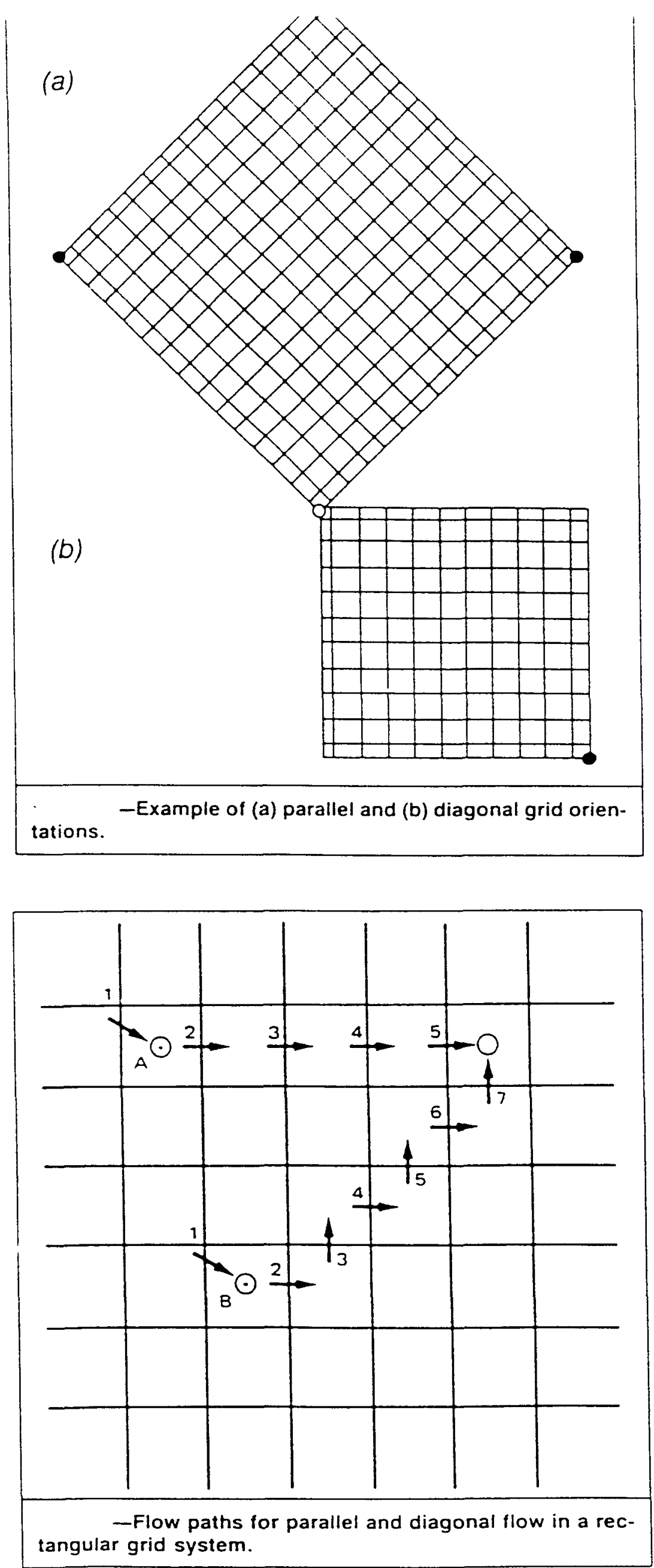


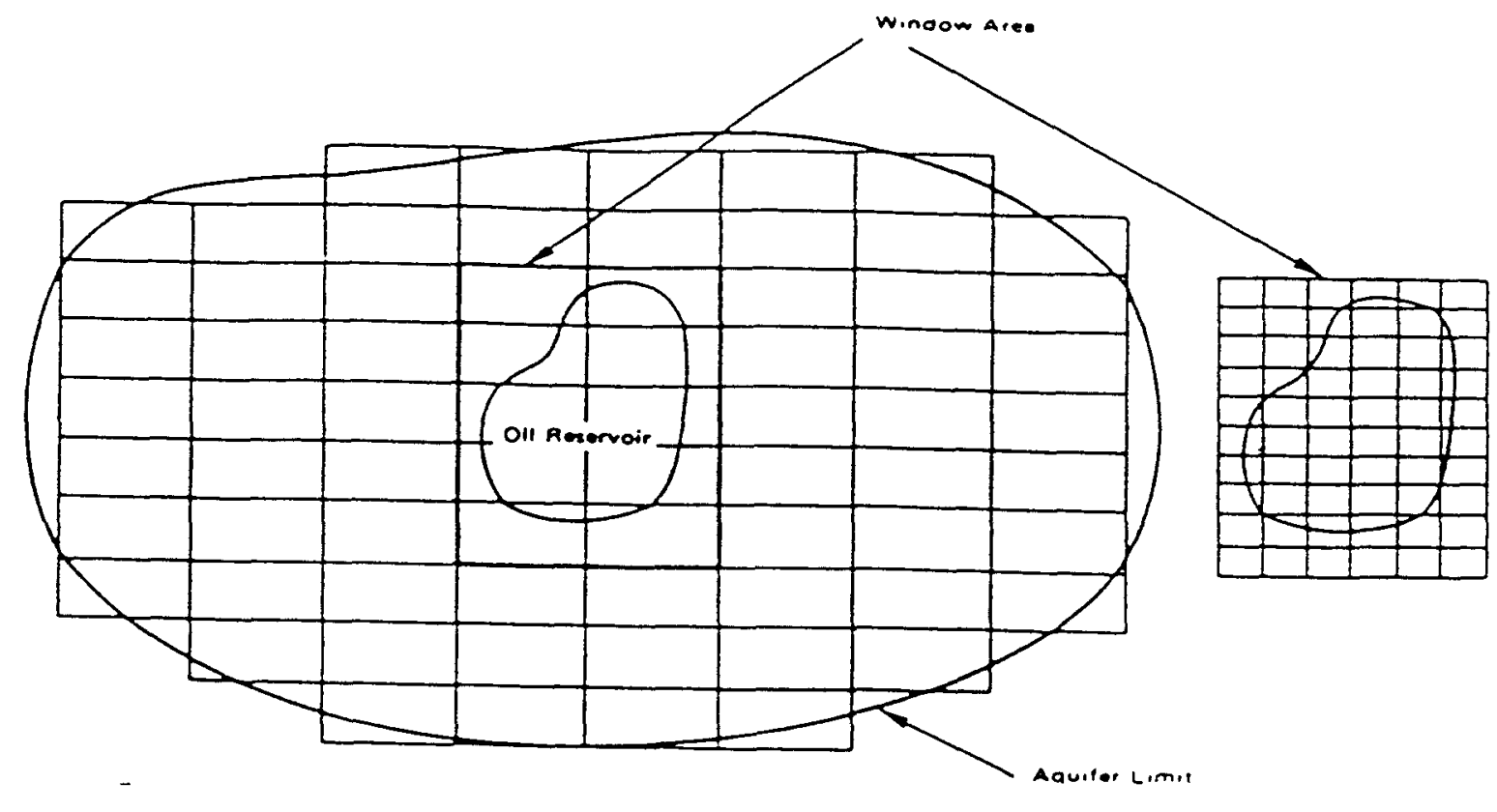

Windowed model.

\section{2 .3}

A coar $\quad 2$ initially to simulate the overall

performance of the reservoir and the aquifer. Then, a window is selected to cover the reservoir only. The region defined by the window is then modeled with finer gridblock. The flux determined by the coarser model at the window boundary is used as a boundary condition for the finer boundary.

The two models can be linked together for the flux to be passed automatically at the end of each time step. 


$$
\begin{aligned}
& \bar{s}_{-}=\frac{\sum_{i=1}\left(\phi h S_{-1}\right)_{i}}{\sum_{i=1}^{n}(\phi h)_{i}} \\
& k_{p r o}=\frac{\sum_{i=1}^{n}\left(k h k_{m o}\right)_{i}}{\sum_{i=1}^{n}(k h)_{i}} \\
& \text { and } \\
& k_{p \sim r}=\frac{\left.\sum_{i=1}^{n}(k h k)_{m i}\right)_{i}}{\sum_{i=1}^{n}(k h)_{i}}
\end{aligned}
$$

Results of the 2-D cross-sectional simulation are processed to give the average saturation and the dynamic pseudofunctions for each column in the model. Dynamic pseudofunctions may differ from column to column due to the difference in initial saturation, velocity of the fluids, and formation stratification. However, these differences are frequently minor otherwise a correlation must be developed to reduce the complexity of the pseudofunctions.

The validity of the dynamic pseudofunctions developed from the 2-D cross-sectional must be tested by running an identical $1-D$ model and the results are compared.

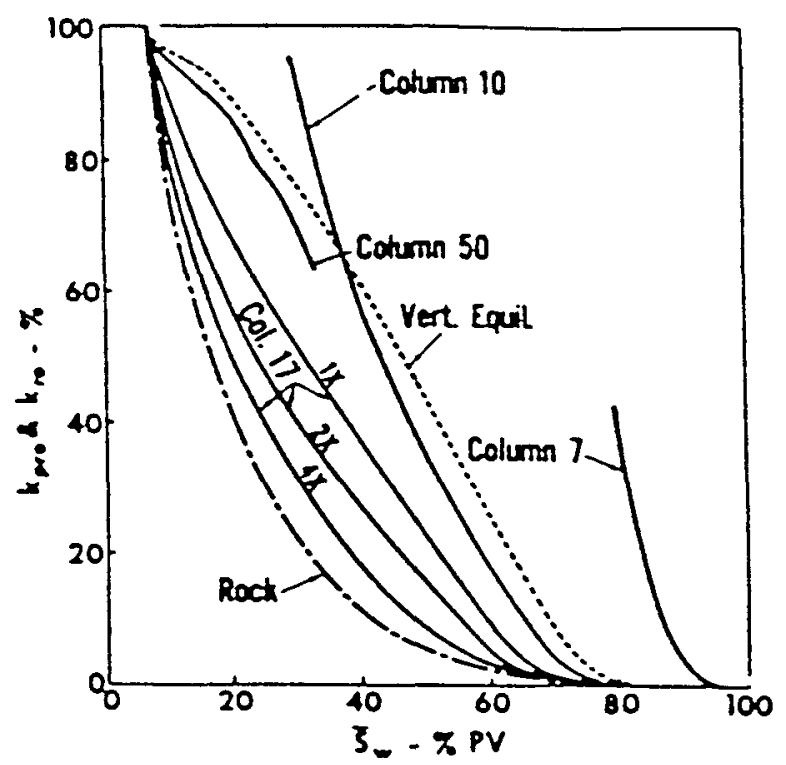

Example of dynamic pseudo-relative permeability. 

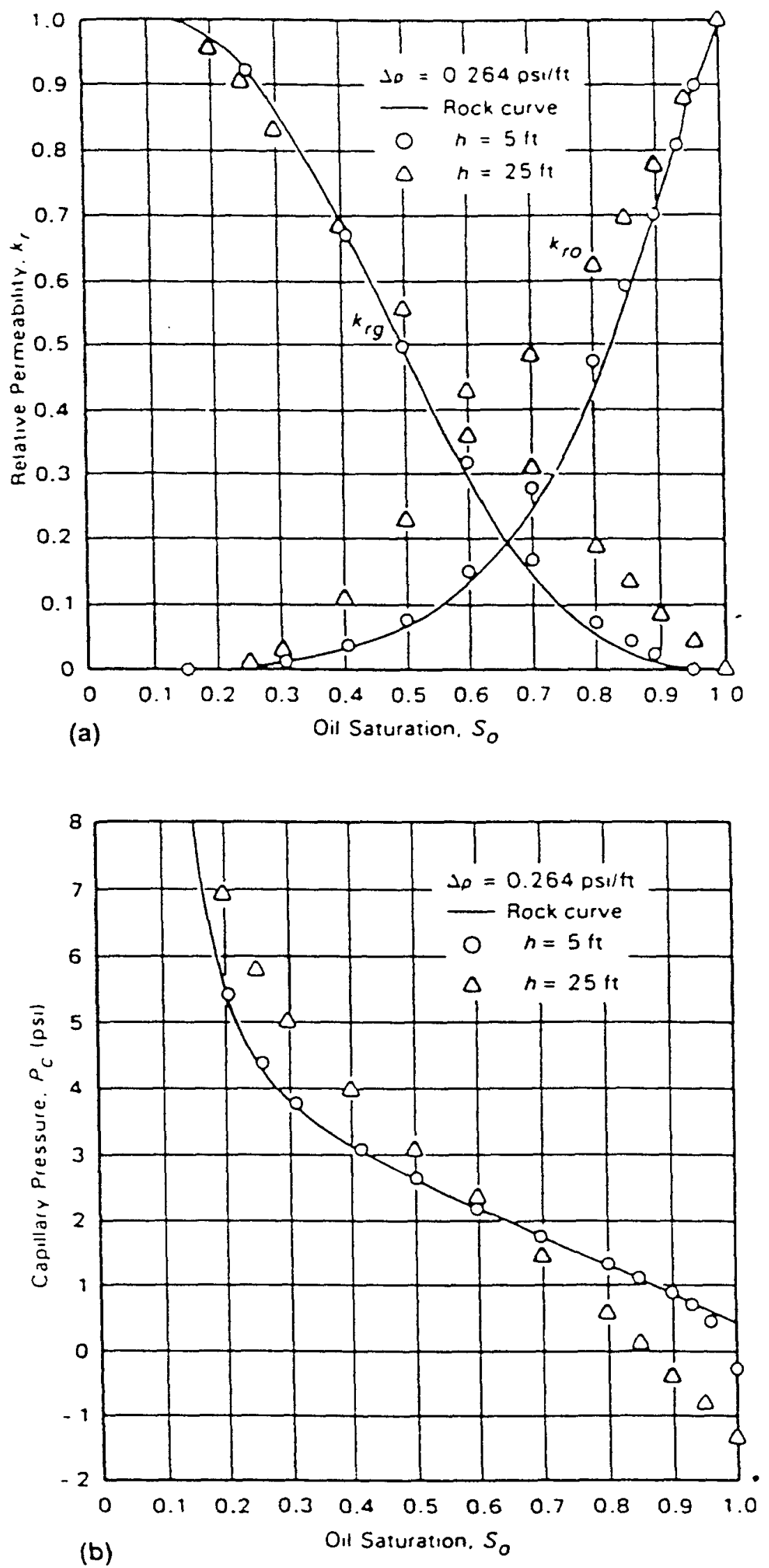

(a) Typical pseudo-relative permeatility.

(b) Pseudo capillary pressure. 


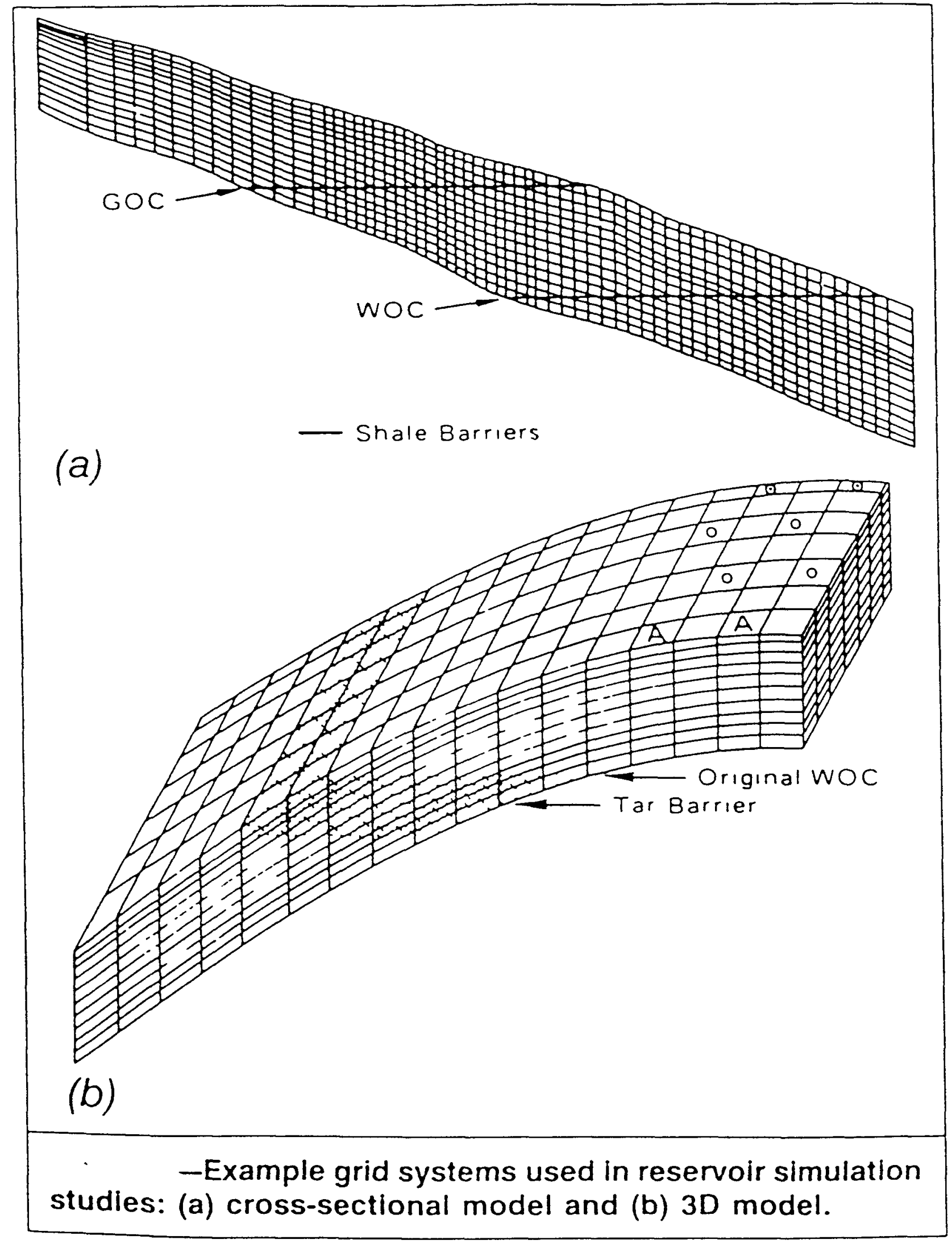




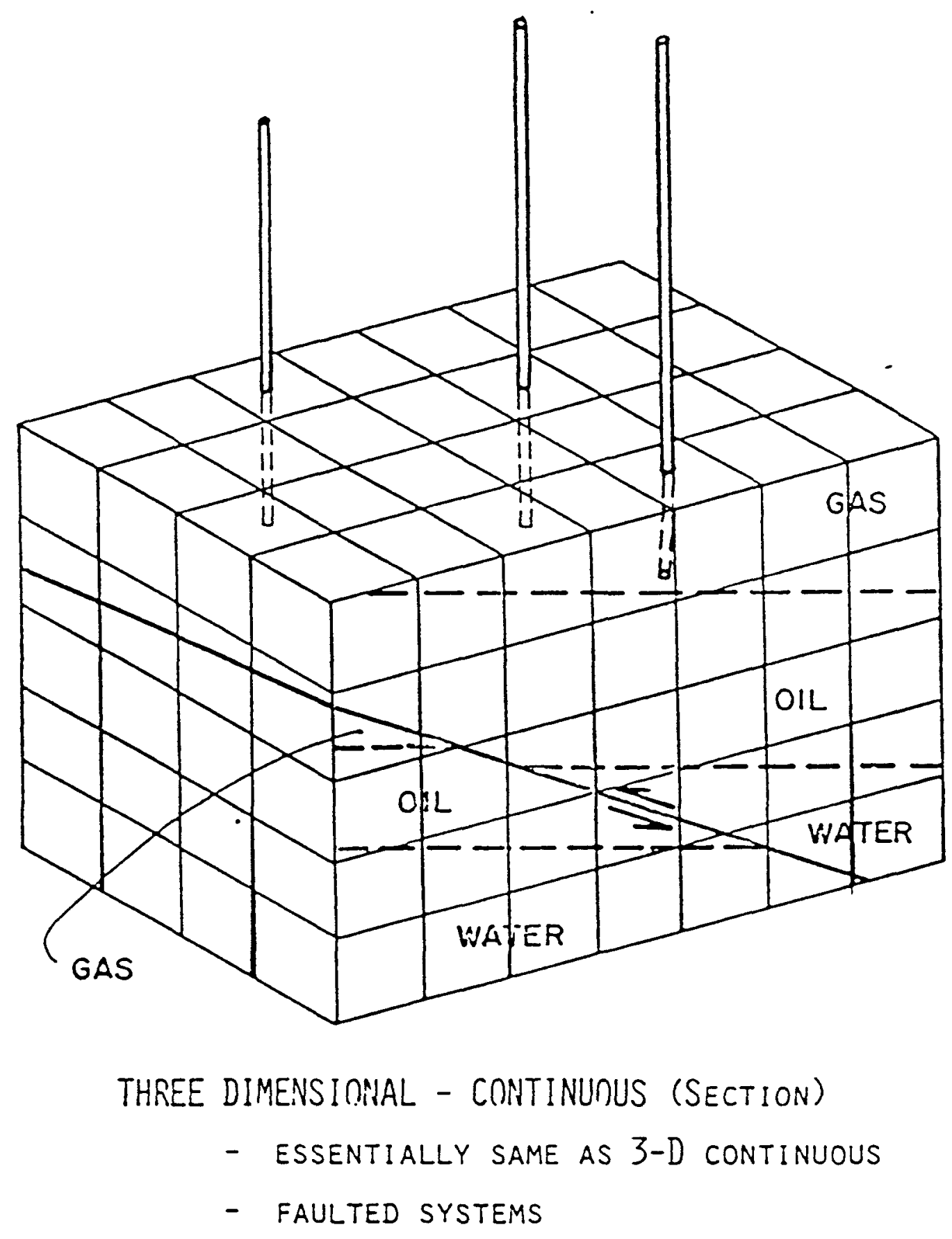




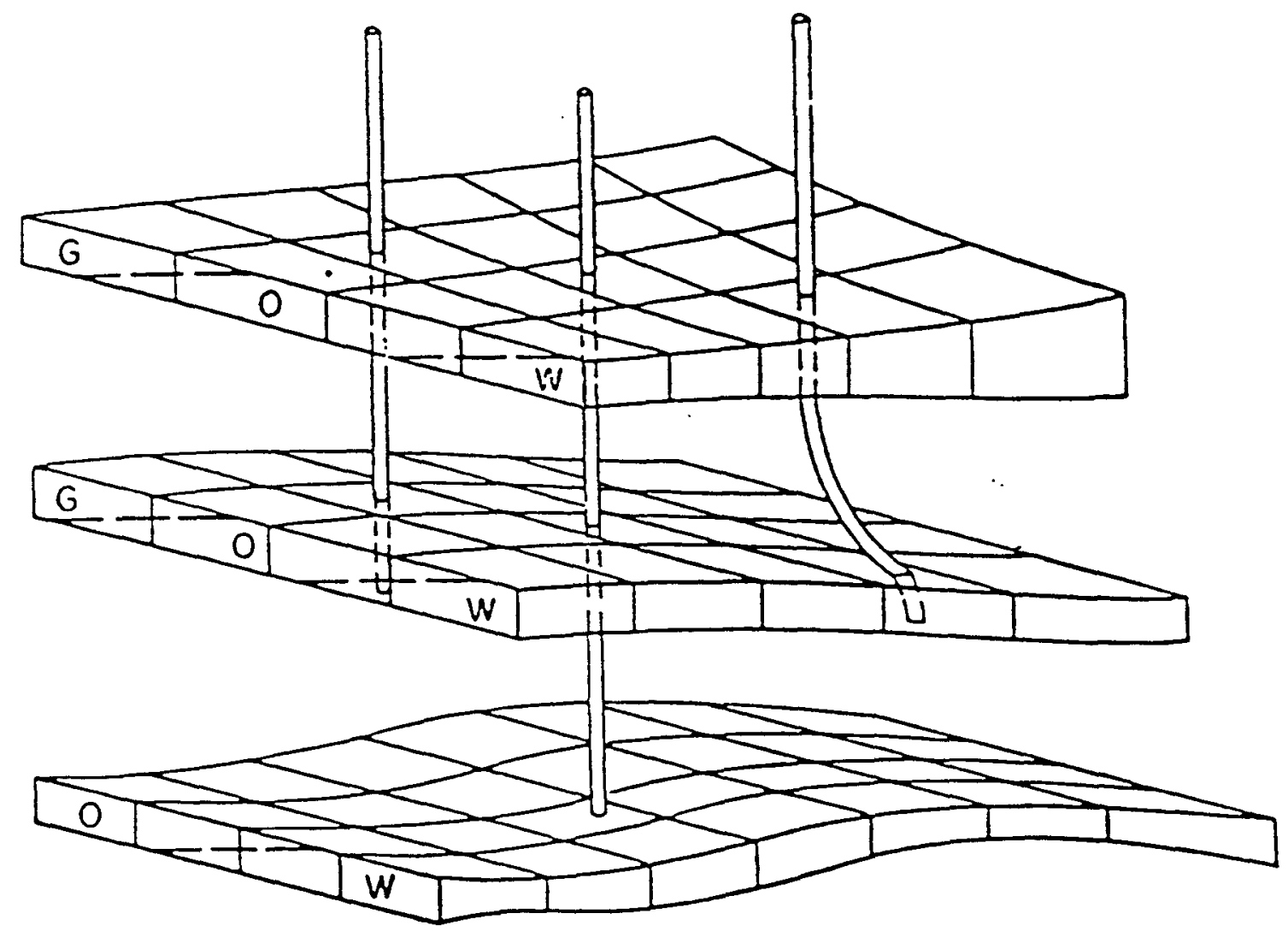

IHFEE DUMEISLLHAL LAYCRED

- SIMULATION OF LARGE RESERVOIRS CONSISTING OF SEVERAL PRODUCING HORIZONS

- COMMINGLED OR NON-COMMINGLED PRODUCTION

- MULTIPLE COMPLETICNS

- THIS MODEL IS IN EFFECT SEVERAL 2-D MODELS STACKED TOGETHER WITH SPSCIAL WELL BORE HYDRAULICS ROUTINES 


\title{
AQUIFER MODELS:
}

\section{- Numerical}

Aquifer and reservoir are simulated in one model using smaller grids to define the reservoir and increasingly larger grid in the aquifer region.

\author{
- Analytical \\ - Pot Aquifer \\ - Steady-State Aquifer. \\ - Carter-Tracy Aquifer.
}




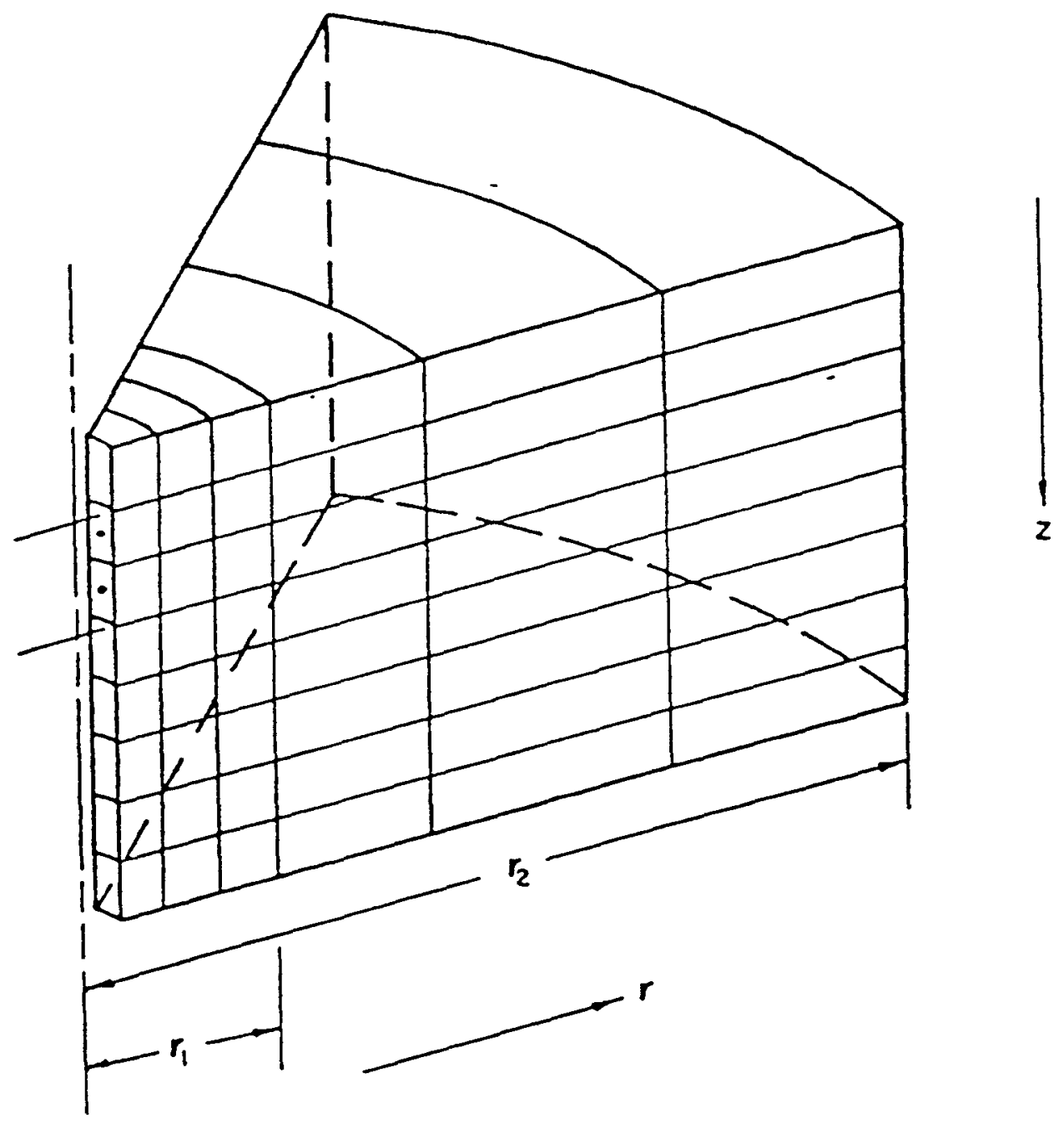

TWO DIMENSIONAL CONING MODEL

- SINGLE WELL OPTIMIZATION STUDIES

-LOCATION OF COMPLETION INTERVALS

- MAXIMUM EFFICIENT RATES

- DELIVERABILITY STUDIES

- WELL TEST ANALYSIS 


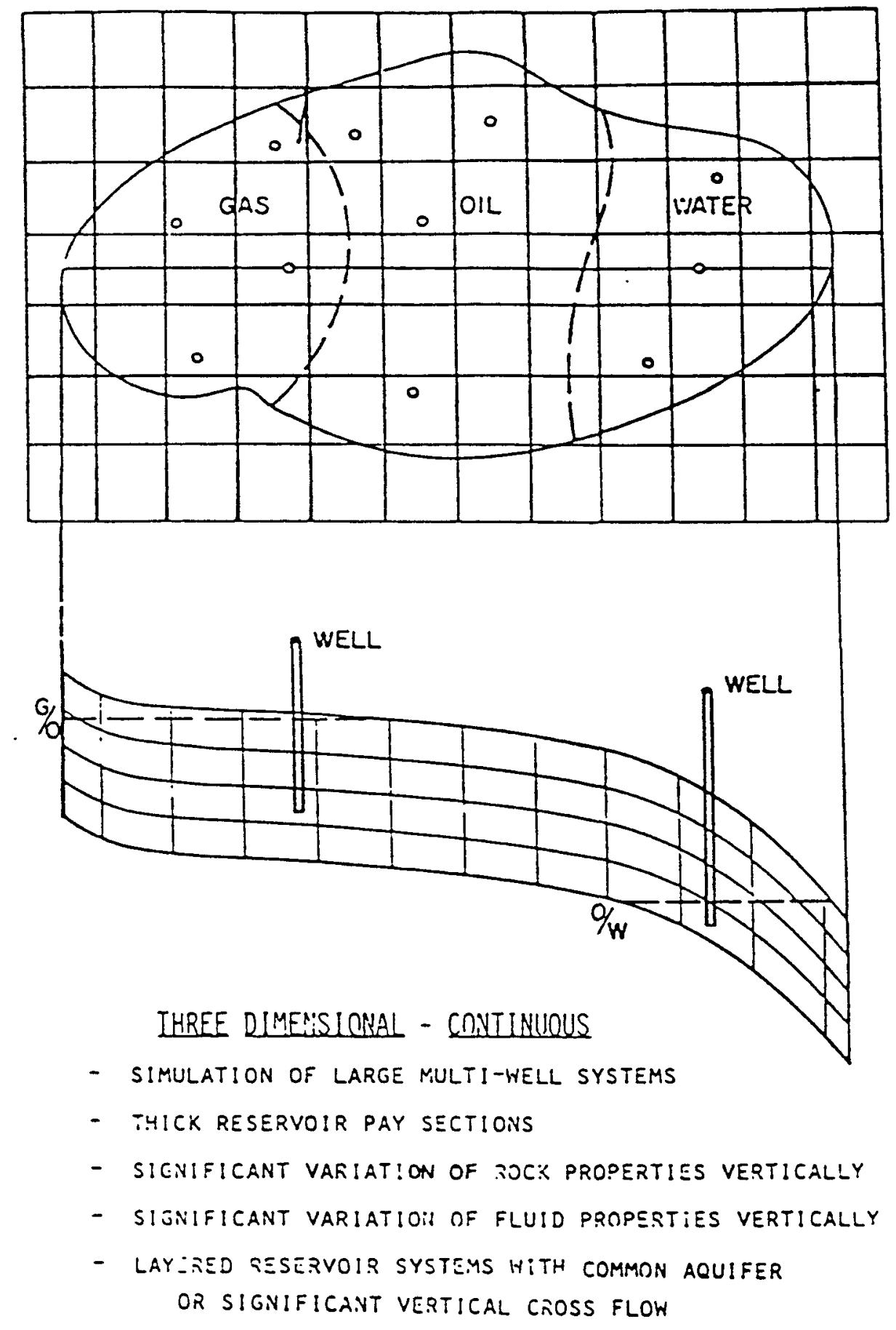




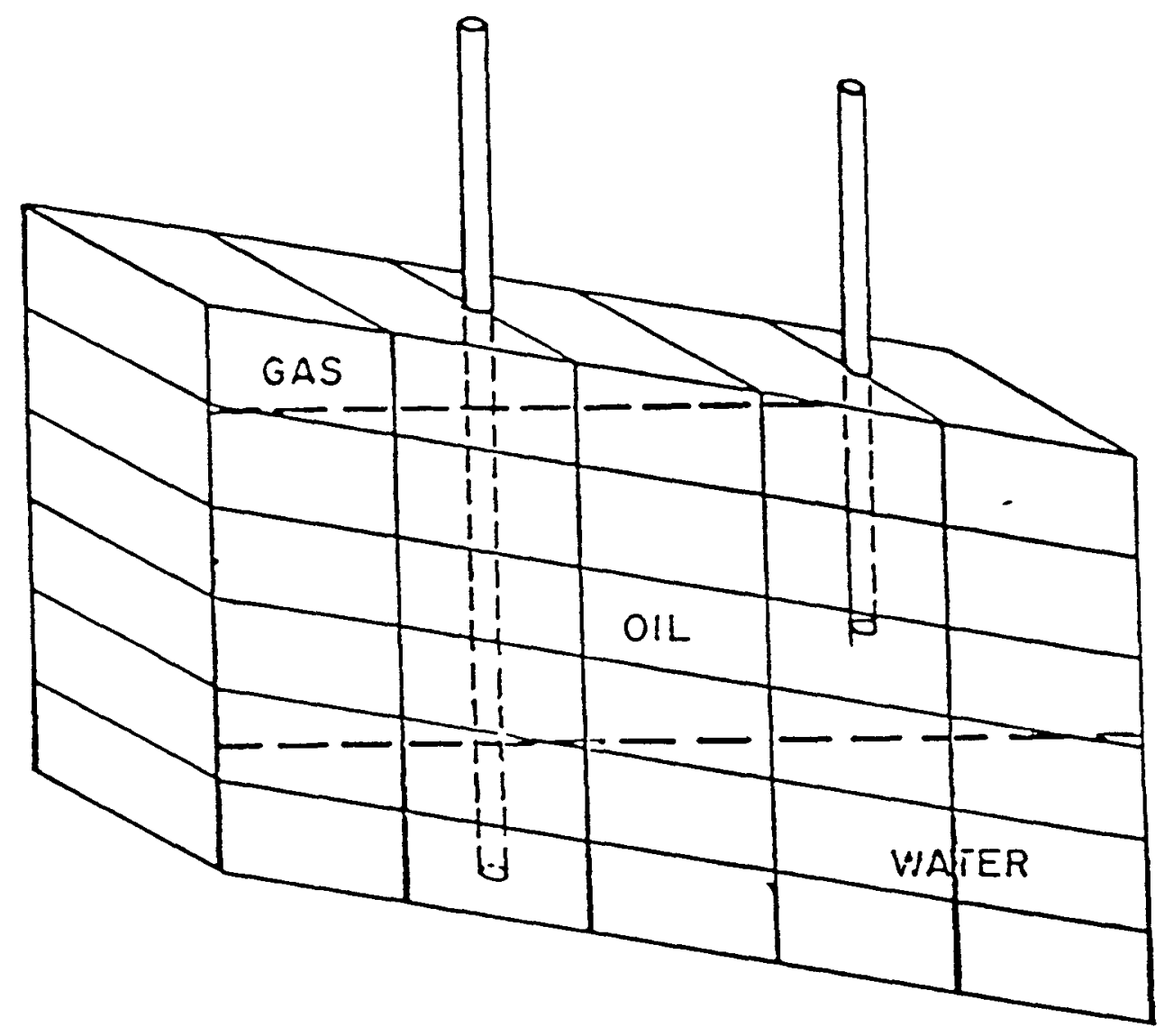

THO DIMENSIONAL YERIICAL

- S!NGLE OR MULTiPLE WELL SIMULATiON

- CROSS-SECTION ANALYSIS OF RESERVOIR

FOR (1) GRAVITY SEGREGATION

(2) EFFECT OF ANISOTROPY ON

FRONTAL DISPLACEMENT 


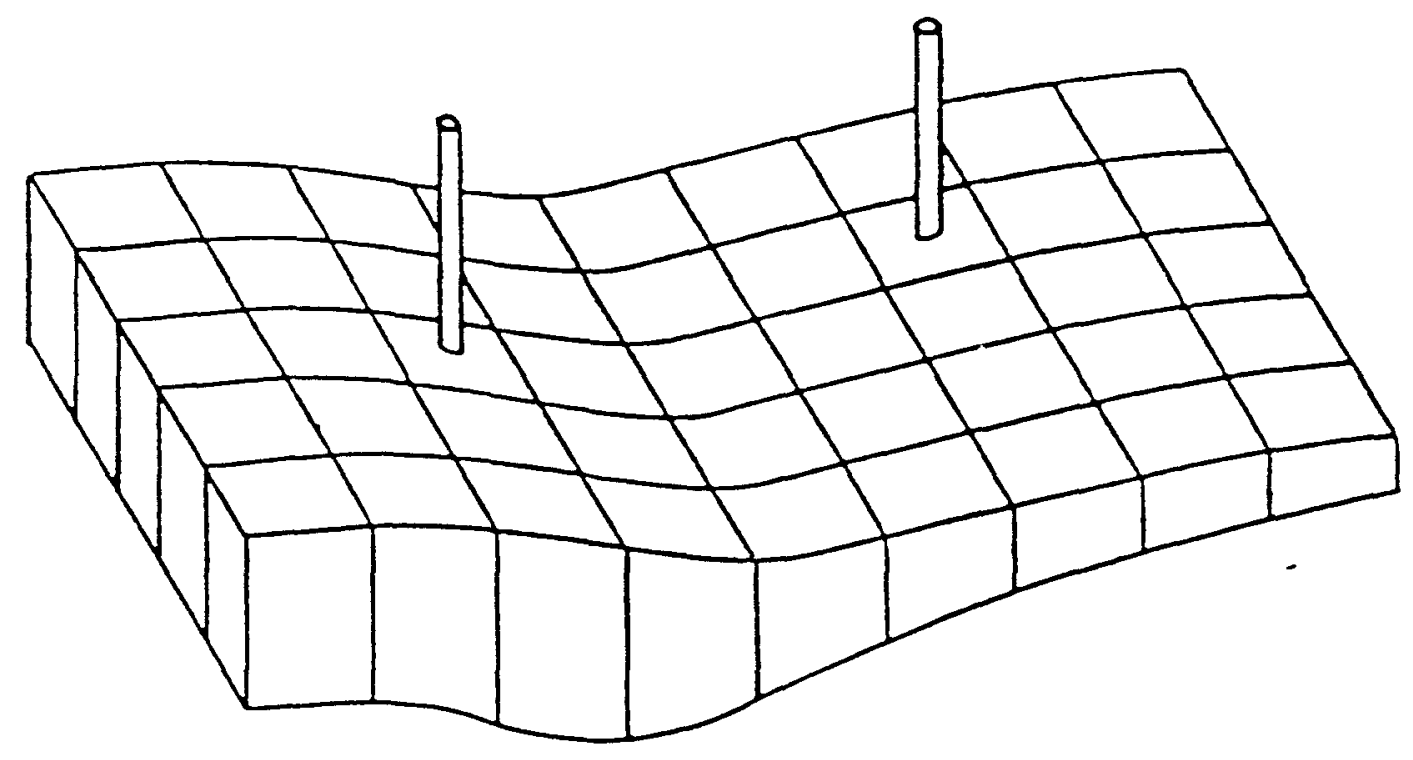

THE DIHE:'SIONAL HORIZOUITAL

MOST GeNERALIZED AND ALL PURPOSE MODEL

- SimUlation OF LARGE MULTI-WELl STRUCTURE

- large reservoir simulations of multi-Unit systems

- HETEROGENOUS ROCK PROPERTIES

- SLIGHT VERTICAL VARIATION IN FLUID PROPERTIES

- ANALYSIS OF MIGRATION ACROSS LEASE LINES

- SELECTION OF OPTIMUMH OPERATIOM:AL SCHEMES IN SECONDARY RECOVERY ANE PRESSLIIE :AAINTENANCE 


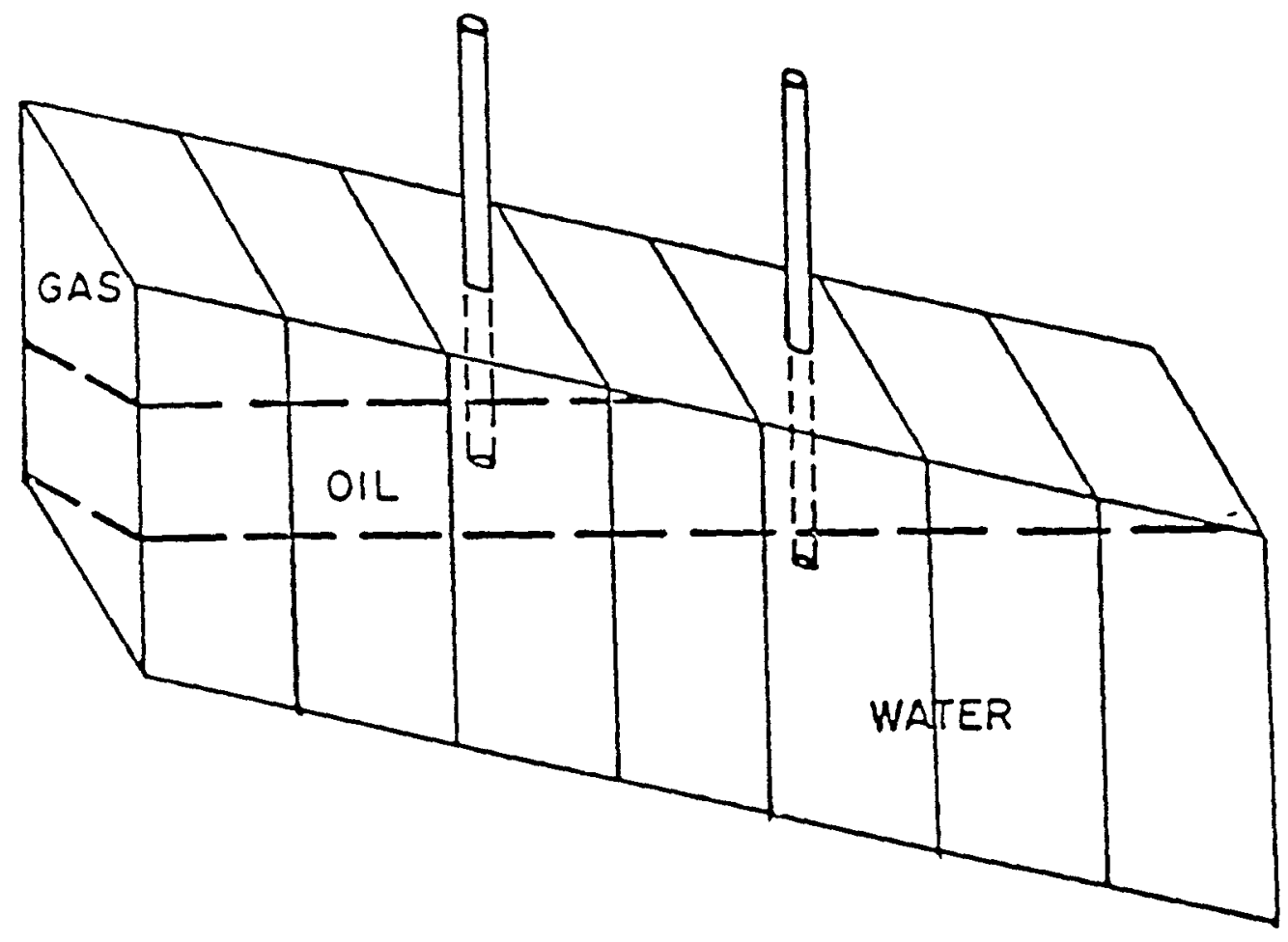

OME DIAEUISIONAL - IIPPING

- SIGHIFICANT GRAVITY OVER-RIDE

- same in geNeral as horizontal

ONE DIMENSIONAL MODEL

- UPDIP gAS INJECTION

- FLANK INJECTION OF WATER 


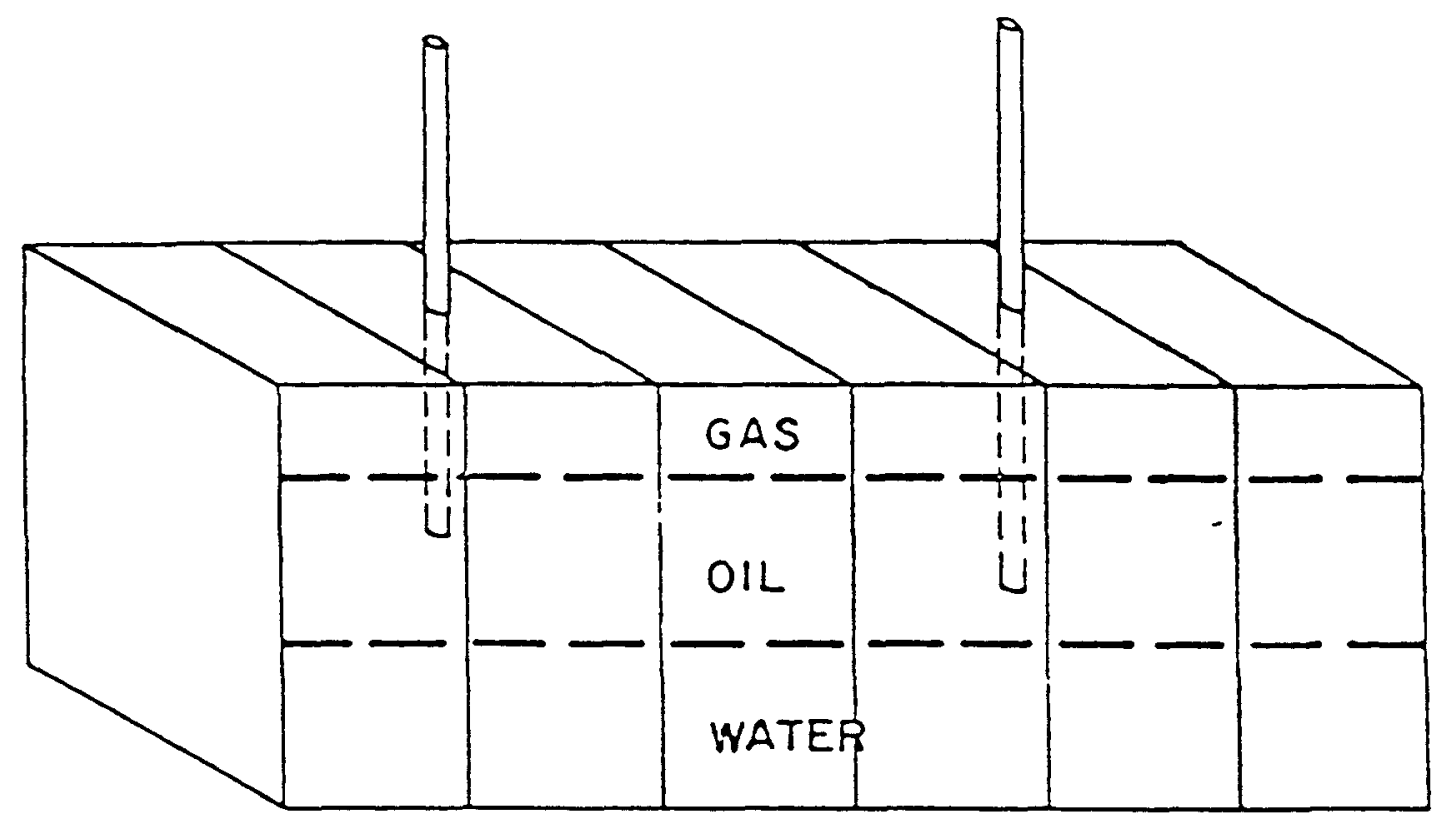

DIE DIMENSIONAL HORIZONTAL

- SIMULATES RESERVOIR SECTIONS

- SPECIALIZED STUdies

- LINE DRIVE BEHAVIOR

- MISCIBLE FLOODING

- PILOT FLOOD SIMULATIONS 


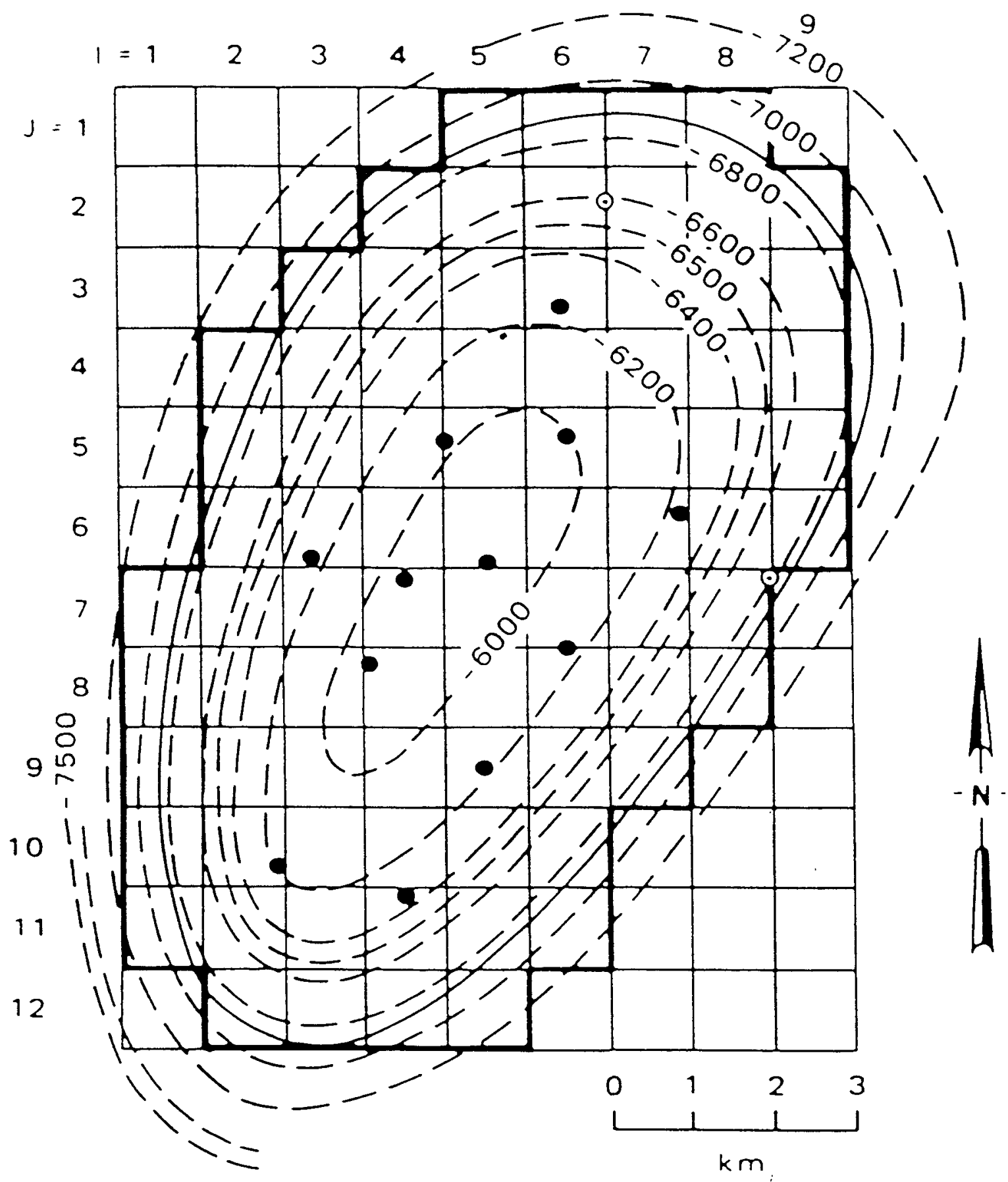

- Leading edge of tar zone

- Reservorr model boundary

Fig. 3.17-Structure contour map showing model grid-top of Reservoir A, Khursaniyah. ${ }^{25}$ 




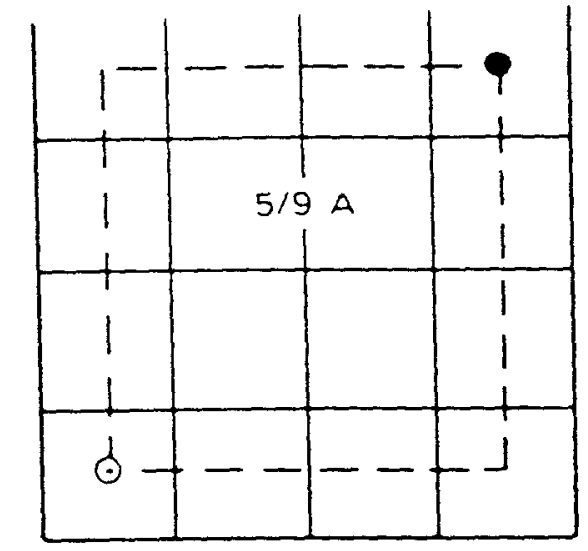

$4 \times 4$
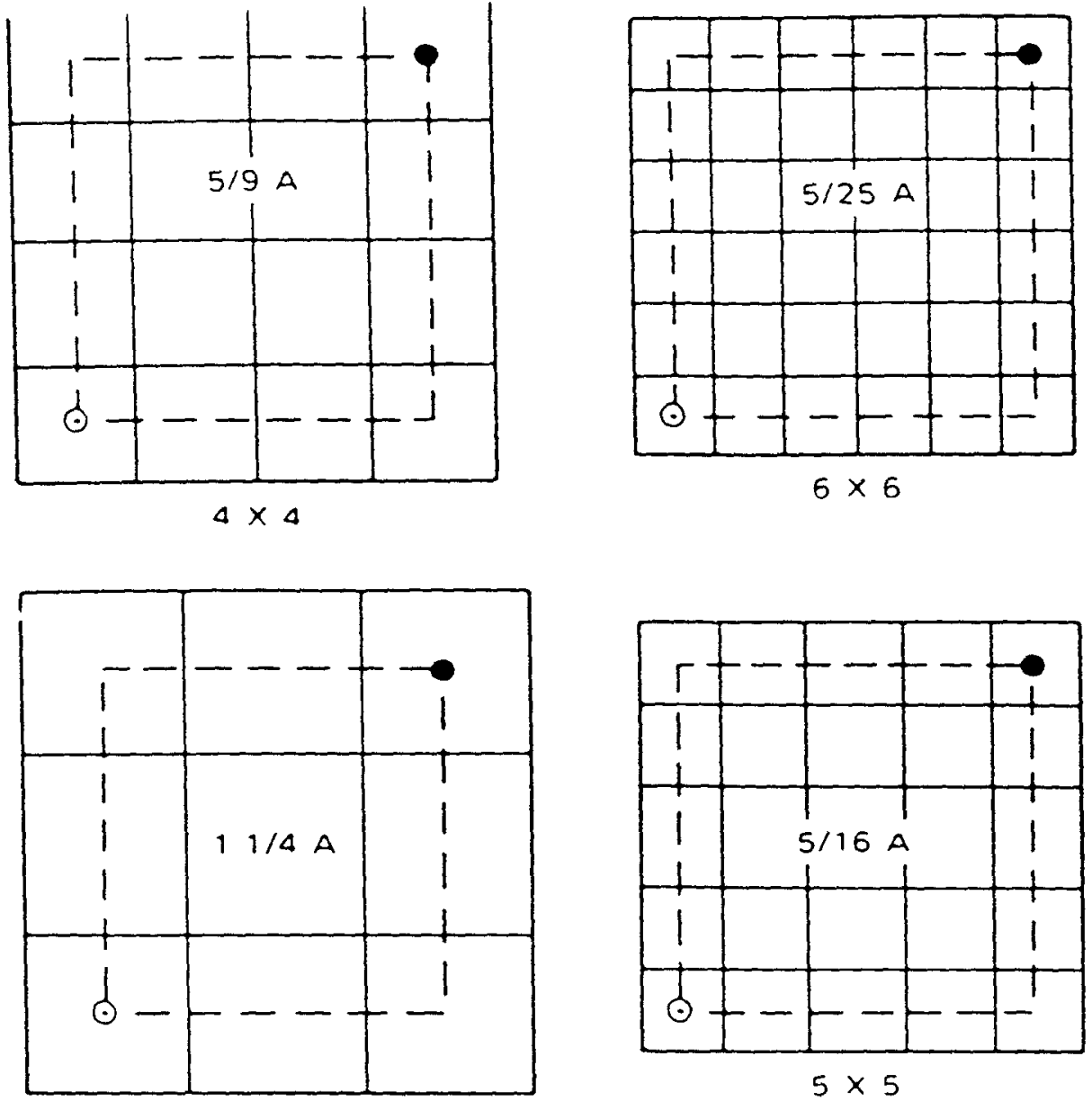

$3 \times 3$

(a)

- Actual 5 -spot element of 5 acres

- Producing well

- Injection well

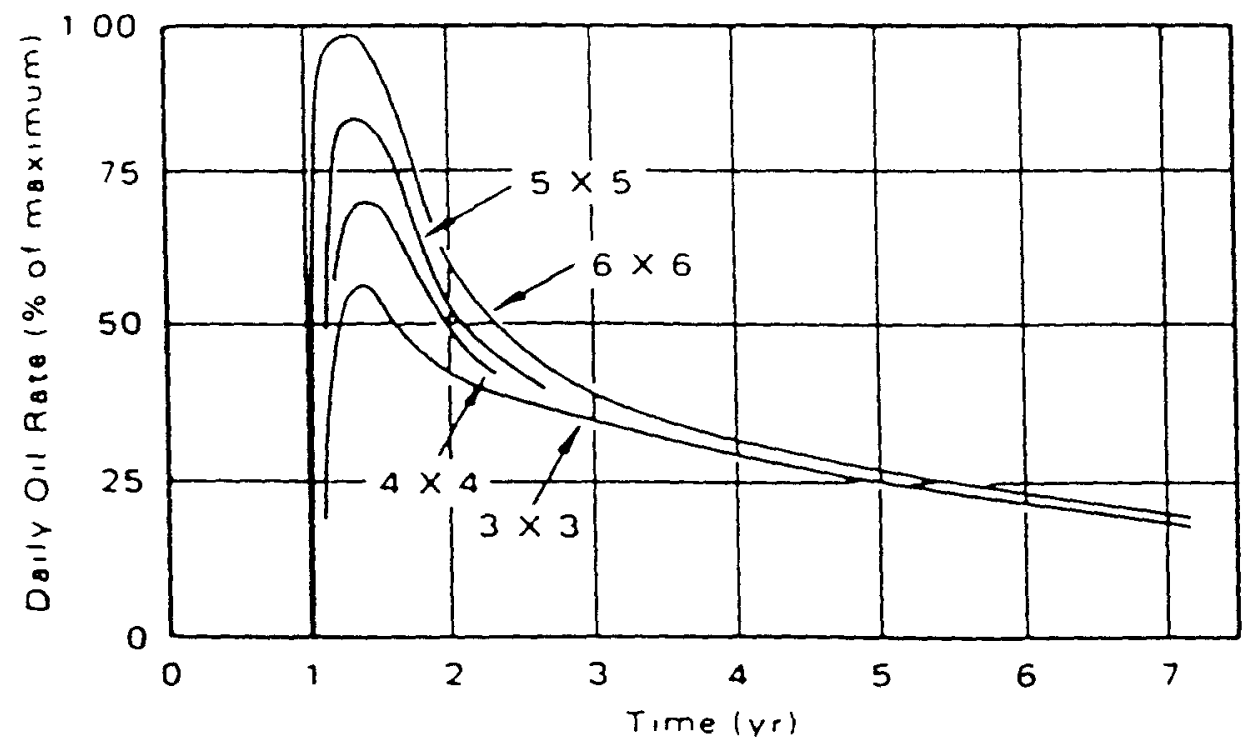

(b)

-Influence of grid spacing on performance prearctions ${ }^{1}$ : (a) models used to study the effect of spacing and (b) oil rates predicted by the models. 


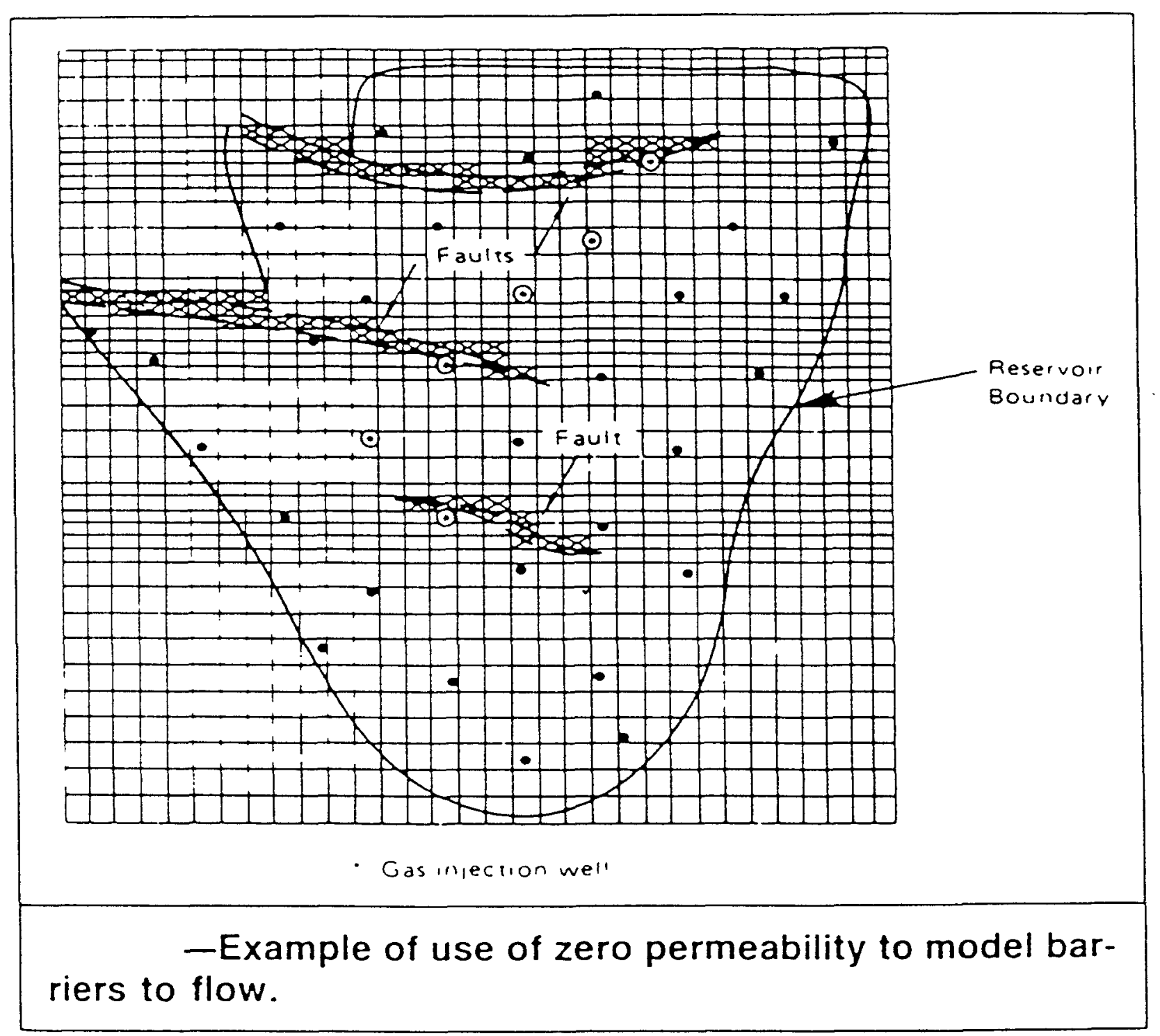


APPENDIX (III) 


\section{GridSTAT $^{\mathrm{TM}}$}

\section{USER'S MANUAL}

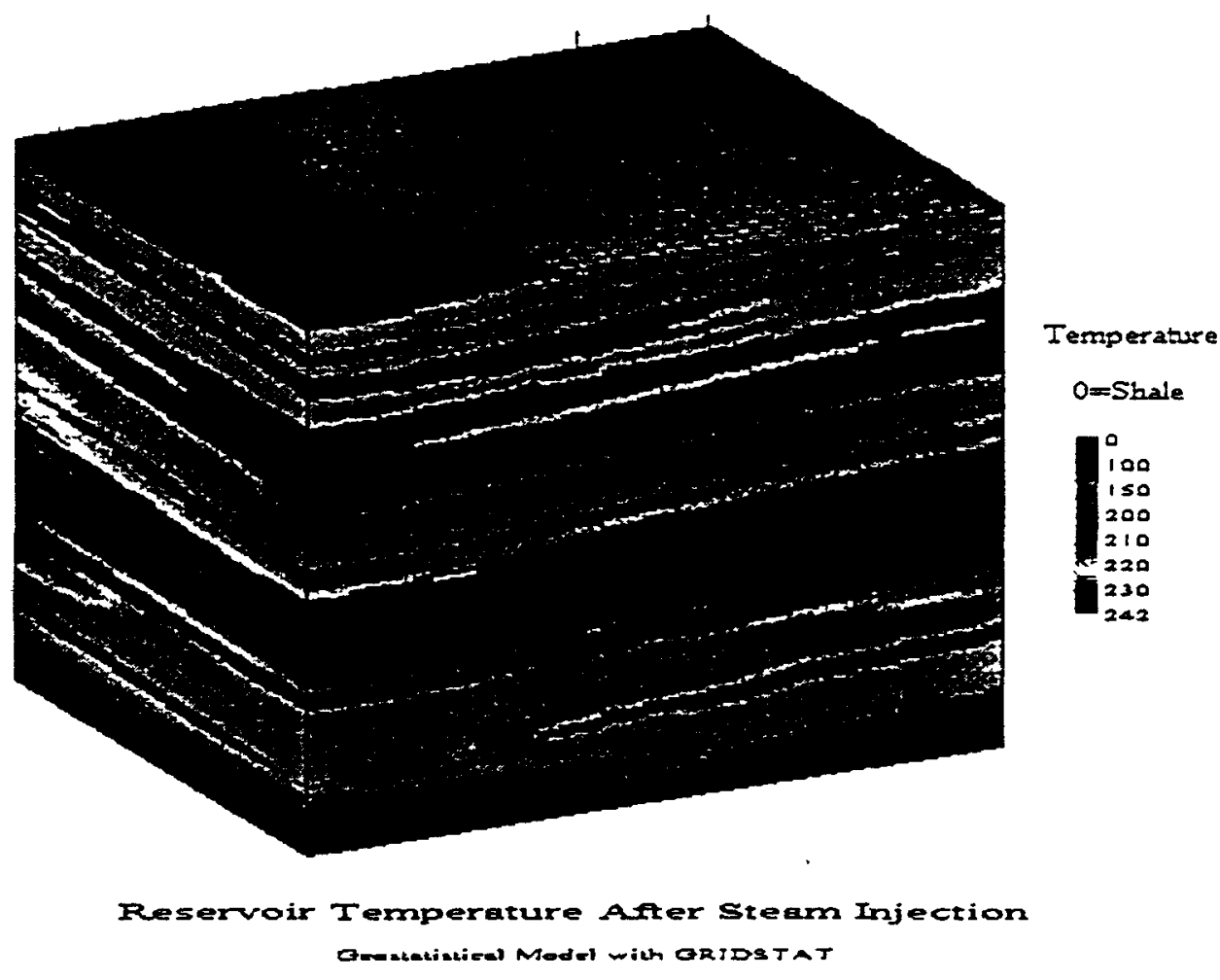

Applied Computer Engineering, Inc. 


\section{GridSTAT ${ }^{\top M}$ User's Manual}

Copyright 1996 by Applied Computer Engineering, Inc. All rights reserved.

No part of this publication may be reproduced or distributed in any form or by any means without the prior written permission from Applied Computer Engineering, Inc.

\section{GridSTAT $^{\text {MM }}$}

Copyright 1990-1996 by Texaco Inc. All rights reserved. 


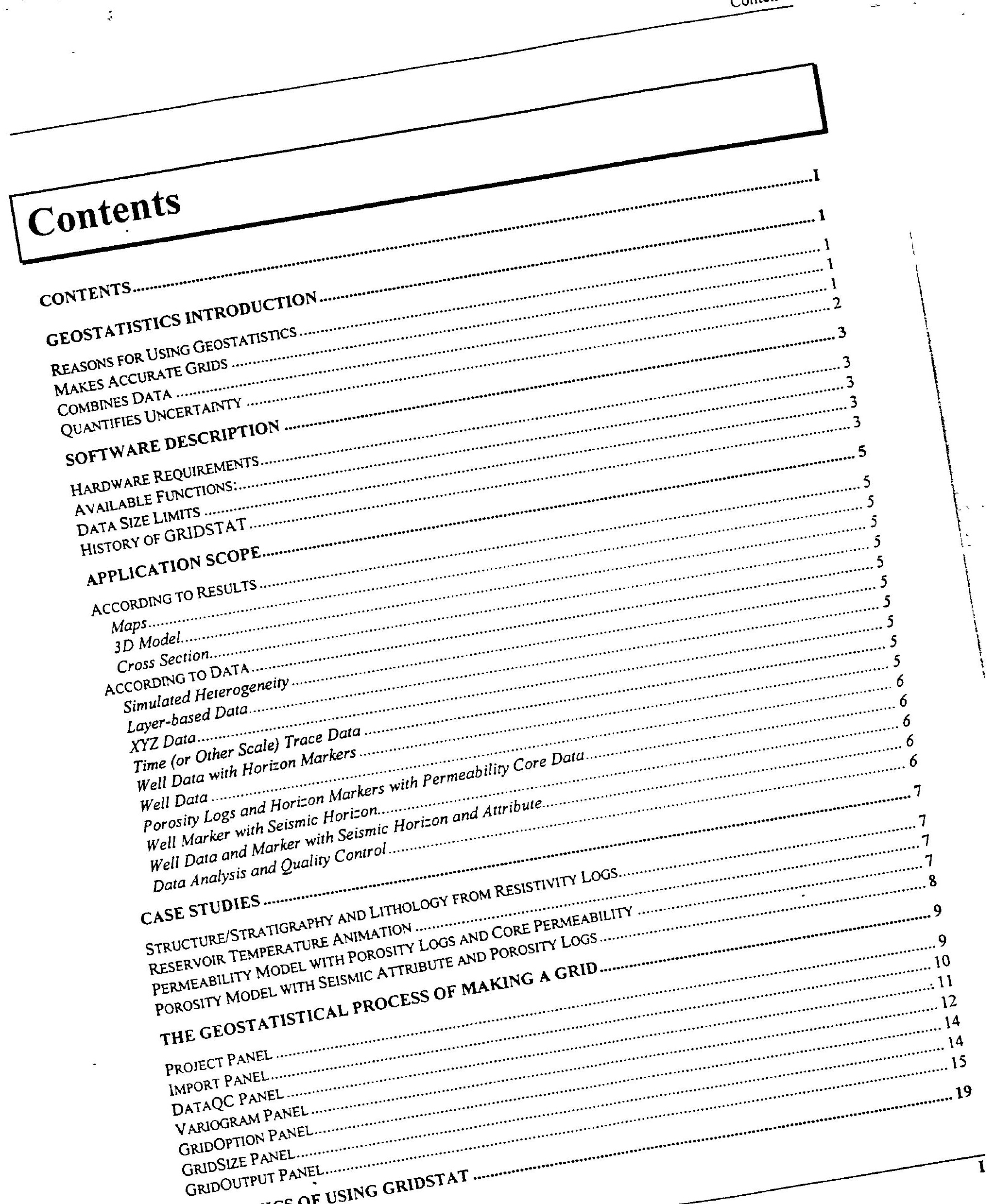




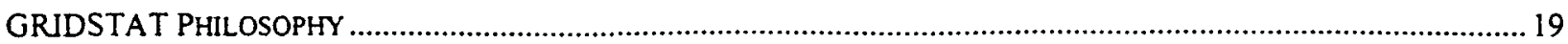

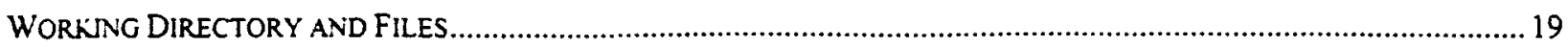

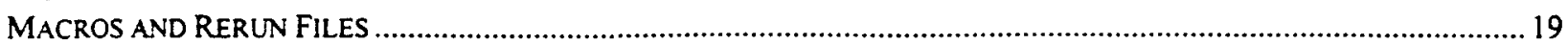

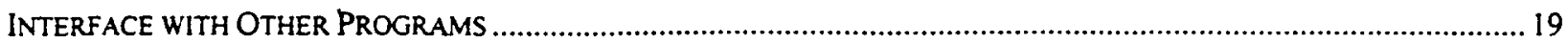

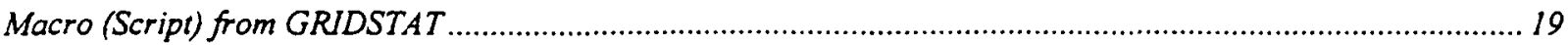

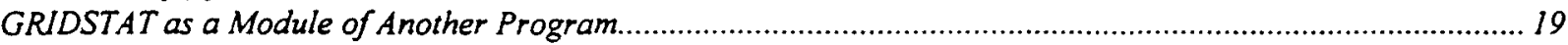

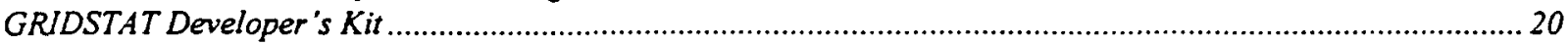

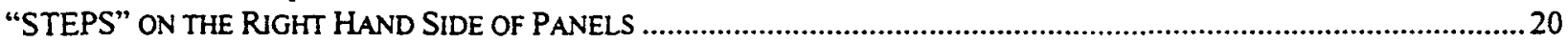

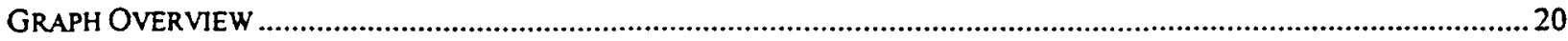

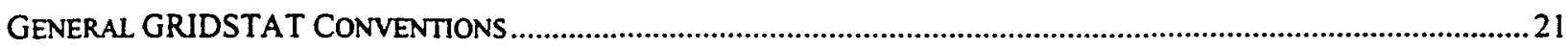

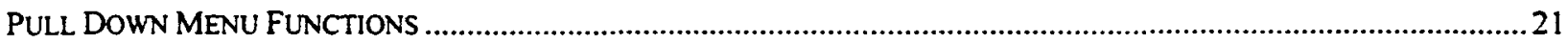

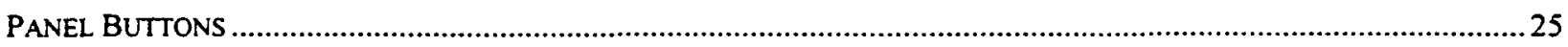

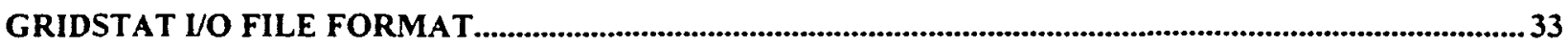

INTRODUCTION

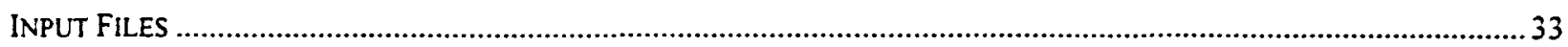

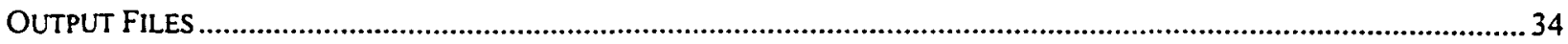

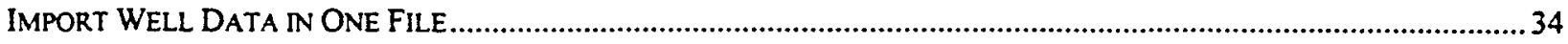

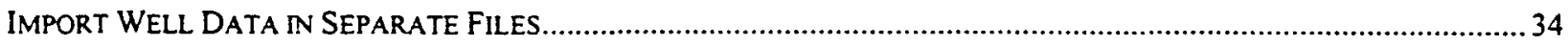

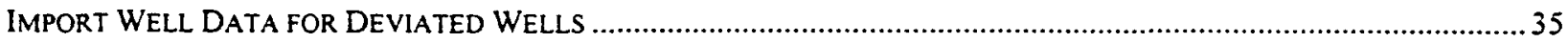

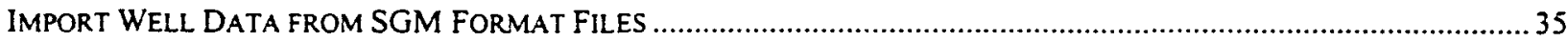

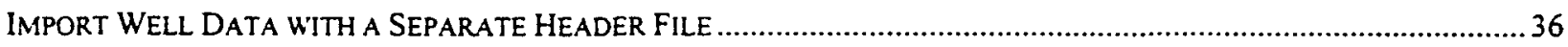

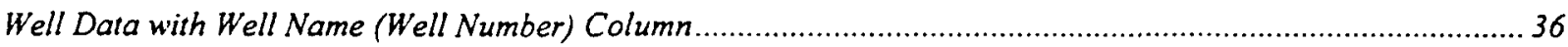

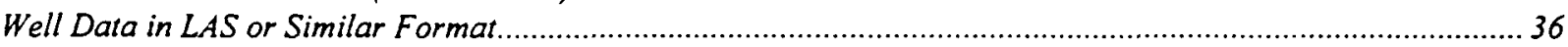

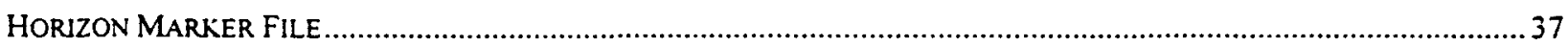

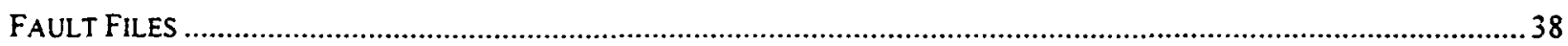

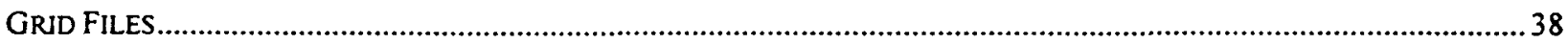

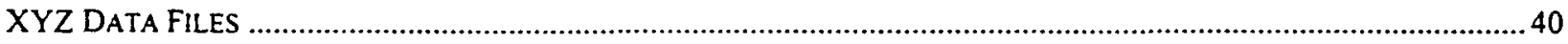

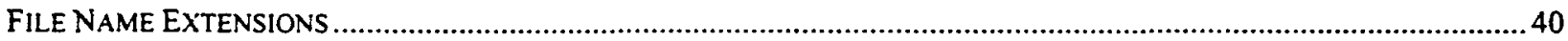

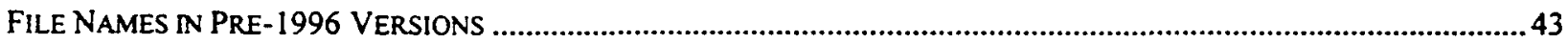

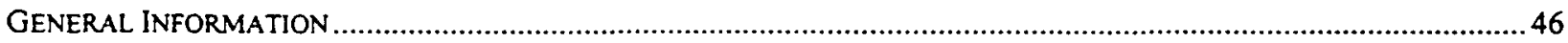

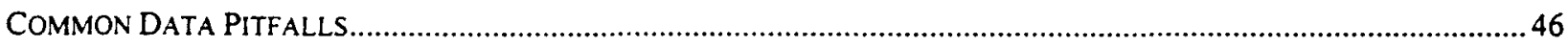

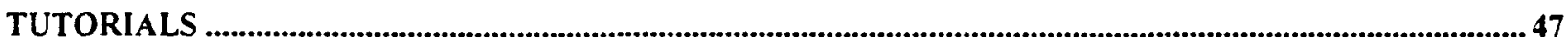

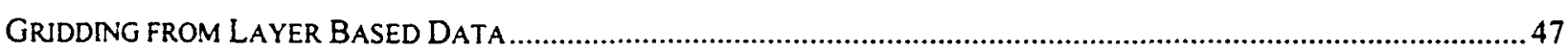

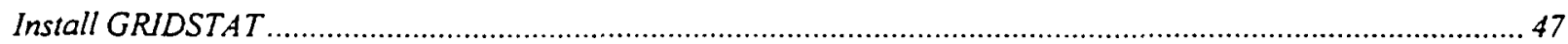

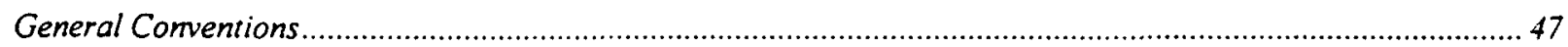

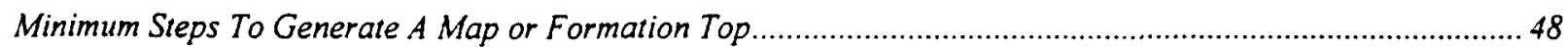

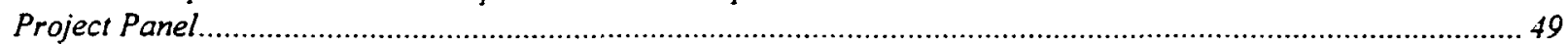

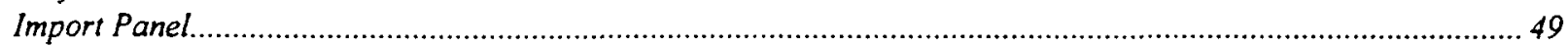

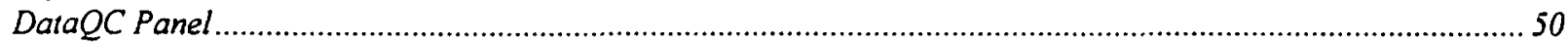

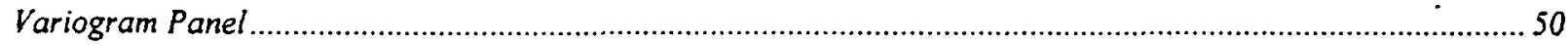

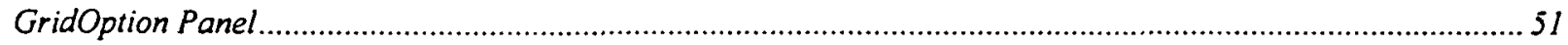

GridSi=e Panel

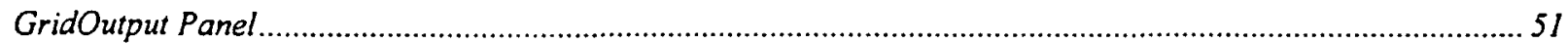

GRIDDNG L.AYER DATA WITH SOFT DATA

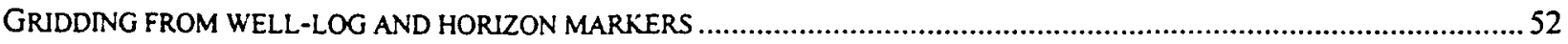

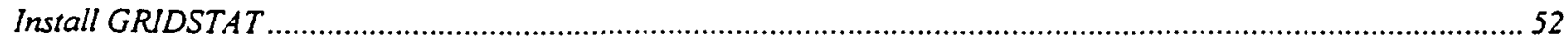

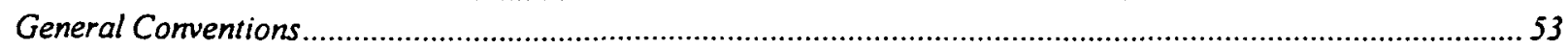

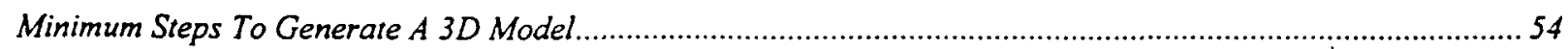

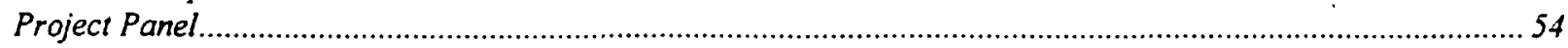

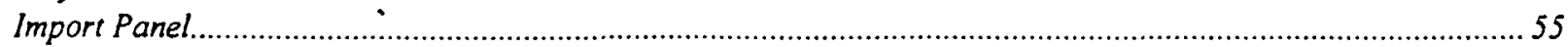

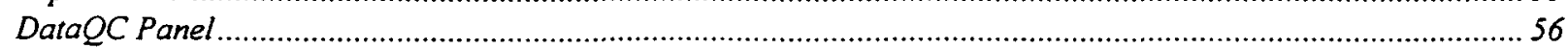




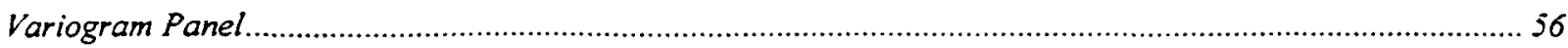

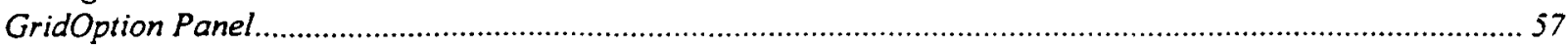

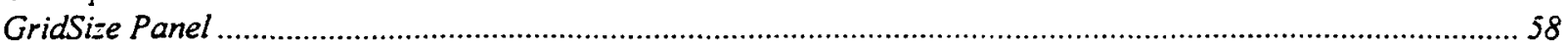

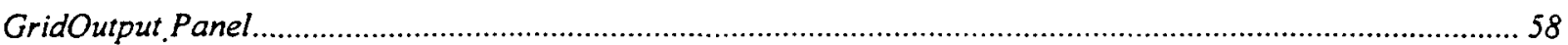

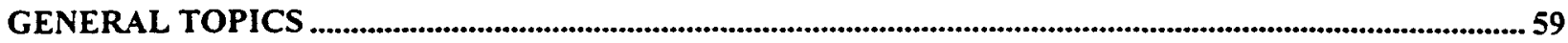

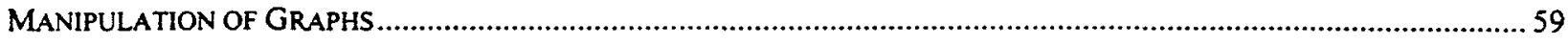

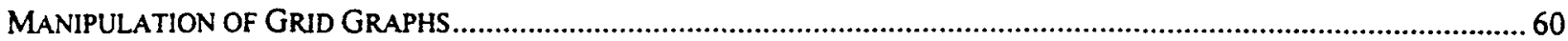

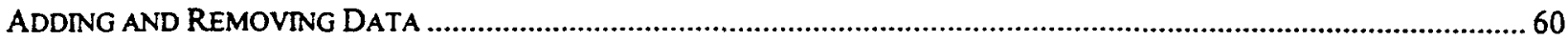

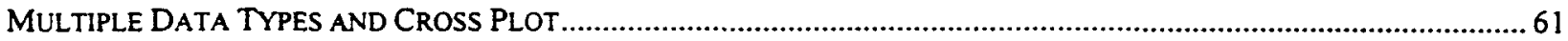

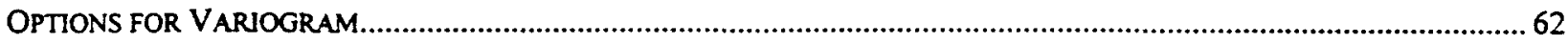

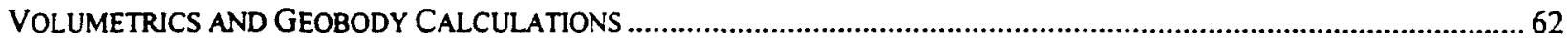

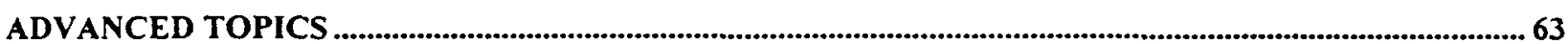

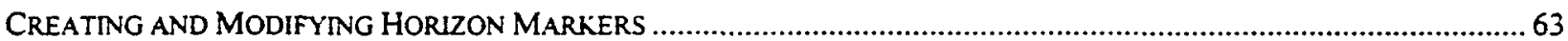

Generate a Correlation Horizon from Well Logs...................................................................................63

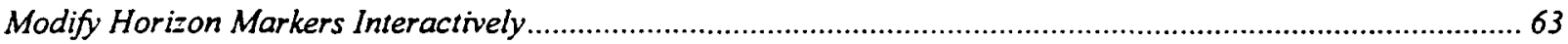

Modify Horizon Markers Using Autopick .........................................................................................63

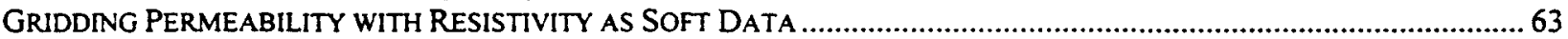

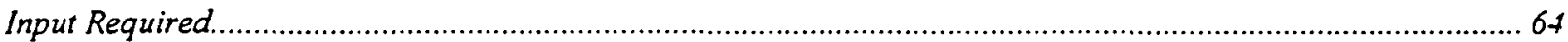

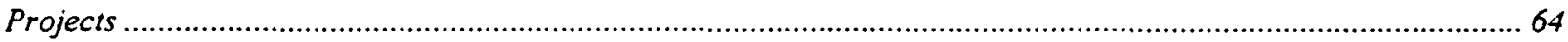

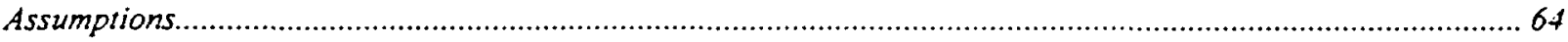

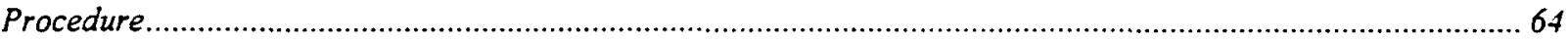

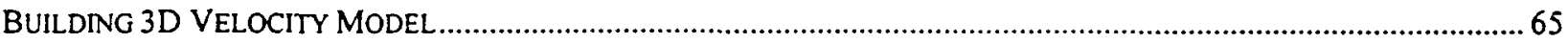

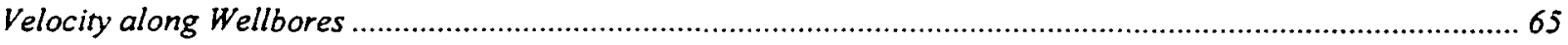

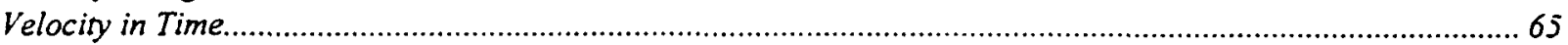

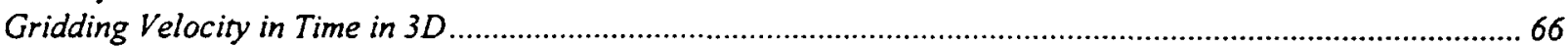

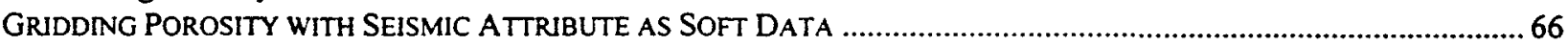

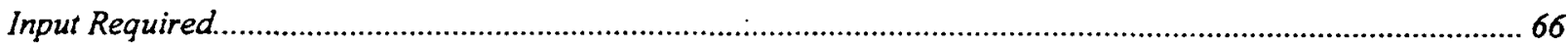

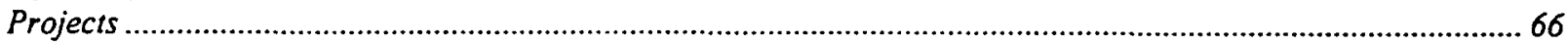

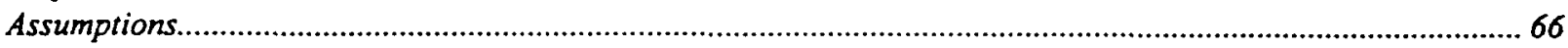

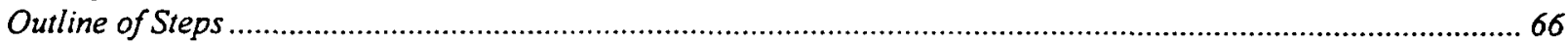

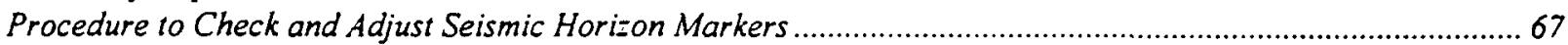

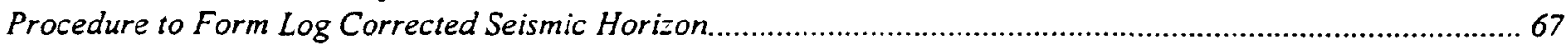

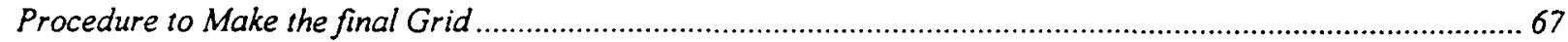

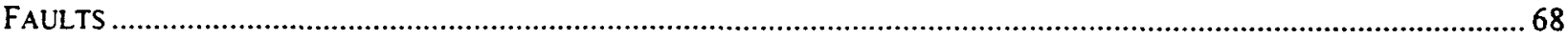

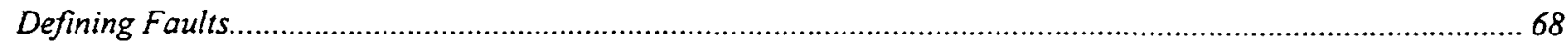

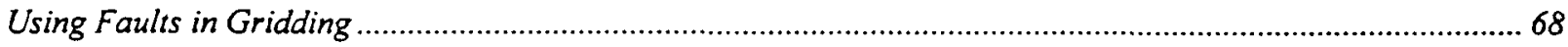

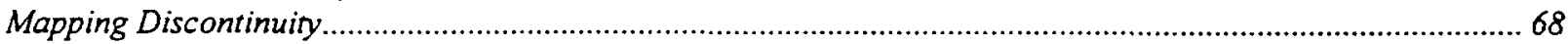

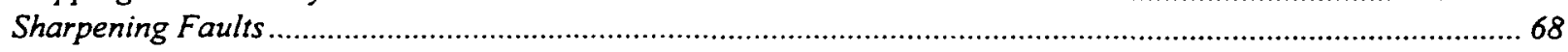

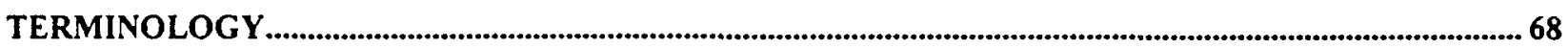




\section{Geostatistics Introduction}

\section{Reasons for Using Geostatistics}

Geostatistics is a modern, effective tool for reservoir characterization. The main purpose of geostatistics is to make property grids, which are needed as input to many types of petroleum industry software, such as cross section and visualization packages, reservoir flow simulators, and material balance programs.

Three main reasons for using geostatistics rather than other gridding methods are:

- geostatistics can make more accurate grids than any other gridding method

- geostatistics can quantitatively combine many different types of hard and soft data

- geostatistics can quantify the uncertainty in a reservoir description

\section{Makes Accurate Grids}

The geostatistical methods of kriging and conditional simulation make more accurate grids than any other gridding methods. Of course when we say this, we are automatically assuming some definitions of accuracy.

One definition of accuracy is to minimize the sum of the squared error between expected and actual values throughout the grid. This is exactly what kriging does because it is the criterion from which the kriging algorithm is derived.

Another definition of accuracy is to duplicate the statistics (mean and standard deviation) and continuity of the input data. These are the criteria upon which the geostatistical method of conditional simulation is based.

In practical terms, kriging and conditional simulation will honor the control data. As far as reproducing heterogeneity in the model with limited data control, conditional simulation is the only practical method today. Other gridding methods tend to produce a grid with less heterogeneity than the real reservoir and that usually contributes to reducing the accuracy of forecasting based on the reservoir model. One typical example is permeability grid for reservoir simulation. If heterogeneity is not accurately represented in the permeability grid, it would be more difficult to make realistic prediction from the simulation study.

\section{Combines Data}

One of the great strengths of geostatistics is that it can quantitatively combine diverse types of data. An example of data combination is seismic and well log data.

Seismic data is considered soft data. There is usually a lot of it but it is not very accurate. On the other hand, well $\log$ data is hard data. Compared to seismic data, there is not much data, but it is substantially more accurate. In geostatistics, these two types of data can be combined using the methods of cokriging or cosimulation.

There are many other types of data that can be combined with well data, which is almost always available to some degree. For example, data from basin deposition models can be readily used and is often valuable when seismic is not available and not many wells have been drilled. Another important type of data that is just now being integrated into geostatistical descriptions is production and well test data. Still another example is to combine well log porosity and core porosity. The relatively plentiful well log porosity is used as soft data and the relatively sparse core porosity is used as hard data.

Among different types of well data, an example is to use well log porosity as soft data to combine with core permeability which is used as harddata. 
Slowly, engineers and geoscientists are realizing that not using all of the data that is available to characterize a reservoir is effectively the same as throwing perfectly good data away.

\section{Quantifies Uncertainty}

For a given set of input data, the geostatistical method of conditional simulation produces a series of grids which are consistent with the input data in terms of statistics (mean and standard deviation) and texture (variogram) in addition to honoring the same set of control data. If the reservoir is well defined (lots of data and a high degree of reservoir continuity), then there will not be much uncertainty in the reservoir description and all of the grids produced by conditional simulation will look similar. If the reservoir is not well defined, then there will be a substantial degree of uncertainty, and the grids produced will look quite different.

It's very important in reservoir management to be able to quantify uncertainty. For example, developing different permeability grids will allow us to predict best and worst case production scenarios. This will help prevent production surprises down the road. Another example is to provide possible range of reserves. For the same set of input data, conditional simulation can provide a range of possible models so that you know how likely the reserve is going to be larger than a certain value, besides providing the most likely value. 


\section{Software Description}

\section{Hardware Requirements}

PC: 386 or Higher, 8MB RAM (16MB recommended), Windows 3.1, Windows 95 , or Windows NT

UNIX: IBM, SGI, SUN, others upon request

\section{Available Functions:}

Graphical User Interface, context sensitive help, basemap, data trace, cross section, distribution, cloud plot, data statistics table, variograms, structure/stratigraphic, deviated wells, faults, data filter, data transformation, well correlation, depth calibration, three-dimensional kriging, cokriging, conditional simulation, cosimulation, threedimensional visualization, volumetrics calculation, geobody identification, export to flow simulation format.

\section{Data Size Limits}

- PC Version small size: 1000 traces, 140000 data points and 350000 grid cells in display.

- PC Version standard size: 5000 traces, 700000 data points and 750000 grid cells in display.

- PC Version large size: 15000 traces, 2100000 data points and 2000000 grid cells in display.

- UNIX small size: 15000 traces, 2100000 data points and 2000000 grid cells in display.

- UNIX standard size: 30000 traces, 6300000 data points and 10000000 grid cells in display.

- UNIX large size: 90000 traces, 13860000 data points and 20000000 grid cells in display.

The limits shown here are for data loading into memory. The number of traces or data points in the data file is not limited. The number of grid cells in the grid file is not limited either. For example, you can produce a grid with 30000000 cells from a PC as long as there is sufficient disk space to hold the grid file. When you try to visualize this huge grid, GRIDSTAT will automatically skip some of the cells.

\section{History of GRIDSTAT}

GRIDSTAT was started by Texaco Exploration and Development Technology Department (EPTD) in 1990 to facilitate the application of geostatistics technology to the development of oil and gas fields. From 1991 to 1992, Texaco EPTD personnel and Texaco Bakersfield geologists jointly developed techniques which made GRIDSTAT a practical and time-saving tool in the day to day operation of reservoir description. In early 1993, Texaco Midland geologists started working with Texaco EPTD personnel to improve GRIDSTAT and successfully applied GRIDSTAT to the infill drilling plan. In 1994, Texaco Denver was working with EPTD to apply GRIDSTAT and the plan to enhance GRIDSTAT user interface was initiated. Outside consultants were employed to device possible plans and evaluate costs. Applied Computer Engineering, Inc was contracted to design and implement a new user interface. At the same time, Texaco New Orlean started working with EPTD to develop techniques to integrate seismic data with well data in building reservoir models. In 1995, as part of the outsourcing strategy, Texaco made the decision to outsource GRIDSTAT to make it commercial. Texaco will keep developing techniques and adding functions to GRIDSTAT but the user interface and most of the coding will be maintained by commercial vendor. Applied Computer Engineering released the new user interface in early 1996 and started marketing GRIDSTAT. Technical enhancements are continuously added to GRIDSTAT by Texaco EPTD personnel with contract services provided by Applied Computer Engineering. Applied Computer Engineering also works with EPTD to provide technical training. 


\section{Application Scope}

\section{According to Results}

The following results can be obtained with GRIDSTAT:

\section{Maps}

Input Data: $\quad \mathrm{XY}$ coordinates, data

Output: $\quad$ grid/map of structure, porosity, permeability, or lithology.

\section{D Model}

Input Data: data vs. depths and XY location, horizon marker

Output: $\quad$ grid of velocity, porosity, permeability, or lithology

\section{Cross Section}

Input Data: data vs. depths and XY location, horizon marker

Output: cross section of velocity, porosity, permeability, or lithology

\section{According to Data}

The following applications are grouped according to the availability of data:

\section{Simulated Heterogeneity}

Input Data:

Output:

Operation: none

grid/map of porosity, permeability, or lithology. Simulated log traces.

unconditional simulation

\section{Layer-based Data}

Input Data: $\quad X Y$ coordinates, data, well name

Output: $\quad \mathrm{grid} / \mathrm{map}$ of data, where data may be depth, thickness, average velocity or porosity, etc.

Operation: kriging or conditional simulation

\section{XYZ Data}

Input Data: $\quad X Y Z$ coordinates, data

Output: $\quad$ grid of data, where data may be velocity, porosity, pressure, temperature, saturation, etc.

Operation: kriging or conditional simulation

\section{Time (or Other Scale) Trace Data}

Input Data: data (seismic attribute, production rate, temperature, etc.) vs. time (or other), $X Y$ location Surpui. grid of data with $Z$ scale as time, map of time animation by slicing $Z$

Operations: 1. Import as Log Data where time is treated as depth

2. kriging or conditional simulation

\section{Well Data with Horizon Markers}

Input Data: well logs or core data vs. depths, $X Y$ location, well name, horizon marker

Output:

Operation: grid/cross section of porosity, permeability, or lithology

kriging or conditional simulation 


\section{Well Data}

Input Data: well logs or core data vs. depths, $X Y$ location, well name

Output: $\quad$ marker(s), Grid/cross section of porosity, permeability, or lithology

Operations: 1 . well correlation or sample marker from another grid

2. kriging or conditional simulation

\section{Porosity Logs and Horizon Markers with Permeability Core Data}

Input Data: porosity data, well markers, permeability core data

Output: grid of permeability

Operations:

1. calibration of porosity logs to permeability

2. cokriging or cosimulation with core permeability as hard data

\section{Well Marker with Seismic Horizon}

Input Data: well markers, seismic horizon

Output: $\quad$ grid/map of horizon, thickness, or average velocity

Operations: 1. calibration of seismic horizons to well markers

2. cokriging or cosimulation with well data as hard data

\section{Well Data and Marker with Seismic Horizon and Attribute}

Input Data: well data, well markers, seismic horizon, seismic attribute

Output:

grid of horizon, thickness, or average velocity, grid/cross section of porosity, permeability, or lithology

Operations: 1. calibration of seismic attribute to porosity and adjusting depth conversion

2. cokriging or cosimulation with well data as hard data

\section{Data Analysis and Quality Control}

Input Data: well logs, well markers, etc.

Output: Data statistics, data consistency check, data distribution (histogram), spatial comelation (variograms), trends (variogram map, dip map, vertical trend, etc.)

Operations: 1 . table display of data information, graph basemap, 3D data views, etc.

2. fan sections in structure and stratigraphic view to check correlations

3. variogram analysis to check data and marker consistency and correlation trends 


\section{Case Studies}

\section{Structure/Stratigraphy and Lithology from Resistivity Logs}

Kern River Field produces heavy oil from a fluvial depositional environment. Resistivity logs are used to define structure/stratigraphy and sand/shale lithology. There are many wells in the field and steam injection has affected more than half of the resistivity logs. Geological cross sections are used to design perforations and steam injections and so on. Before GRIDSTAT was used, conventional approaches were used to manually correlate wells, identify faults, and draw cross sections. Since 1991, GRIDSTAT has been used by geologists to identify bad data, correct the temperature effect in resistivity logs, correlate the wells, identify faults, and generate cross sections and threedimensional models. It is now possible to produce a cross section in more detail and in much shorter time. A study was done to compare the GRIDSTAT cross sections produced by one geologist with the hand-drawn cross sections produced by another group of geologists (in much longer time, of course). They found that away from the neighborhood of faults, GRIDSTAT cross sections are similar to the hand-drawn sections in more than $90 \%$ of the time. When GRIDSTAT was used in the automatic mode to locate the faults, there are more differences. The conclusion was that "In the hands of a competent geologist, GRIDSTAT is a powerful tool for distributing lithology and performing well-to-well correlations, as long as the data base has been cleared of wells with suppressed resistivity responses. The advantage of increased speed of cross section generation more than compensates for the small differences in lithology distribution." The study was reported in "The Impact of Geologic Reservoir Characterization on the Flow Unit Modeling at the Kern River Field, California, USA" by Elliott P. Ginger, William R. Almon, Susan A. Longacre, and Cynthia A. Huggins, SEPM Short Course No.34 Hydrocarbon Reservoir Characterization, Organized and Edited by Emily L. Stoudt and Paul M. Harris, Houston, March 4-5, 1995.

\section{Reservoir Temperature Animation}

Temperature surveys are taken to monitor the progress of steam injection in the Kern River Field. GRIDSTAT has been used to build four-dimensional models of temperature to visualize the heating of the reservoir (by animating the change in temperature over time) and identify where the steam may be leaking to upper layers and where there is oil left (cold region). Structure/stratigraphy information is used from the resistivity lithology model. The lithology model from resistivity is overlaid to the temperature model to confirm that the higher temperature is in the sand and to help concentrate viewer's attention in the sand.

\section{Permeability Model with Porosity Logs and Core Permeability}

The Mabee field in west Texas is a carbonate reservoir with over 800 wells. There are limited amount of core data from about 80 wells. Because of diagenesis, the correlation between permeability and porosity is poor. Coefficient of correlation is about 0.6 . GRIDSTAT was used to build a three-dimensional model of permeability to help identif; infi!l drilling locations. Three horizon markers are used to define the reservoir stratigraphic frame work. Core permeability is used as hard data. Log porosity is calibrated to core permeability and then used as soft data. Co-kriging is then used to produce the permeability grid. With a permeability cut-off, a permeability-thickness (KH) map is produced. Infill well locations are picked from the high K-H areas and production rates has been so satisfactory that less number of infill well are required to reach the production target. The study was reported in "Reservoir Characterization and the Application of Geostatistics to Three-Dimensional Modeling of a Shallow Ramp Carbonate, Mabee San Andres Field, Andrews and Martin Counties, Texas" by Dennis W. Dull, SEPM Short Course No.34 Hydrocarbon Reservoir Characterization, Organized and Edited by Emily L. Stoudt and Paul M. Harris, Houston, March 4-5, 1995. One of the conclusions was that "The ability of the GRIDSTAT program to 
integrate three-dimensionally (1) the structure of all three zones, (2) spatial variability (fractal variogram), (3) the "hard data" or core permeability, (4) the "soft data" - the normalized porosity logs transformed to permeability, and (5) the randomness of the porosity-permeability relationship are vital to the development of an accurate reservoir model."

\section{Porosity Model with Seismic Attribute and Porosity Logs}

When wells are relatively far apart and seismic data are available, GRIDSTAT can be used to build reservoir models using both well data and seismic data. In an offshore field with a dozen wells and 3D seismic data, a 3D porosity model was built using GRIDSTAT with details and accuracy that could not have been realized with either well data or seismic data alone. In this case, the porosity logs are used as hard data. A top horizon and a base horizon were picked in the seismic and in the wells. The seismic amplitudes were converted to impedance. In GRIDSTAT, transforms were performed to convert impedance to pseudo porosity and calibrated to the porosity logs. The second step in GRIDSTAT is to fine-tune the seismic depth, because the uncertainty in seismic depth is about $50 \mathrm{ft}$ which is not good enough for porosity modeling. Then co-kriging is used to generate the 3D porosity grid with transformed and adjusted seismic data as soft data, after transforming to stratigraphic coordinates. The grid is then exported to eclipse format for reservoir simulation after depth-shifting back to the original depth. 


\section{The Geostatistical Process of Making a Grid}

\section{Project Panel}

\section{Minimum steps in this panel}

1. Click the Next button on the lower left.

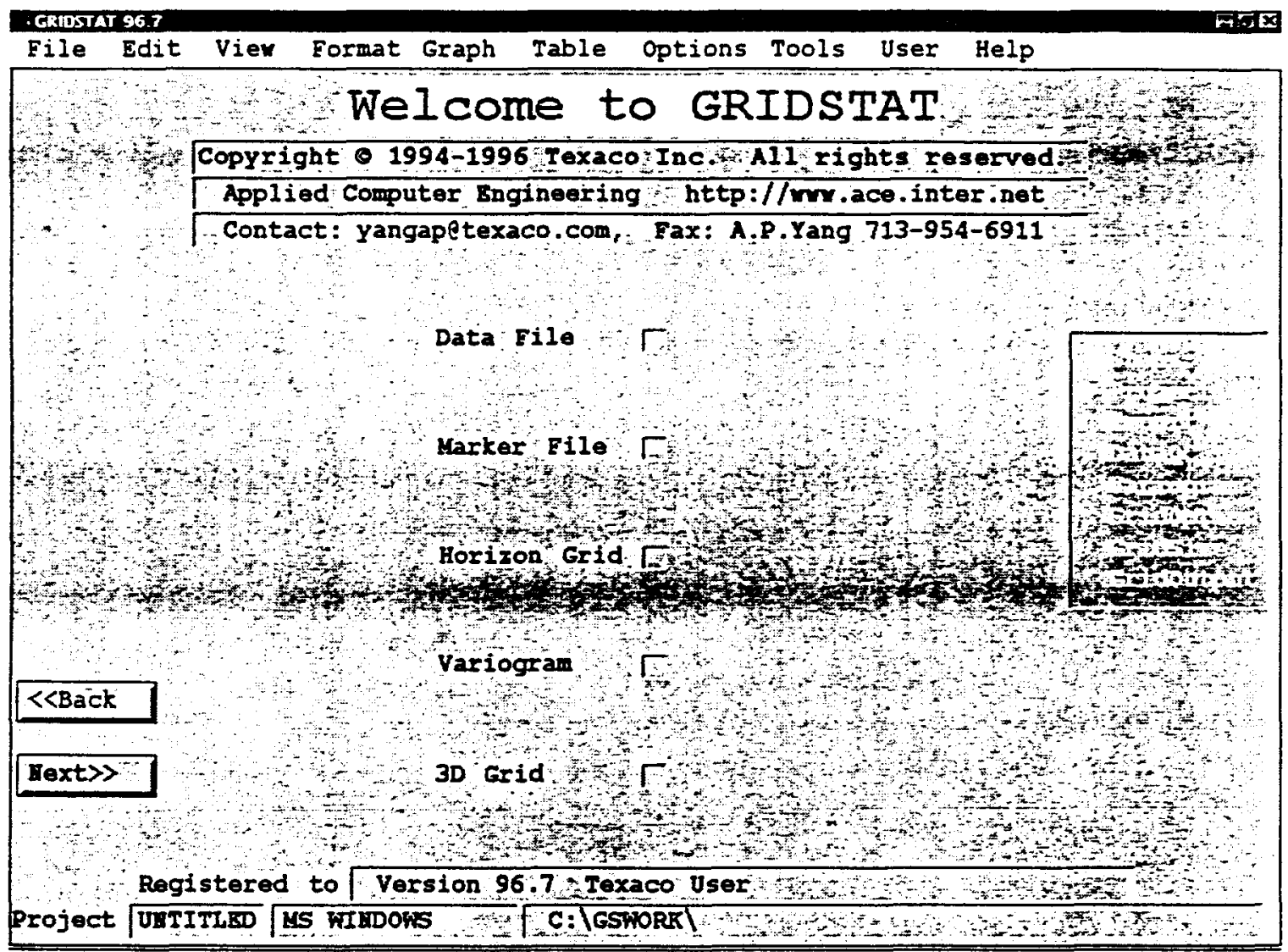

\section{Points to check in this panel}

1. At the first field on the left of bottom line, check if you are in the correct project. If the bottom line is outside the viewing area, move it to the viewing area.

2. At the bottom line, check if you are in the correct working directory.

3. If you expect to have data file available, there should be a check mark in the box to the right of Data File.

4. If you expect to have marker file available, there should be a check mark in the box to the right of Marker File. 
5. If you expect to have calculated variograms, there should be a check mark in the box to the right of Varogram

6. If you expect to have generated a grid, there should be a check mark in the box to the right of ID Grid

7. If you want to see more information, click the View pulldown menu and select More.

Import Panel

\section{Minimum steps in this panel}

1. Click the pulldown list-Data Import-at the top, then select the import type, e.g. From Layer Data

2. Check the box in front of file in Files list to import, e.g. TESTMRK.DAT

3. Click the Preview button, then select As Text or As Data

4. Click the Convert button

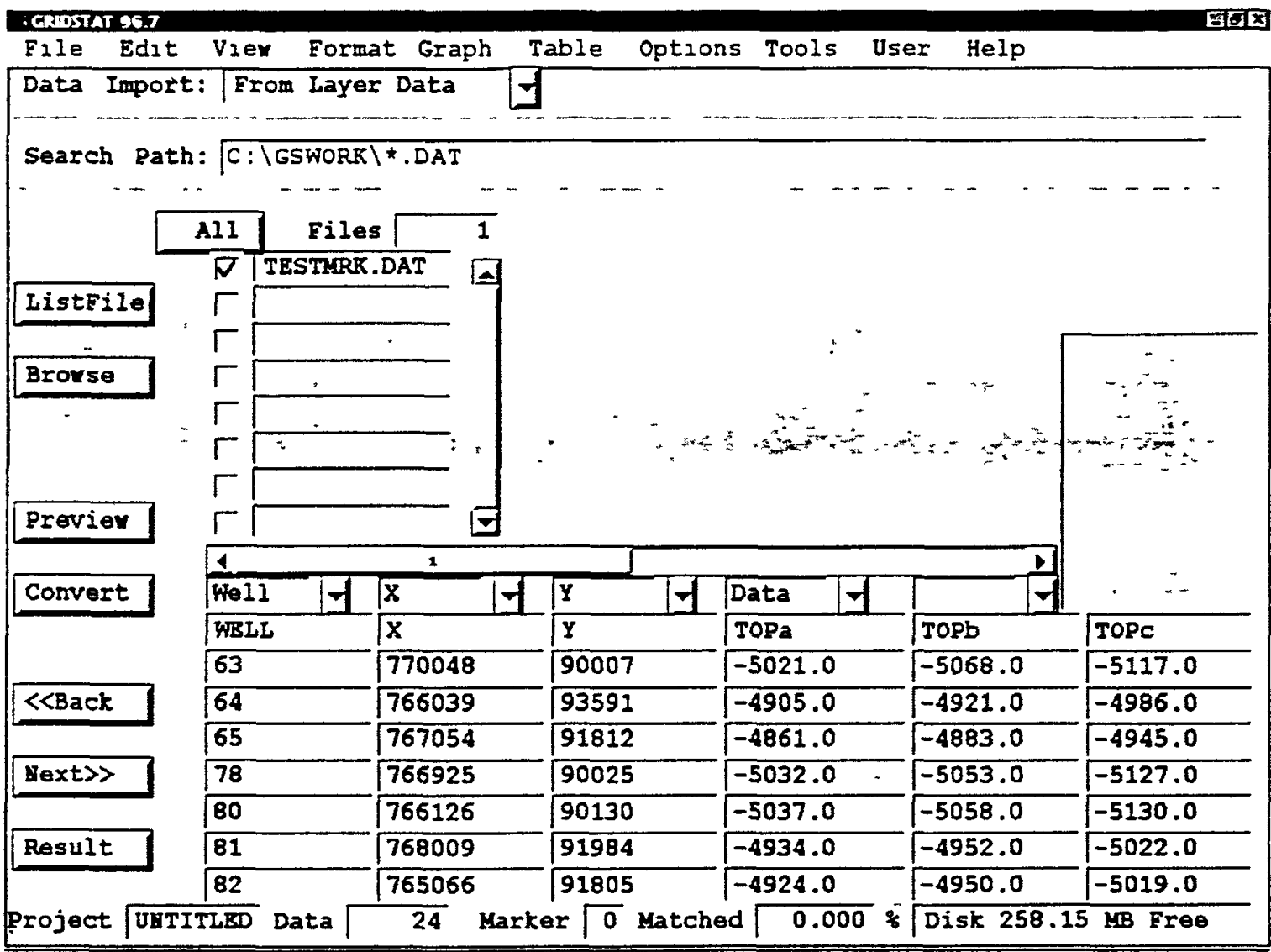

If data files are already in GRIDSTAT format and in the correct subdirectory and of correct file name, either because you have imported them before or copied from somewhere, you do not need to import data now. In that case you may skip the Import Panel.

All horizon markers are called "top" here The last "top" will be used as a bottom. The marker depths should be in subsea (negative belou sea level). Deeper markers should be to the right of shallower markers.

If you need to chech or change import parameters, pulldown the Options menu and select ImportPar... 


\section{Points to check in this panel}

1. At the bottom line, check if you are in the correct project.

2. At the bottom line, check if you already have data in this project

3. At the bottom line, check if you have enough disk space free for adding data

4. Select the correct type of import at the top of the panel.

5. Select the correct file to import

6. Check or select the correct label for the data columns after preview.

7. Make sure the marker file has the same well names as the well log data file.

8. Make sure the marker file has the same well names as the well log data file.

\section{DataQC Panel}

\section{Minimum steps in this panel}

i. Click the Next button on the lower left.

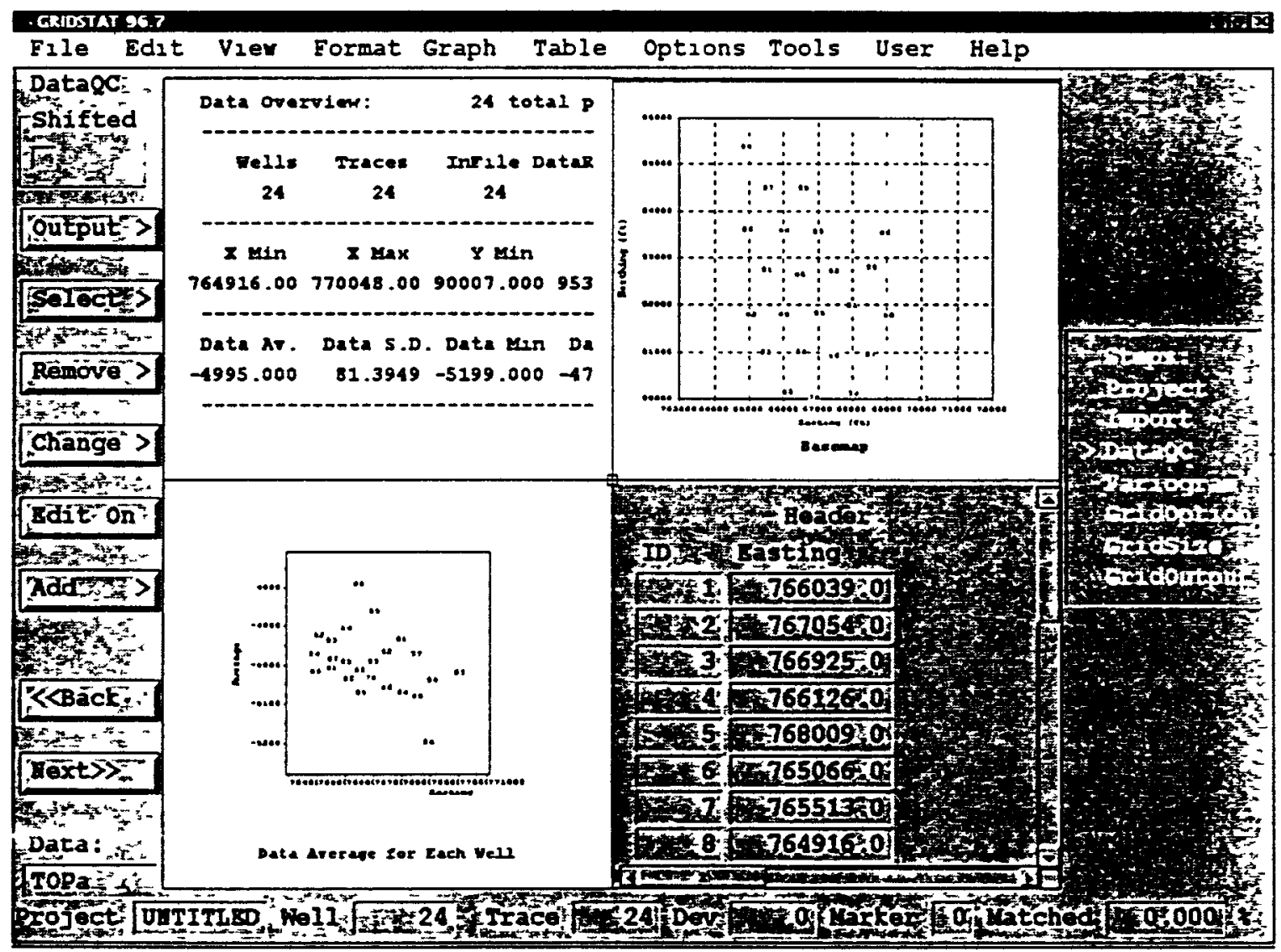

This panel is used to quality control $(\mathrm{QC})$ the data before further analysis and gridding.

Use the Table and Graph pulldown menus to open more tables or graphs to look for potential errors in the data. Click at one of the four picture areas to make it active. When you open a graph, it will be placed in the active area. 
You may select some of the wells to graph. With the basemap in display, click the Select button on the left of the panel and turn Pick Well on. Now you can pick the wells you want to graph. Data trace, traces, fan-section, etc. will follow the selected well sequence. The first two groups of the graphs in the Graph pulldown menu are linked in the well selections. We may select or deselect a well in any one of those graphs and the selection will show up in other graphs of those two groups. You may need to use Redraw from the View pulldown menu to refresh the graphs.

\section{Points to check in this panel}

1. Check if the well locations are correct in the basemap.

2. Look through the Data Overview table to make sure the numbers are what you expect.

3. For markers, make sure that all wells have corresponding markers (ideally there should be $100 \%$ match), that there is data in the corresponding zones (you may also compare graphs of Depth Range and Markers), and that the zone thickness is positive.

4. For trace by trace details open Statistics from the Table pulldown menu, and modify it from the Tools pulldown menu Table Design.

Variogram Panel

\section{Minimum steps in this panel}

1. Click the Points button on the left of the panel

2. Click the Curve button, then select Spherical

3. Click the Next button on the lower left. 


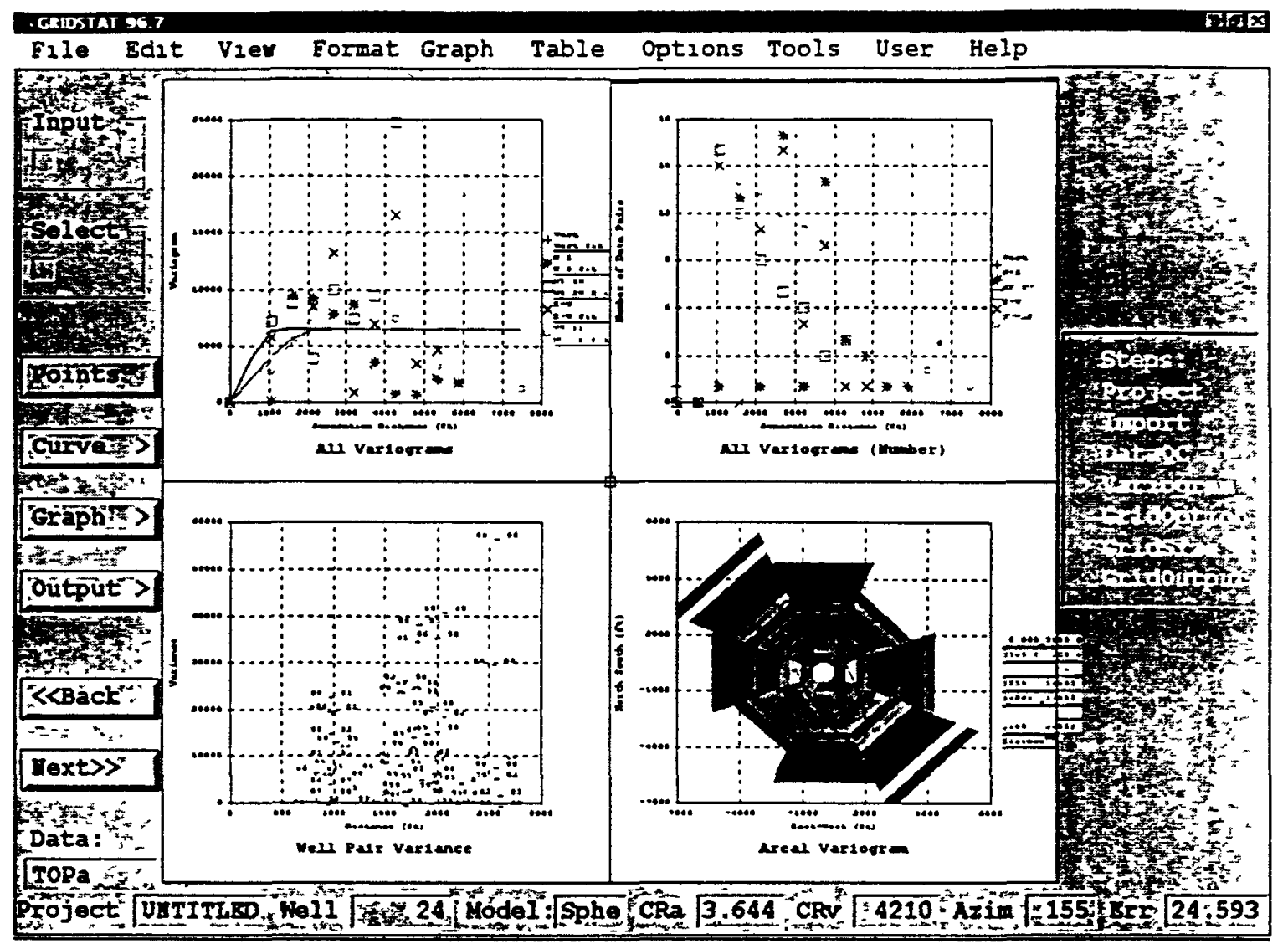

\section{Points to check in this panel}

1. Make sure you have multiple wells if you want to calculate areal variogram.

2. You need multiple data points in each trace to calculate vertical variogram.

3. Make sure you already have correct markers (check in DataQC panel) if you want to honor the horizons.

4. If you don't have markers, areal variograms will be calculated in the horizontal direction.

5. You can turn off a marker or markers from the Options pulldown menu Markers panel.

6. In the current version each project should contain one type of data for variogram calculation.

7. Calculate the variogram points first.

8. Curve fit the results. The fit is automatic as soon as you choose a model.

9. Variograms usually increases with distance.

10. Well Pair Variance graph is a good indicator of data quality. For those well pairs that are in short distance but shru'ing relatively large variance, there is usually problem in the data, well location (including adjustment for deviated wells), or marker depth.

11. Correlation Ratio to Vertical (CR_v) is usually larger than $10(50,100,1000$ depending on the data) if the vertical scale is depth. If vertical scale is layer index (when imported as layer data), it depends on the layer thickness and whether the data in different layers are correlated. 


\section{GridOption Panel}

\section{Minimum steps in this panel}

1. Click the Next button on the lower left.

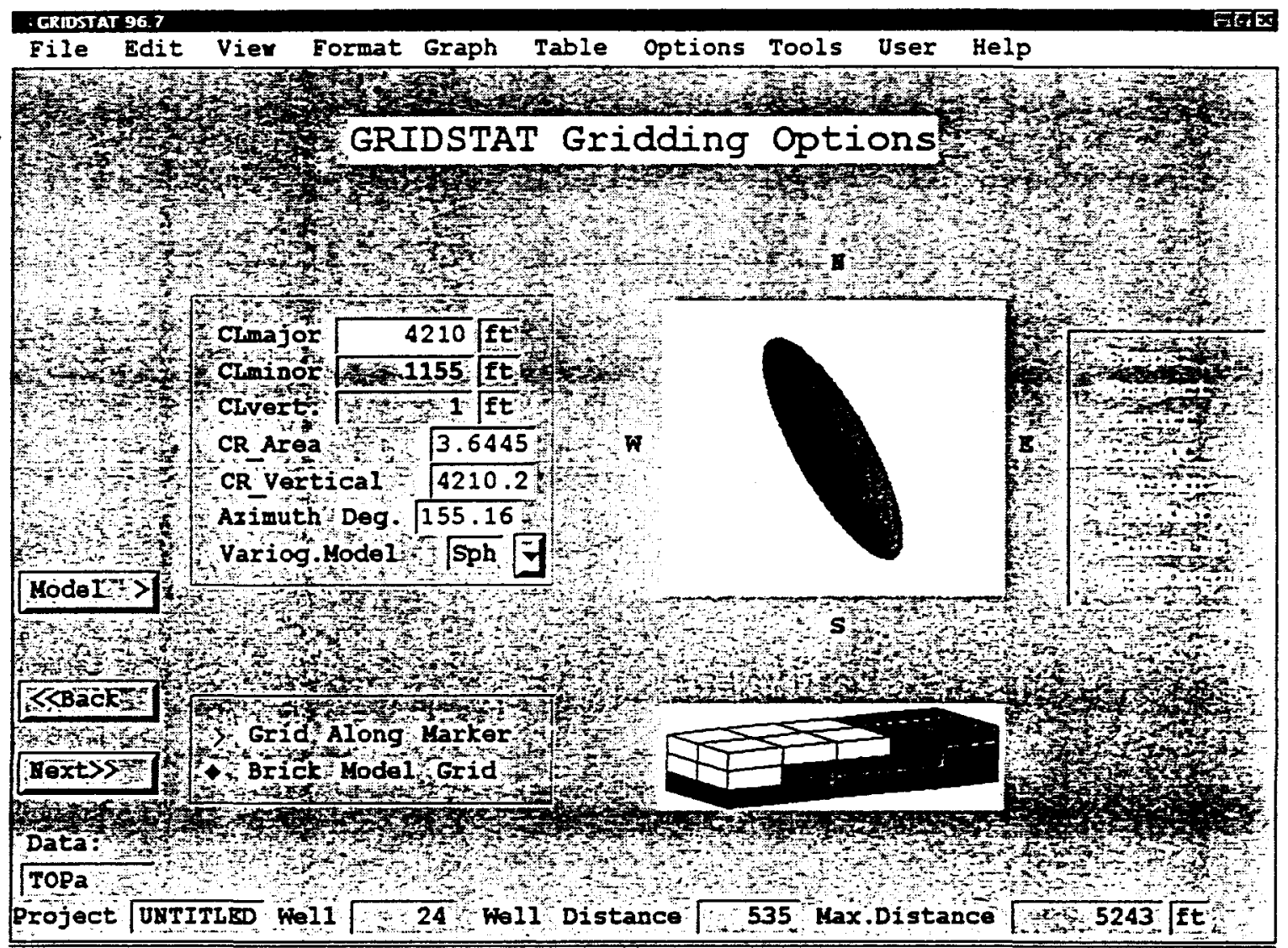

The parameters from variogram modeling on this panel are automatically copied from other calculation.

\section{Points to check in this panel}

1. Make sure the major correlation length, which is the longest correlation length of the correlation ellipsoid and the distance limit of data search, is reasonable. You may need to increase it to cover areas far from any wells.

2. Make sure Correlation Ratio to Vertical (CR_v) is reasonable. Too small a CR_v will disrupt the layer-like character while too large a CR_ $v$ will make the layering too continuous.

3. If you only want see the results within zone boundaries, such as for flow simulation, and you have markers included, select Grid Along Marker. Otherwise use Brick Model Grid.

4. To draw a fan section or cross section, tum on the Fan Section Only option.

\section{GridSize Panel}

\section{Minimum steps in this panel}


1. Click the Start button on the upper right

2. Click the Next button on the lower left

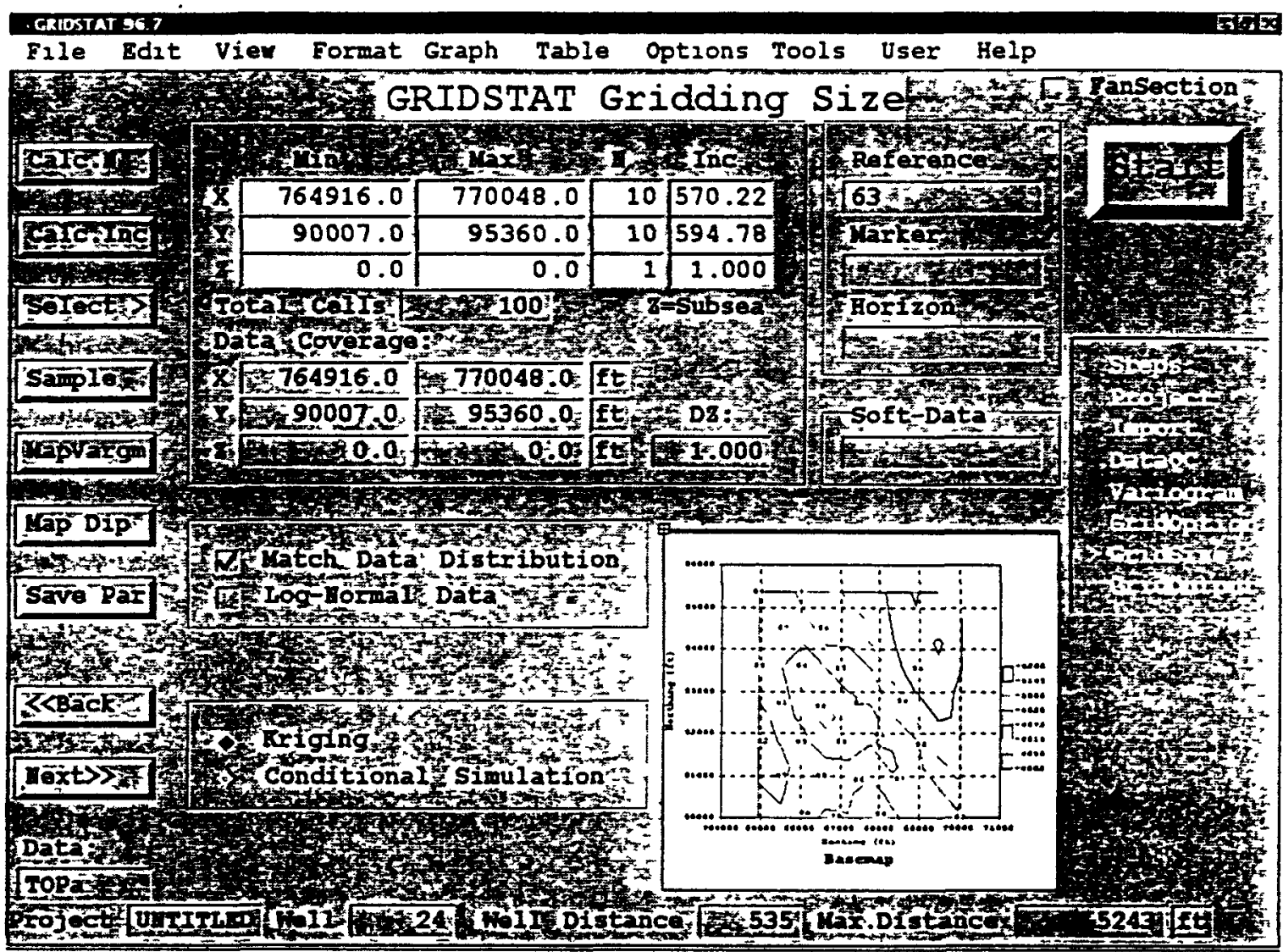

\section{Points to check in this panel}

1. The initial grid dimension is designed to cover all the data and have 10 cells in each horizon direction. Make a small grid first You can redefine the cell sizes to make a finer grid or covering more area later.

2. Make sure the grid definition is consistent with the data coverage

3. From Table pulldown menu you can open DataView or Statistics table to check available information.

4. Make sure Log-Normal Data option is on if the data is resistivity or permeability.

5. Do Kriging first even when your final goal is conditional simulation. This will give you a base case.

6. If you don't have any data, conditional simulation will become unconditional simulation and a grid can be generated (simulated heterogeneity).

7. If you have changed some paratmeters and want to reset to the defaults (for example changing from fansection to $3 \mathrm{D}$ grid), use View pulldown menu Reset and not to use the saved parameters.

\section{GridOutput Panel}

\section{Minimum steps in this panel}




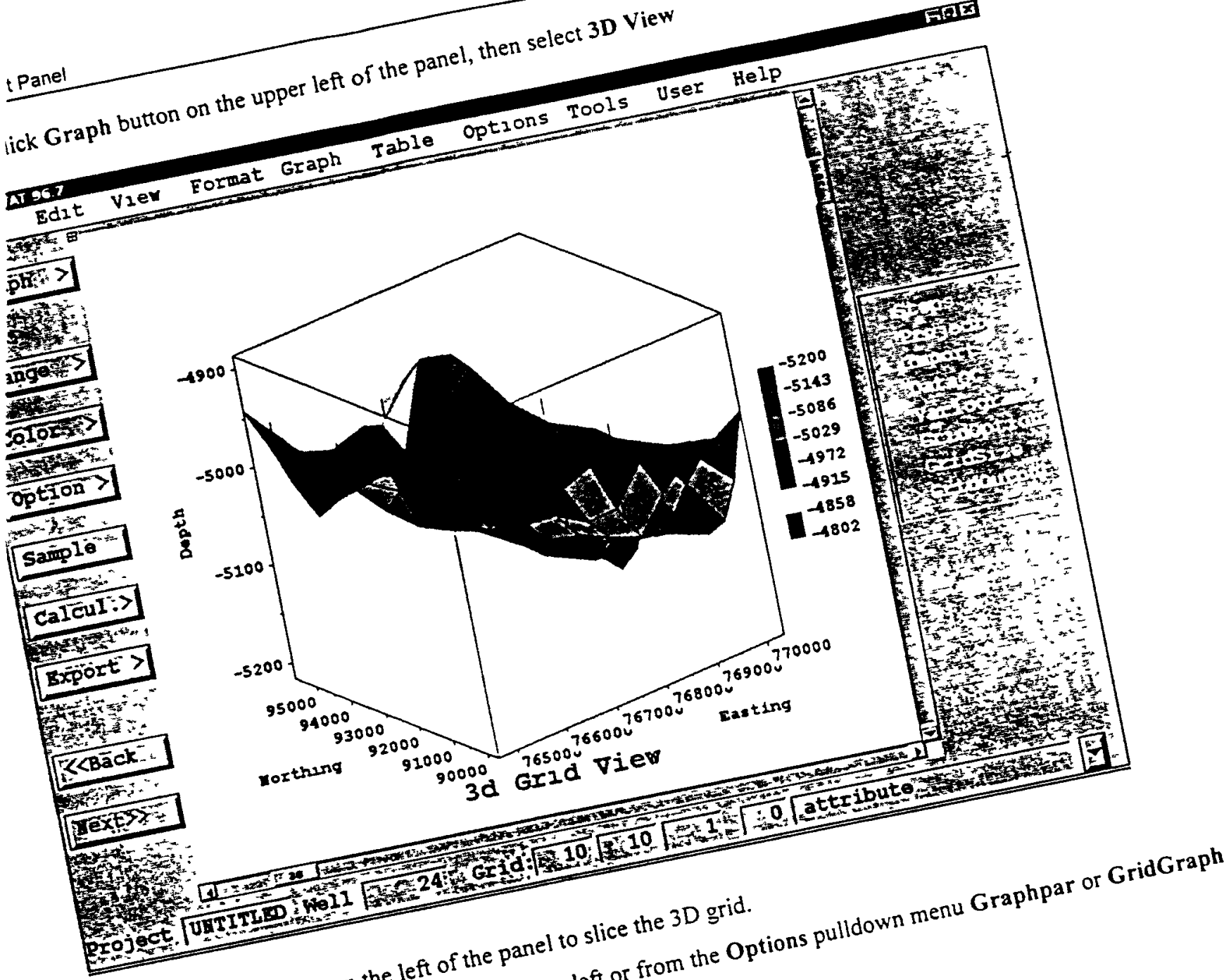

Click the Range button on the left of the panel to slice the

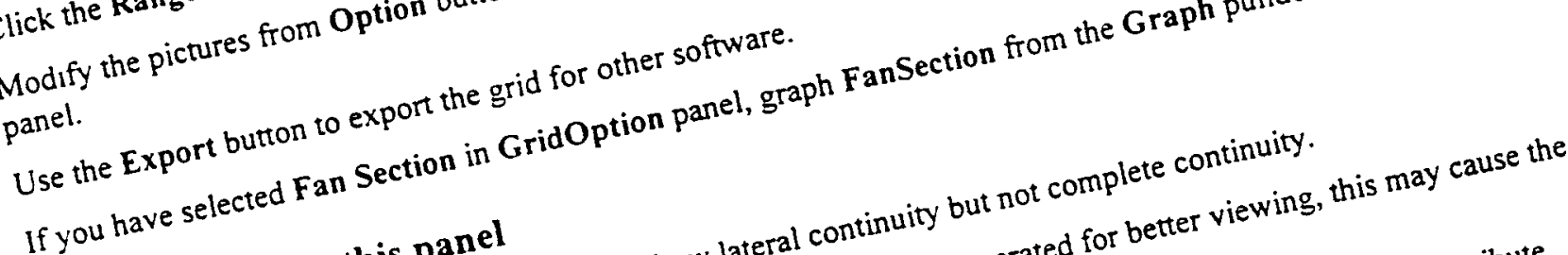
Points to check in this panel

1. For most data, the graphed grid should sho the vertical scalion.

2. Be aware of the aspect ratio. Tyus in the horizon continuou should be able to show the result in sth result to appear less con to follow markers, you should be abe

3. If the grid has been made
option option 4. If $N Z$ is 1 or the Data The result in Structure for Depthe check the following
be able to show the 
6. If you don't see the whole grid in display, check if grid dimension is consistent with data coverage and, if markers are used, there is data within the zones, checking from DataQC panel and GridSize panel. 
APPENDIX (IV) 


\section{Prairie View A\&M University \\ Technology Resource}

Center

Reservoir Simulation

Workshop Sep. 26

Company

Atapco

Vastar Resorces

American Exploration

PICES, Inc.

Consultant

Exxon

PVAMU

Laine \& Assocs.

Mobil

PVAMU

North \& Assoc.

Fairchild,Ancell\&Wells

Mobil

\section{Phone}

713-460-2355

713-584-3672

713-756-6209

713-706-3295

713-358-5064

713-656-0194

409-857-2427

713-855-1078

713-775-2125

409-857-2427

713-367-1767

713-497-8990

713-775-2192 


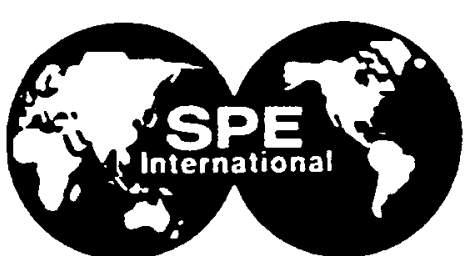

Society of Petroleum Engineers

\section{GULF \\ COAST \\ SECTION}

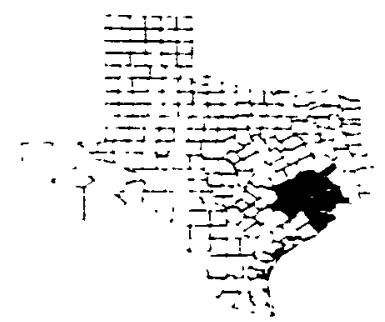

Read by over 9000

petroleum professionals monthly

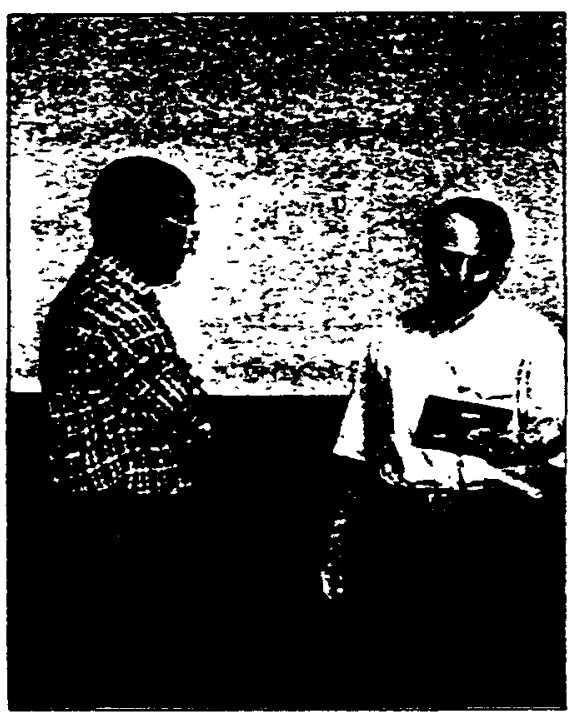

Mike Black, 1995-96 Chairman, presented Kermit Walrond, Amoco Exploration \& Production Co., a Regional Section Award for Amoco's past support of the GCS and donation of office furniture to the new office.

\section{SOUTH LOUISIANA STUDY GROUP}

$\mathrm{T}$ The SPE Gulf Coast Section is starting a new study group to focus on South Louisiana operations. The South Louisiana Study Group seeks to examine issues concerning exploration and production technology, marketing, financing, and other important topics that relate to this unique producing region.

If you are interested in becoming an active member of the leadership team for this group, if you have suggestions for presentation topics or speakers, or if you have a topic to present to the group, please contact Steve Hendrickson with Shell Western E\&P Inc. at (713) 544.2889 or SHendrickson@shell.com.

\section{GENERAL MEETING}

Tee D. Danner, Project Manager Lfor Paragon Engineering Services, will present "Innovative Platform Allows Production of Otherwise Uneconomic Gas," at the Hyatt Regency Downtown on Thursday, September 12 .

\section{ANNUAL MEETING} The Society of Petroleum cal Conference and Exhibition will be held 6-9 October 1996 at the Colorado Convention Center in Denver. The upstream oil and gas industry's most comprehensive international event, this year's edition of the ATCE will feature some 350 technical presentations in 61 sessions on the latest practical applications in drilling, formation evaluation, production, reservoir engineering, and many related topics.

Registration information can be obtained from the SPE office in Richardson (214-952-9393). Program and registration details may be accessed on the SPE home page: http://www.spe.org.

\section{EXPRESS REGISTRATION}

$\mathrm{T}$ The Express Reservation system will allow you to make quick, simple reservations for any of the Gulf Coast Section luncheon meetings. seminars, or continuing education courses. The Express Reservation system only requires your SPE number, event reservation code number, and your daytime phone number. Only SPE members listed in the

\section{HIGHLIGHTS}

Chairman Marilyn Wilson's column (p. 3)

On-Line with the ECC...(p. 4)

Boy Scouts of America (p. 5)

Tennis (p. $6 \& 7$ )

Electric Submersible Pump

Workshop (p. 8)

Subsurface Fluid Control

Symposium (p. 15)

Latin America Seminar (p. 19)

Auxiliary (p. 25)

\section{Continuing Education}

An Introduction To Resevoir

Simulation (p. 27)

An Introduction to Coiled

Tubing Technology (p. 27)

Oil Patch Orientation (p. 27)

Gulf Coast Section can use the Express Reservation System. Dial 952-4011 to access the reservation system. For express registration, follow these steps:

Step 1 - Enter the first 6 digits of your SPE membership number. including any preceding zeros. Press the \# key.

Step 2 - Enter your daytime phone number, including area code. Press the \# key.

Step 3 - Enter the event code. Press the \# key. 


\section{AN INTRODUCTION TO RESERVOIR SIMULATION}

\section{Thursday, September 26}

$\begin{array}{ll}\text { Instructor } & \text { Dr Farouk M Allam } \\ \text { Location } & \frac{\text { Praure View A\&M }}{50525 \text { State Highway 249, Suite } 100} \\ & \frac{\text { (Compaq Computer Center, Entrance 5) }}{830 \text { ) }}\end{array}$

Time

$830 \mathrm{am}$ to $500 \mathrm{p} \mathrm{m}$

Cost

$\$ 175$ for SPE members,

$\$ 250$ for nonmembers

Registration or cancellation by noon, Thursdav, September 12

Phone 952.4011

Reservalion code 09265

$\mathrm{T}$ his is an intensive one-day seminar designed for petroleum engıneers with mınımum or no background in reservoir simulation who may need help getting started The seminar introduces participants to severd concepts in reservoir modeling These concepts are presented in terms of their pracucal relevance to reservorr engineering rather than mathematics Terms such as implicit pressure-explicit saturation (IMPES) mobility weighing numerical dispersion. along with a host of other simulation terms will be discussed Representation of reservoir fluids and rock, selecting grid size and type, coupling between well and reservoir, aquifer treatment, and selecting the method of solution are also covered The seminar briefly covers the mechanics of performing a reservorr simulduon study. which includes adjusung the model to match actual production history (history match) as well as using the model to predict future performance The US Department of Energy simulator BOAST II $u$ Ill be used to demonstrate a case study paricipants $u$ ill be able to obtain a free copy of the BOAST II simulator

Dr Farouk Allam is the Director of the U S Department of Energy technology transfer project at Prairie View A\&M University $\operatorname{Dr}$ Allam has 28 years experience in the petroleum industry which includes field operations reser boir engineering research and industry teaching He has conducted over 50 short industry courses worldwide in reservor engineering well testing, reservorr smuldion and enhanced oil recover, Dr Allam has authored several computer softuare systems and traınıng manuals

\section{AN INTRODUCTION T́TO COILED TUBING TECHNOLOGY}

\author{
Thursday, October 24
}

$\begin{array}{ll}\text { Instructor } & \text { Ken Newman } \\ \text { Location } & \text { SPE Gulf Coast Section } \\ & 7500 \text { San Felipe, Suite } 4 \\ & \text { Houston, TX } 77063 \\ \text { Time } & 830 \text { a m to } 500 \mathrm{p} \mathrm{m} \\ \text { Cost } & \$ 175 \text { for SPE members, } \\ & \$ 250 \text { for nonmembers }\end{array}$

Registration or cancellation by noon, Thursday, October 10 Phone, 952,-4011 Reservation code 10245

$\mathrm{T}$ his presentation reviews the recent history of developments in the colled tubing (CT) industry and the forces that have driven these developments Developments in progress are discussed and a vision of the future of the CT industry is presented in light of current developments These developments range from directional open hole drilling to CT completions and unproved telemetry sy stems for CT sem!s

Kenneth Neu man is Vice-President of Marketıng for Drexel CT Products Group and President of CTES Inc in Conroe He previously was CT engineenng manager for Dowell Schlumberger in Rosharon and worlduide CT business manager for Dowell in Pau, France He started and managed a CT task force, joined Drexel Colled-Tubing Products Group in 1993, and a CT engineenng service. CTES

\section{OIL PATCH ORIENTATION}

\section{Thursday, November 21}

Instructor John Farına, Consultant

Location Prarie View A\&M

50525 State Highway 249, Sulte 100

(Compaq Computer Center, Entrance 5)

Time $\quad 830 \mathrm{dm}$ to $500 \mathrm{p} \mathrm{m}$

Cost $\$ 125$ tor SPE members and nonmembers

Registration or cancellation br noon. Thursday, November 7

Phone 952.4011

Reseriation code 11215

This seminar is the most popular SPE program The guided tour through the oil patch illustrating the basic equipment and techniquer used in the discovery development and production of petroleum The course objecture is to expose the nontechnical participant to the terminology and varied challenges of our exciting dynamic industry 